\title{
La ciudad diversa: el uso de tres plazas de Madrid en primavera $^{1}$
}

\author{
NAGORE URrutia del CAmpo \\ Madrid (España), 6 de septiembre de 2010.
}

\begin{abstract}
Resumen: Este trabajo recoge los resultados del estudio de las características físicas, funcionales y climáticas de tres plazas de la ciudad de Madrid, así como el uso que las personas hicieron de ellas durante los meses de primavera; éstos muestran la relación existente entre los condicionantes físicos y ambientales y el modo de ocupación del espacio por parte de los ciudadanos en los días analizados, pero también ponen de manifiesto la dificultad de generalizar el concepto de confort en el espacio público. En esta investigación se ha verificado la utilidad de ciertas herramientas de caracterización climática de plazas y se ha puesto de manifiesto que aquellas plazas que ofrecen al ciudadano una mayor mezcla de posibilidades, en lo referente a situarse en lugares con condiciones ambientales y posibilidades de utilización del espacio diversas, han sido las más empleadas durante los periodos analizados. Así, se evidencia la necesidad de conservación y creación de la ciudad compleja, con mezcla de usos y que ofrece al ciudadano la posibilidad de elección, transformándose así, en un lugar más habitable y democrático.
\end{abstract}

\section{Introducción}

Problema y motivo de elección del tema de investigación . . . . . . . . . . . . . . . . 8

Selección de las plazas . . . . . . . . . . . . . . . . . . . . . . . . . 9

$\begin{array}{ll}\text { Objetivos } & 11\end{array}$

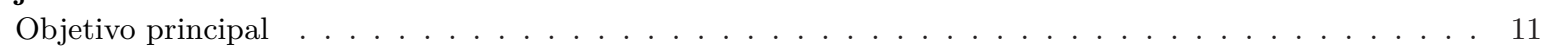

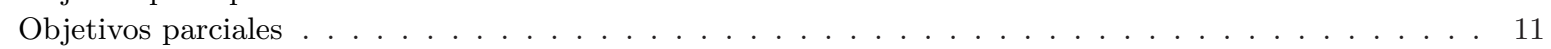

Pregunta de investigación e hipótesis de trabajo 11

$\begin{array}{lr}\text { Metodología } & 11\end{array}$

Elaboración del marco teórico . . . . . . . . . . . . . . . . . . . . . . . . . 11

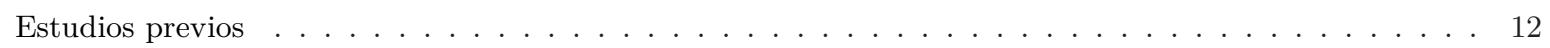

Fase de análisis . . . . . . . . . . . . . . . . . . . . . . . . . . . . 12

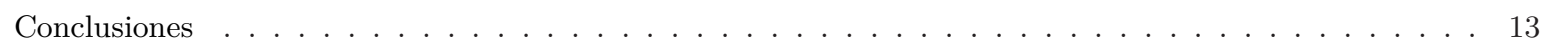

$\begin{array}{lr}\text { Estudio climático } & 13\end{array}$

Contexto climático: Madrid . . . . . . . . . . . . . . . . . . . . . . . . . . . . 13

Estudio climático de Madrid en primavera . . . . . . . . . . . . . . . . . . . . . . . . 16

Estudio climático y ambiental de las plazas en primavera . . . . . . . . . . . . . . . . . . . 19

Mediciones en las plazas . . . . . . . . . . . . . . . . . . . . . . . . . 23

Planos resumen del estudio climático de las plazas . . . . . . . . . . . . . . . . . . . . . . . 31

Estudio de las características físico-espaciales de las plazas $\quad 34$

Evolución histórica de las plazas . . . . . . . . . . . . . . . . . . . . . . . . . . 34

Características físicas y materiales f . . . . . . . . . . . . . . . . . . . . . . 39

Planos resumen de las características físico-espaciales de las plazas . . . . . . . . . . . . . . . . . 40

Funciones y usos de las plazas $\quad 45$

Función general del espacio . . . . . . . . . . . . . . . . . . . . . . . . . . . . 45

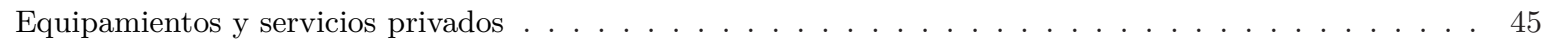

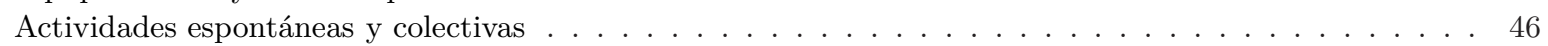

Planos resumen de funciones y usos en las plazas . . . . . . . . . . . . . . . . . . . . . 46

$\begin{array}{ll}\text { El empleo de las plazas } & 46\end{array}$

Actividades desarrolladas en las plazas . . . . . . . . . . . . . . . . . . . . . . . . . . 47

Usuarios . . . . . . . . . . . . . . . . . . . . . . . . . . . . 47

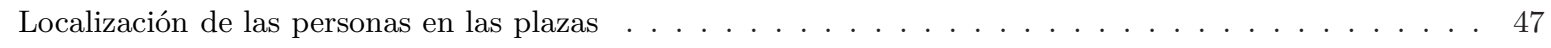

Planos resumen de la utilización de las plazas por parte de las personas en primavera . . . . . . . . . 66

${ }^{1}$ El presente trabajo es resultado de un Trabajo Fin de Máster dirigido por el profesor AGustín HeRnÁndez AJA dentro del Máster Universitario en Planeamiento Urbano y Territorial impartido por el Departamento de Urbanística y Ordenación del Territorio de la Universidad Politécnica de Madrid durante el curso 2009-2010. 
$\begin{array}{ll}\text { Resultados } & 66\end{array}$

Resultados del estudio climático f . . . . . . . . . . . . . . . . . . . . . . 66

Resultados del estudio físico espacial de las plazas . . . . . . . . . . . . . . . . . . . . 78

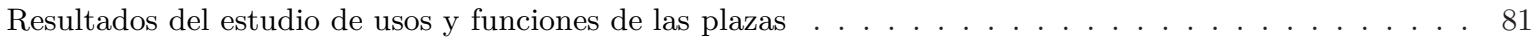

Resultados del estudio de utilización de las plazas en primavera . . . . . . . . . . . . . . . . . . 82

Comparativa entre plazas . . . . . . . . . . . . . . . . . . . . . . . . 87

$\begin{array}{lr}\text { Conclusiones } & 89\end{array}$

Calidad ambiental de las plazas . . . . . . . . . . . . . . . . . . . . . . . . . 89

Posibilidades de ocupación de las plazas . . . . . . . . . . . . . . . . . . . . . . . . . . . 90

Localización de la gente en las plazas . . . . . . . . . . . . . . . . . . . . . . . . . . . . 95

Verificación de la hipótesis . . . . . . . . . . . . . . . . . . . . . . . . . . 102

Consideraciones finales . . . . . . . . . . . . . . . . . . . . . . . . . 103

$\begin{array}{lr}\text { Bibliografía } & 104\end{array}$

Otros documentos digitales . . . . . . . . . . . . . . . . . . . . . . . 108

\section{Introducción}

\section{Problema y motivo de elección del tema de investigación}

Mientras que hasta el siglo XIX las transformaciones en los centros urbanos se daban en un espacio dilatado en el tiempo, actualmente son numerosas y constantes las intervenciones a pequeña escala en el espacio público de todas las ciudades.

Los distritos centrales de la ciudad de Madrid sufrieron, durante los años 80 y hasta principios de los años 90 del siglo XX, un decaimiento arquitectónico y urbanístico que se ha visto frenado por las intervenciones urbanas llevadas a cabo los últimos 20 años (Plan general de ordenación urbana municipal (PGOUM 1997), Rehabilitación Integrada del Casco y Centro Histórico de Madrid).
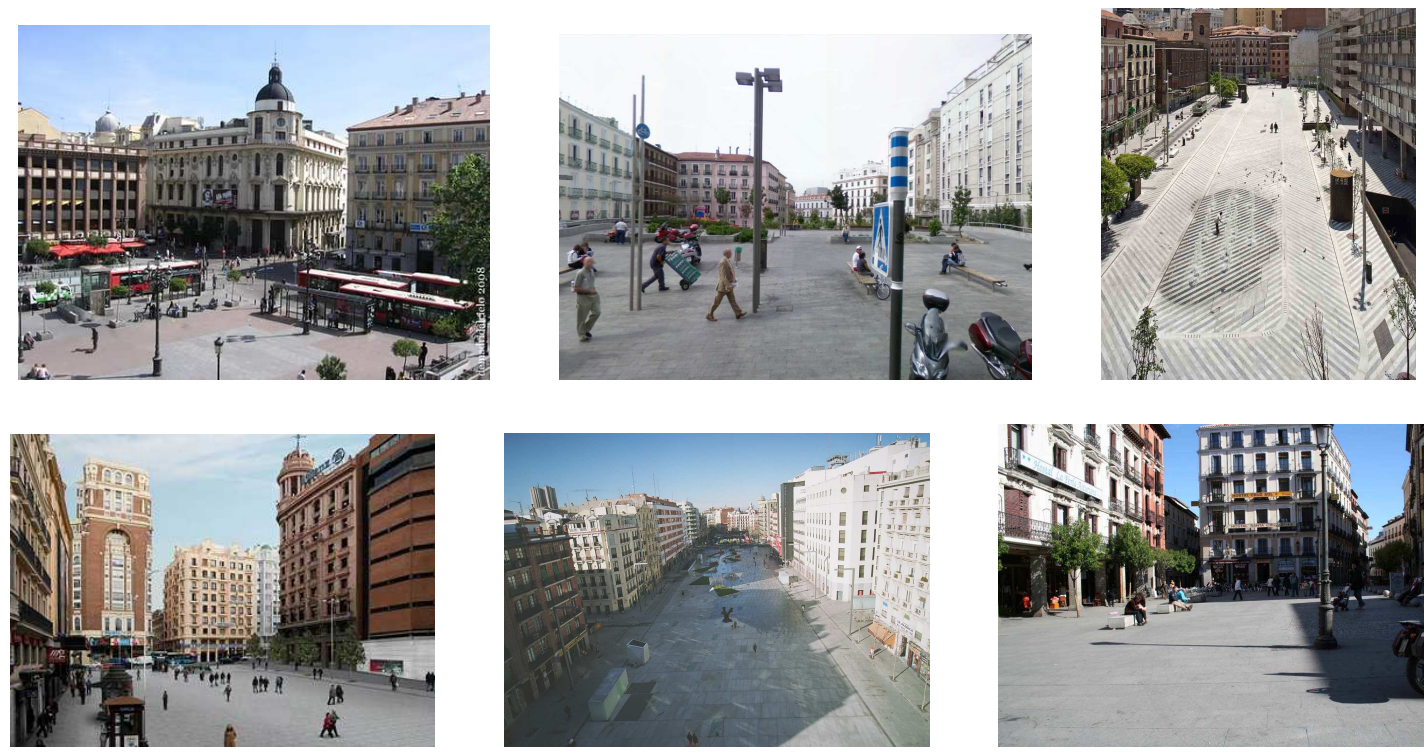

Figura 1: Rehabilitación de las plazas en el centro de Madrid

Las imágenes corresponden a las plazas de Jacinto Benavente, Santo Domingo, Soledad Torres Acosta, Callao,

Felipe II y Santa Cruz, respectivamente (de izquierda a derecha). Fuente:ND

Estas intervenciones de rehabilitación y revitalización del espacio público se han venido realizando en muchas ocasiones con sistemas que no responden a las necesidades actuales, pues no tienen en cuenta muchos de los condicionantes urbanos preexistentes ni la búsqueda de confort de los usuarios, dando lugar a un diseño desligado de las funciones sociales que éste debe cumplir. 
La Real Academia de la Lengua Española, en su segunda acepción define plaza de la siguiente manera: «Aquel donde se venden los mantenimientos y se tiene el trato común de los vecinos, y donde se celebran las ferias, los mercados y fiestas públicas.»

Existe una carencia clara de intervenciones de rehabilitación del espacio público más cercano a las viviendas que tomen en cuenta a la gente. Así, en ocasiones, se pierden las virtudes del espacio público a pequeña escala, tradicionalmente valorado por el ciudadano.

Las herramientas de trabajo cotidianas y las nuevas tecnologías, al tiempo que han supuesto una nueva forma de expresión y que permiten trabajar con datos antes inimaginables, también nos han alejado de la realidad material de las ciudades y de su funcionamiento, dando lugar a lo que ToYo ITO denomina las dos ciudades (Iто, 2000), la material y la ciudad como fenómeno.

En el empobrecimiento de los espacios tradicionales de relación de las ciudades es donde se plasma la lejanía entre nuestra capacidad tecnológica e intelectual y las realidades más tangibles. Es por ello que en este trabajo se ha optado por analizar las plazas como espacios de relación y de vida de las ciudades, estudiando estos espacios físicos y el uso que los habitantes han hecho de ellos durante varios días de abril, mayo y junio de 2010 .

Durante los años 60 y 70 del siglo XX se realizaron numerosos estudios sobre la influencia del diseño urbano en el uso que los ciudadanos hacían del mismo, destacando los realizados por White (1980), LYNCH (1960) o GEHL (1968), así como estudios de confort climático del espacio, como los realizados por OlgyAy (1963), Givoni (1976) o Humphreys (1978), por ejemplo.

Actualmente, existe una renovada atención a la calidad de los espacios públicos ligada a la necesidad de un ambiente físico confortable que dé pie al fomento de las relaciones sociales y entendiendo su estado como un claro indicador de la salud cívica y democrática de la sociedad. Así, por ejemplo, en el ámbito de la mejora del diseño urbano, en el año 2000, organizado por el Centro de Cultura Contemporánea de Barcelona, se celebró por primera vez el certamen bienal Premio Europeo del Espacio Público Urbano, para el fomento de la conservación y la mejora del espacio público urbano. Y por otra parte, se han llevado a cabo investigaciones para el desarrollo de nuevos índices de confort térmico de los espacios públicos como las realizadas por Aroztegui (1995), Nikolopoulou et AL. (2004) o Scudo (2005), que señalan la calidad, cantidad y forma de uso de los espacios públicos como determinantes de las condiciones microclimáticas de los mismos y de su confort.

En el presente trabajo se quiere poner de manifiesto la necesidad de hacer más compleja y habitable la ciudad completa, centros y periferias, a través del estudio de pequeños espacios como son las plazas. Al igual que en los últimos años se habla de la necesidad de una ciudad con mezcla de actividades y gentes, resultan necesarios espacios urbanos de calidad con mezcla de posibilidades y que permitan al ciudadano hacer un uso de los mismos acorde a sus necesidades. Así, desde la pequeña escala se pretende poner de manifiesto la importancia de la creación y recuperación de la ciudad con diversidad de posibilidades en su uso, que es la que ofrece al ciudadano la opción de elegir.

\section{Selección de las plazas}

\section{Las plazas y su localización}

Las plazas objeto de estudio son:

- Plaza del 2 de Mayo, distrito Centro, barrio Universidad.

- Plaza de Chamberí, distrito Chamberí, barrio Almagro.

- Plaza de Vázquez de Mella, distrito Centro, barrio Justicia.

\section{Localización}

Las plazas se localizan en la ciudad de Madrid (véase la figura 2). Las coordenadas de la ciudad son $40^{\mathrm{O}} 26^{\prime} \mathrm{N} 3^{\mathrm{O}} 41^{\prime} \mathrm{O}$ y la altura media sobre el nivel del mar de $667 \mathrm{~m}$.

Tanto la plaza 2 de Mayo como Vázquez de Mella se encuentran en el distrito Centro, en aquella zona de Madrid que creció a partir de 1561, cuando se asienta la corte real en Madrid, y que en los siguientes 60 años fue creciendo desde la ciudad medieval hacia el este, rodeada de las últimas murallas que tuvo Madrid, construidas en 1625 y derribadas 200 años más tarde. Este ensanche de la ciudad medieval no tenía plazas, a excepción de vacíos urbanos originados por el cruce de calles. Ambas plazas no fueron configuradas como tal hasta mediados del siglo XIX.

La plaza Chamberí se encuentra al norte, fuera de las últimas murallas de Madrid, en el ensanche del siglo XIX. 


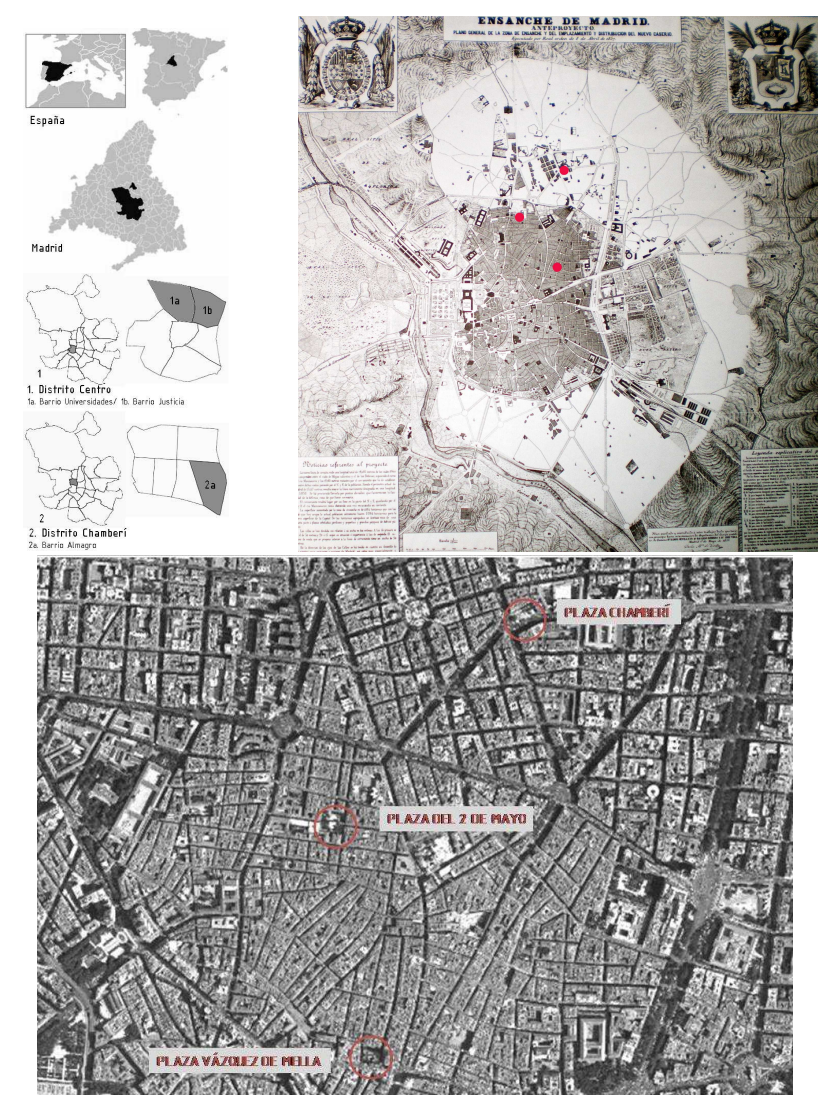

Figura 2: Localización de las plazas Fuente:ND 


\section{Razones de su elección}

- Se han escogido plazas del centro de Madrid por ser lugares consolidados con mezcla de usos y posibilidades diversas de utilización.

- Se ha evitado la selección de plazas con un carácter predominantemente turístico. Aquellas plazas estudiadas combinan tanto turistas como residentes y en ellas prevalece el carácter doméstico.

- Se han seleccionado tres plazas que tienen unas superficies en planta similares.

- Se han escogido plazas con diferencias en su diseño para poder evaluar los condicionantes climáticos, funcionales y físicos derivados de esas diferencias y su influencia en las personas.

\section{Objetivos}

\section{Objetivo principal}

El objetivo principal es determinar la relación existente entre los condicionantes climáticos y ambientales de tres plazas de Madrid y el uso que los habitantes hacen de estos espacios durante la primavera. De este modo, se pretende evaluar la eficiencia de las herramientas teóricas de caracterización ambiental, al contrastar los resultados derivados del empleo de éstas con el comportamiento real de los ciudadanos, pudiendo también identificar los espacios que mejor acogida encuentran entre los usuarios.

\section{Objetivos parciales}

- Desarrollo y empleo de un proceso para la caracterización de plazas a nivel físico y ambiental y para el conocimiento del empleo que hacen los ciudadanos de estos espacios, que marque las pautas para posibles intervenciones futuras tomando en cuenta los condicionantes del lugar, con la finalidad de crear espacios lo más confortables posibles para el ciudadano.

- Establecer las características físicas a estudiar de las plazas para su conocimiento y caracterización de las mismas.

- Determinar las funciones y actividades que se desarrollan en las plazas.

- Conocer el uso que hacen los ciudadanos de los espacios estudiados.

- Realizar un estudio climático para espacios urbanos del centro de Madrid para los meses de primavera, identificando las condiciones climáticas teóricas y reales de estos tres espacios.

\section{Pregunta de investigación e hipótesis de trabajo}

¿Los espacios con mayor variedad de características físicas, de uso y microclimáticas son los más confortables por ofrecer al usuario más opciones de elección?

En unas condiciones climáticas tan variables como la primavera madrileña, aquellas plazas que ofrezcan al usuario un mayor número de espacios con condiciones físicas, de uso y microclimáticas diversas, serán más confortables y más empleadas por la gente.

\section{Metodología}

Para la verificación de la hipótesis planteada el trabajo se ha centrado en el estudio de las características de tres plazas y la utilización que la gente ha hecho de ellas en tres días de los meses de abril, mayo y junio de 2010, empleando para ello herramientas teóricas y realizando trabajos de campo. Así, el proceso seguido se resume en la la figura 3.

\section{Elaboración del marco teórico}

La búsqueda bibliográfica se centró en la búsqueda de libros, proyectos y artículos científicos relacionados con el diseño bioclimático y el establecimiento de confort en espacios abiertos, así como en la influencia del diseño urbano en la ocupación del espacio.

Resultados: establecimiento de criterios sobre urbanismo sostenible, índices de confort en espacios exteriores, influencia del diseño urbano en la ocupación del espacio. 


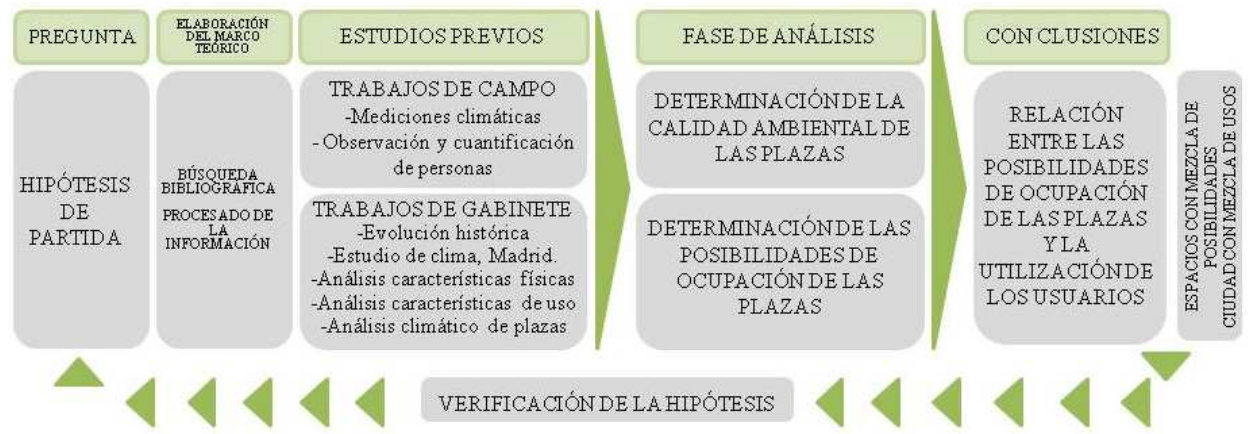

FIgURA 3: Proceso seguido en la investigación

Fuente: elaboración propia

\section{Estudios previos}

\section{Trabajos de campo}

Se trataron de la realización de mediciones de la temperatura del aire, humedad relativa, temperaturas de contacto y velocidad del viento, durante las mañanas, tardes y noches de tres días de abril, mayo y junio con un data logger Testo 400 y con el apoyo de una cámara termográfica FLIR Systems.

Esos mismos días se realizaron fotografías para contabilizar a las personas que se encontraban en las plazas. Fueron un total aproximado de 1.000 fotografías, que fueron procesadas identificando el número de personas, su localización al sol o a la sombra, la actividad que realizaban y si se encontraban de pie o sentadas.

Resultados: Mapeo de la localización de personas en las plazas. Esta información se puede consultar en los planos resumen de la utilización de las plazas por parte de las personas en primavera, correspondientes al punto 1

\section{Trabajos de gabinete}

Se centraron en el conocimiento de la evolución histórica de las plazas, su caracterización física, la identificación de usos y funciones existentes en éstas, así como en el estudio climático de las mismas a través de simulación mediante el software Ecotect v.5.60., determinando sus características de iluminación y radiación solar.

Resultados: Se pueden consultar en los puntos 1,1 y 1 de la presente memoria de trabajo, así como los resultados expuestos en el punto 1.

\section{Fase de análisis}

\section{Calidad del diseño}

Los resultados extraídos del análisis de las características físicas y del uso realizado engvi cada una de las plazas, así como las mediciones in situ, han sido comparados para establecer la plaza que tiene un diseño más acorde a los principios señalados por el urbanismo bioclimático y por el diseño orientado al peatón.

Resultados: Se pueden ver en el punto 1 (sobre Calidad ambiental de las plazas), perteneciente al apartado 1 (correspondiente a Conclusiones).

\section{Posibilidades de utilización de las plazas}

En esta fase también se han determinado las posibilidades de ocupación en condiciones ambientales diversas que ofrece cada una de las plazas a través del cruce de las variables climáticas y de localización de mobiliario y equipamientos.

Resultados: Están expuestos en el punto 1 (Posibilidades de ocupación de las plazas). 


\section{Relación entre el estudio de clima y utilización de las plazas}

Finalmente, en la fase de análisis se realizó una comparativa entre las estrategias obtenidas en el estudio de clima teórico y la localización de las personas en las plazas para poder establecer la existencia de una relación entre las estrategias recomendadas para alcanzar el confort y el comportamiento de la gente en las plazas.

Resultados: Descritos en el punto 1 (Localización de la gente en las plazas).

\section{Conclusiones}

\section{Verificación de la hipótesis}

En esta última fase del trabajo se ha analizado la relación existente entre la utilización del espacio que hacen las personas en las plazas y las posibilidades de ocupación que ofrece cada una de ellas, para comprobar la hipótesis de partida.

Resultado: Verificación de la hipótesis inicial, que puede verse en el punto 1 de la presente memoria de trabajo.

\section{Estudio climático}

\section{Contexto climático: Madrid}

Madrid se localiza a una latitud de $40.4^{\circ}$ y una longitud de $-3.7^{\circ}$ y tiene un clima continental mediterráneo, de inviernos fríos y veranos muy calurosos, con acusados contrastes de temperatura, de hasta casi $30^{\circ} \mathrm{C}$ de invierno a verano, e incluso en un mismo día, con diferencias día-noche de hasta $17^{\circ} \mathrm{C}$ en agosto y $7^{\circ} \mathrm{C}$ en invierno.

\section{Temperatura}

Los máximos térmicos en Madrid se sitúan en el Centro, en la calle Alcalá y en la Castellana. Se pueden ver gráficos relacionados con temperaturas y radiación en las figuras 4 y 5 .

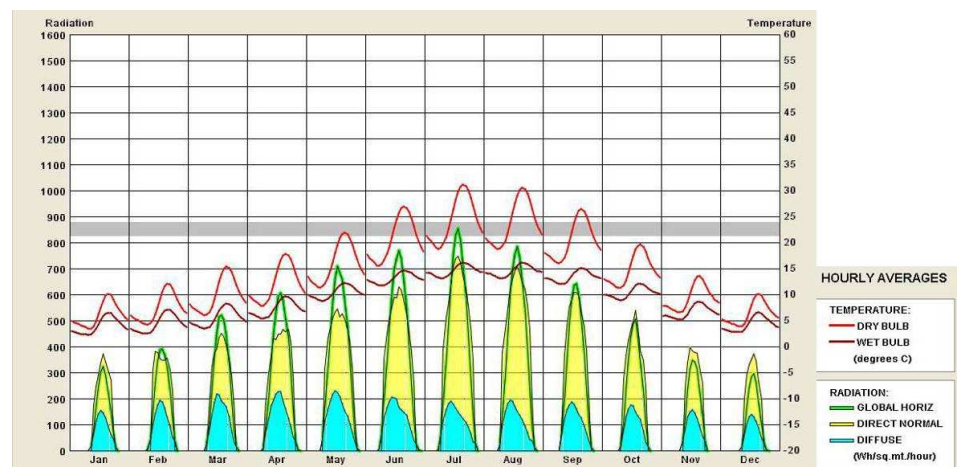

FigurA 4: Temperatura y radiación

Simulación e imágenes creadas en software Climate Consultant. Fuente:ND

\section{Humedad}

En general la humedad relativa en Madrid Retiro es baja. Exceptuando los meses de enero y diciembre, la mayor parte del año, a lo largo del día, la humedad se encuentra entre el $20 \%$ y el $40 \%$. La humedad relativa media anual es de $57 \%$. En la figura 6 se pueden ver las simulaciones sobre humedad relativa.

\section{Viento}

Las condiciones de invierno y verano respecto al viento son muy similares en la estación meteorológica de Madrid Retiro, véase la figura 7. Existe un alto porcentaje de calmas, como se puede ver en la figura 8. 


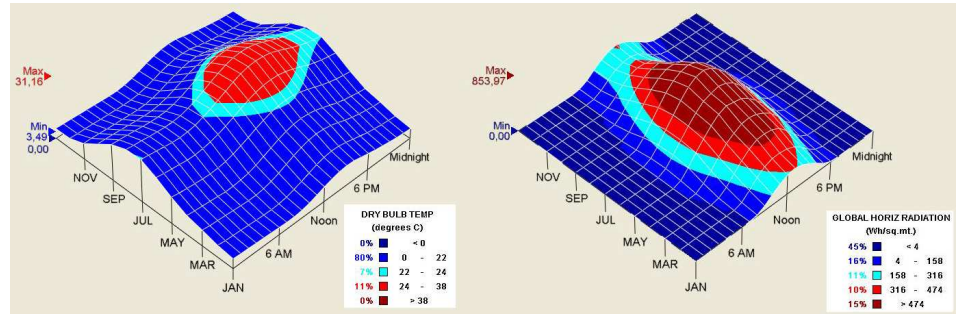

Figura 5: Temperatura y radiación

Simulación e imágenes creadas en software Climate Consultant. Fuente:ND

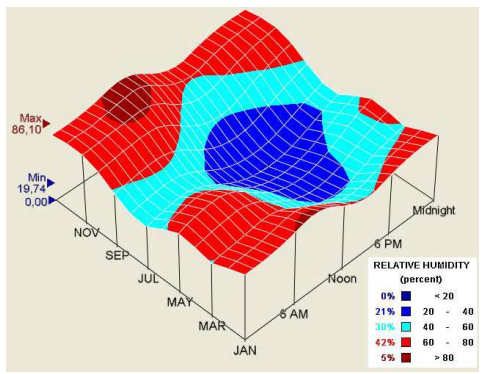

FIGURA 6: Humedad relativa

Simulación e imágenes creadas en software Climate Consultant. Fuente: ND

\begin{tabular}{lll} 
viento & verano & invierno \\
\hline viento dominante & $45^{\circ}(12,11 \%) \mathrm{NE}$ & $45^{\circ}(10,45 \%) \mathrm{NE}$ \\
\hline vientos minimos & $335^{\circ}(1,74 \%) \mathrm{NO}$ & $335^{\circ}(1,16 \%) \mathrm{NO}$ \\
\hline calmas & $21 \%$ & $30 \%$ \\
\hline velocidad promedio & $2-4 \mathrm{~m} / \mathrm{s}(45,91 \%)$ & $2-4 \mathrm{~m} / \mathrm{s}(33,53 \%)$ \\
\hline
\end{tabular}

Figura 7: Viento

Fuente: Higueras, 2009 
Retiro

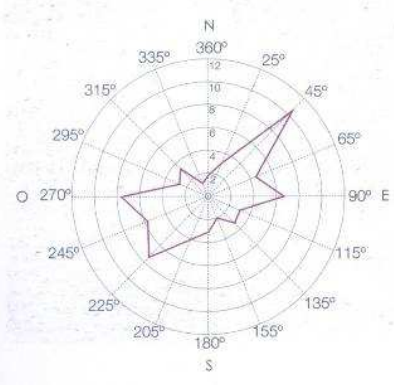

invierno

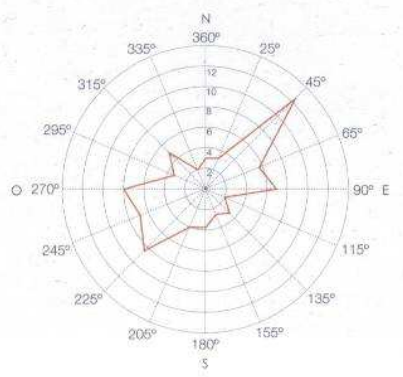

verano

$\begin{array}{lr}\text { calmas } & 30 \% \\ \text { velocidades } & \\ 0.5-2 \mathrm{~m} / \mathrm{sg} & 23.84 \% \\ 2-4 \mathrm{~m} / \mathrm{sg} & 33.53 \% \\ 4-8 \mathrm{~m} / \mathrm{sg} & 10.77 \% \\ >8 \mathrm{~m} / \mathrm{sg} & 1.96 \%\end{array}$

Figura 8: Viento

Fuente: Higueras, 2009

\section{Pluviometría y balance hídrico}

Existe una clara escasez de agua en Madrid a partir del mes de mayo y hasta octubre.

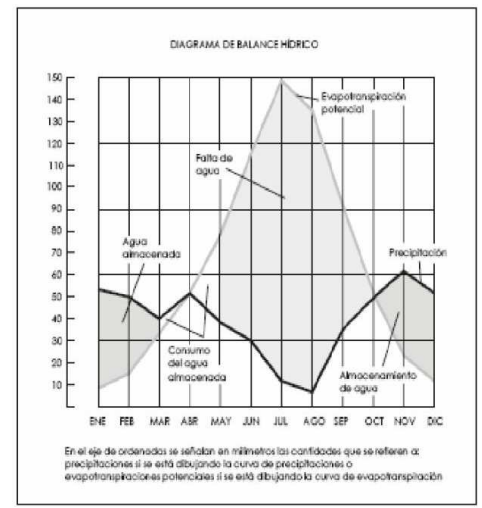

Figura 9: Balance hídrico

\section{Isla térmica en Madrid}

En Madrid existe una diferencia de $6^{\circ} \mathrm{C}$ en el centro respecto a la periferia y sube a $9^{\circ} \mathrm{C}$ en verano con tiempo estable y despejado (Higueras, 2009), existe un gradiente decreciente desde el centro hacia la periferia. Esta diferencia de temperatura está condicionada por tres factores:

- Inercia térmica de los materiales

- Recepción de calor solar

- Situación

Hay que tener en cuenta que, en los espacios exteriores urbanos, las variables que definen el clima van a ser modificadas por diferentes condicionantes dando lugar a un microclima urbano:

- Edificaciones

- Isla térmica

- Contaminación

- Actividades y arropamiento 


\section{Confort climático en Madrid}

Según los estudios de Higueras (2009), a través del estudio de los climogramas de bienestar desde la 11:00 a las 18:00 horas, mes a mes, con los diferentes grupos de edad y escalas de arropamiento se determina el confort en los espacios exteriores de Madrid del siguiente modo:

- En las zonas de actividades sedentarias (1.15met)

- Confort: 15,4\% de los días del año, primavera y otoño.

- Disconfort por frío: 84,6\%. Necesidad de radiación, no aportar humedad y evitar el viento.

- En las zonas con actividades moderadas (2.95met)

- Confort: 27,1\% de los días del año, primavera y otoño.

- Disconfort por frío: $63,7 \%$ de los días del año.

- Disconfort por calor: 9,2\% de los días del año, precisan sombra y sistemas de enfriamiento evaporativo (entre el $30 \%$ y $80 \%$, NeILA, 2004) y ventilación de los espacios $(0.2$ a $2 \mathrm{~m} / \mathrm{s}$, NEILA, 2004).

En estos datos señalados, será especialmente importante tener en cuenta la capacidad de la radiación solar en los espacios exteriores para modificar estas situaciones de confort o de disconfort.

\section{Estudio climático de Madrid en primavera}

\section{Datos climáticos empleados}

Los datos climáticos se han tomado del Instituto Nacional de Meteorología y corresponden a la estación meteorológica de Madrid Retiro. Se tratan de medias mensuales de los últimos 30 años.

\section{El confort en espacios exteriores}

En un espacio interior el confort está estrechamente ligado a la temperatura del aire y a la humedad relativa, por lo que se puede garantizar un confort actuando en las condiciones termohigrométricas. Pero en los espacios exteriores entran otros muchos factores en juego que pueden influir en el confort incluso más que la temperatura del aire, como por ejemplo, la radiación solar directamente recibida por el usuario, siendo ésta una ganancia de calor fundamental.

De modo general, el confort climático se define como aquella situación en la que le cuerpo humano requiere de la mínima energía para ajustarse al ambiente para un individuo con ropa ligera, con baja actividad muscular y a la sombra (ÁLVAREZ ET AL., 1992).

Generalmente el confort está limitado por los $21^{\circ} \mathrm{C}$ entre un $20 \%$ y $80 \%$ de humedad relativa y los $25^{\circ} \mathrm{C}$ con humedad del $70 \%$ o los $26^{\circ} \mathrm{C}$ es necesario el sombreamiento dentro de los condicionantes anteriormente citados.

El confort ampliado está entre los $20^{\circ} \mathrm{C}$ con humedad entre $20 \%$ y $80 \%$ y entre los $26^{\circ} \mathrm{C}$ con $70 \%$ de humedad o los $27^{\circ} \mathrm{C}$ con humedad de $20 \%$ y $50 \%$. La vestimenta amplía esta zona de confort.

Las variables que condicionarán el confort en los espacios exteriores serán los siguientes:

- Temperatura seca: plano horizontal (color, material, pendiente), altura de los edificios y sus sombras y fachadas y sus materiales y colores.

- Humedad ambiental: vegetación y aumento de la humedad por la fotosíntesis, fuentes y láminas de agua (en Madrid el agua deberá ser reciclada, si no, no es rentable).

- Viento: altura de los edificios, orientación y cambios de rasante.

- Tipo de actividad (NeILA, 2004):

- Persona sentada: $1.15 \mathrm{met}$

- Adulto jugando a la petanca: 2.95met

- Niño jugando: 2.95met

- Escala de arropamiento: 0.7 ó 1clo (arropado y al sol se puede conseguir el confort, o con poca ropa y a la sombra). 
CuAdro 1: Datos climáticos, temperaturas y humedad

\section{Datos climáticos}

\begin{tabular}{|l|l|l|l|l|l|l|l|l|}
\hline Meses & $\mathbf{T}\left({ }^{\mathbf{0}} \mathbf{C}\right)$ & $\mathbf{T M}\left({ }^{\mathbf{0}} \mathbf{C}\right)$ & $\mathbf{T M}\left({ }^{\mathbf{0}} \mathbf{C}\right)$ & $\mathbf{H}(\mathbf{\%})$ & $\mathbf{H M}(\mathbf{\%})$ & $\mathbf{H m}(\mathbf{\%})$ & $\mathbf{R}(\mathbf{m m})$ & $\mathbf{V x}\left({ }^{\mathbf{o}} / \mathbf{k m} / \mathbf{h}\right)$ \\
\hline Abril & 12,3 & 17,5 & 7,2 & 55 & 66 & 33 & 47 & $250 / 94$ \\
\hline Mayo & 16,1 & 21,4 & 10,7 & 54 & 74 & 37 & 52 & $40 / 77$ \\
\hline Junio & 21,0 & 26,9 & 15,1 & 46 & 68 & 32 & 25 & $270 / 81$ \\
\hline
\end{tabular}

T: temperatura media mensual, TM: Media mensual de las temperaturas máximas diarias Tm: Media mensual de las temperaturas mínimas diarias, H: Humedad relativa media R: Precipitación mensual media, Vx: Racha de viento máxima en el mes, dirección y velocidad

Temperaturas horarias

\begin{tabular}{|l|l|l|l|}
\hline Hora & Abril & Mayo & Junio \\
\hline $3: 00$ & 8,2 & 11,7 & 16,2 \\
\hline $6: 00$ & 7,2 & 10,7 & 15,1 \\
\hline $9: 00$ & 9,8 & 13,4 & 18,1 \\
\hline $12: 00$ & 14,9 & 18,7 & 24,0 \\
\hline $15: 00$ & 17,5 & 21,4 & 26,9 \\
\hline $18: 00$ & 16,5 & 20,4 & 25,8 \\
\hline $21: 00$ & 13,9 & 17,7 & 22,8 \\
\hline $24: 00$ & 10,8 & 14,4 & 19,2 \\
\hline
\end{tabular}

Humedad

\begin{tabular}{|l|l|l|l|}
\hline Hora & Abril & Mayo & Junio \\
\hline $3: 00$ & 73 & 72 & 62 \\
\hline $6: 00$ & 78 & 77 & 67 \\
\hline $9: 00$ & 65 & 64 & 55 \\
\hline $12: 00$ & 47 & 46 & 38 \\
\hline $15: 00$ & 39 & 39 & 32 \\
\hline $18: 00$ & 42 & 41 & 34 \\
\hline $21: 00$ & 50 & 49 & 41 \\
\hline $24: 00$ & 61 & 60 & 50 \\
\hline
\end{tabular}


- Temperatura de las superficies circundantes a una distancia menor de 2 metros.

Climogramas de bienestar adaptado y diagramas de isopletas.

Se han realizado los correspondientes Climogramas de Bienestar Adaptado (CBA) ${ }^{2}$ para la determinación de estrategias para alcanzar el confort climático en estos espacios exteriores durante los meses de abril, mayo y junio.

Los climogramas se han realizado diferenciado tres actividades metabólicas diferentes: persona caminando o niño jugando (2,95met), persona de pie (1,65met) y persona sentada (1,15met), así como el arropamiento, que para los meses de abril y mayo será de 1 clo, mientras que para junio se reduce a 0.7 clo (véanse figuras 10 y 11 respectivamente).
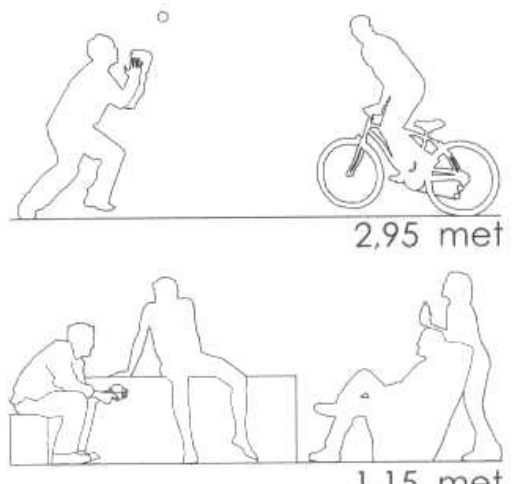

Indice de actividad
Tabla 2.7 Rangos de actividad de las actividades en el espacio exterior

\begin{tabular}{lccc} 
& $\begin{array}{l}\text { actividad } \\
\text { reposada } \\
\text { sentarse }\end{array}$ & $\begin{array}{l}\text { actividad } \\
\text { moderada } \\
\text { caminar }\end{array}$ & $\begin{array}{l}\text { actividad } \\
\text { alta } \\
\text { deporte }\end{array}$ \\
niños & & $2,95 \mathrm{met}$ & $2,95 \mathrm{met}$ \\
\hline adultos & & $2,95 \mathrm{met}$ & $>2,95 \mathrm{met}$ \\
\hline ancianos & $1,15 \mathrm{met}$ & $2,95 \mathrm{met}$ & - \\
\hline
\end{tabular}

Datos extraidos de I.Neila, Acondicionamiento térmico, 2004, ed. Munilla Leria
Figura 10: Actividades metabólicas

Fuente: NeILA, 2004

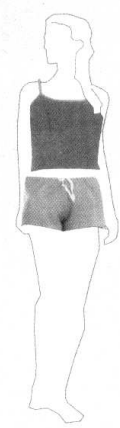

0,5 clo

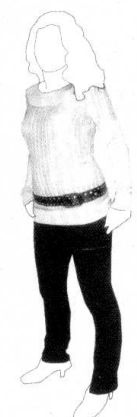

1,0 clo

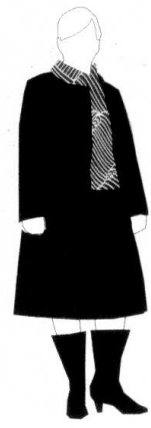

1,5 clo
Tabla 2.8 Escala de arropamientos

\begin{tabular}{ll} 
Arropamiento & Tipo de vestimenta \\
\hline $0,5 \mathrm{clo}$ & Ropa ligera de verano \\
\hline 1,0 clo & $\begin{array}{l}\text { Ropa de entretiempo, } \\
\text { primavera y otoño en el exterior } \\
\text { e invierno en interior }\end{array}$ \\
\hline
\end{tabular}

$1,5 \mathrm{clo}$

Escala de de arropamientos

\section{Figura 11: Arropamiento}

Fuente: Higueras, 2009

Para cada una de las actividades señaladas anteriormente se ha elaborado un diagrama de isopletas que determina:

\footnotetext{
${ }^{2}$ Los Climogramas de Bienestar Adaptado combinan la estructura del diagrama de OlgYay (1963), con las estrategias básicas de Givoni (1976) y la teoría del bienestar de ASHRAE (1992) (Neila, 2004)
} 
- épocas del año en las que es necesaria la radiación solar para alcanzar el confort;

- épocas en las que se alcanza el bienestar (10\% de insatisfechos);

- momentos en los que se alcanza el bienestar ampliado (20\% de insatisfechos);

- necesidad de sombreamiento (se establece a partir del momento en el que se alcanza el bienestar);

- necesidad de ventilación;

- momentos de calor excesivo.

\section{Determinación de las necesidades y estrategias para primavera}

En los meses intermedios de abril y mayo, al igual que en los meses más fríos, se necesitará radiación solar. En mayo gran parte del día se está en condiciones de bienestar.

En junio se alcanzará bienestar admisible prácticamente todo el día.

Se puede observar que en las horas del día de mayor temperatura de abril y mayo se alcanza la zona de confort, así como en las horas del día de temperaturas más bajas de junio.

\section{Resumen necesidades-estrategias}

A través del estudio de las temperaturas y humedades horarias y con los rangos de bienestar establecidos en los climogramas de bienestar adaptado, se han determinado las necesidades y estrategias (véase figura 12) a adoptar para diversas actividades metabólicas y arropamientos.

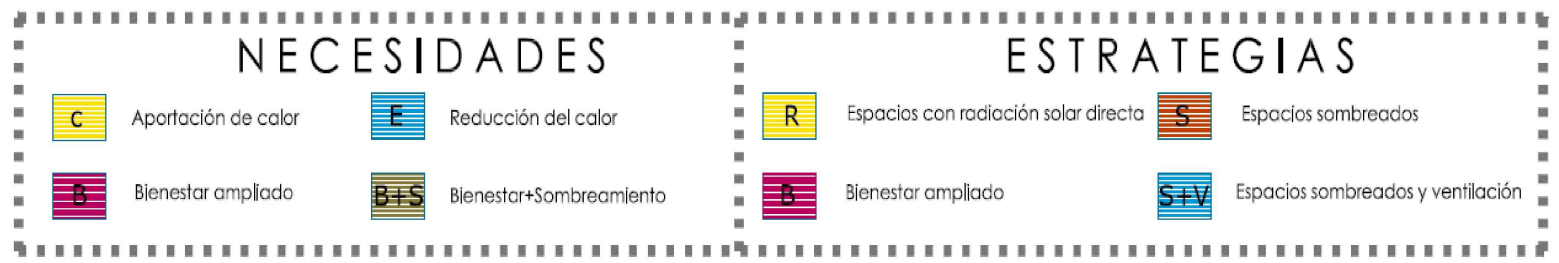

FigurA 12: Necesidades y estrategias

Fuente: elaboración propia

\section{Estudio climático y ambiental de las plazas en primavera}

\section{Estudio de sombras}

Se ha realizado el estudio de sombras para los días de primavera de los meses de abril, mayo y junio en los que se realizaron los trabajos de campo, con la finalidad de poder establecer las posibles relaciones existentes entre los condicionantes ambientales y el uso que hace la gente de las plazas estudiadas.

El estudio de sombras se ha realizado a través de la simulación de iluminación natural de las plazas con el software Ecotect v.5.60 de Autodesk, para lo que se ha realizado un levantamiento 3D de las plazas, incluyendo arbolado de características y tamaño similar al existente en ellas. Los planos de estos análisis se pueden consultar en las figuras 13, 14 y 15.

Así, se han determinado las sombras para los días:

- 29 de abril de 2010;

- 27 de mayo de 2010;

- 24 de junio de 2010 . 
Cuadro 2: Estudio de sombras. Plaza del 2 de Mayo

Fuente: elaboración propia

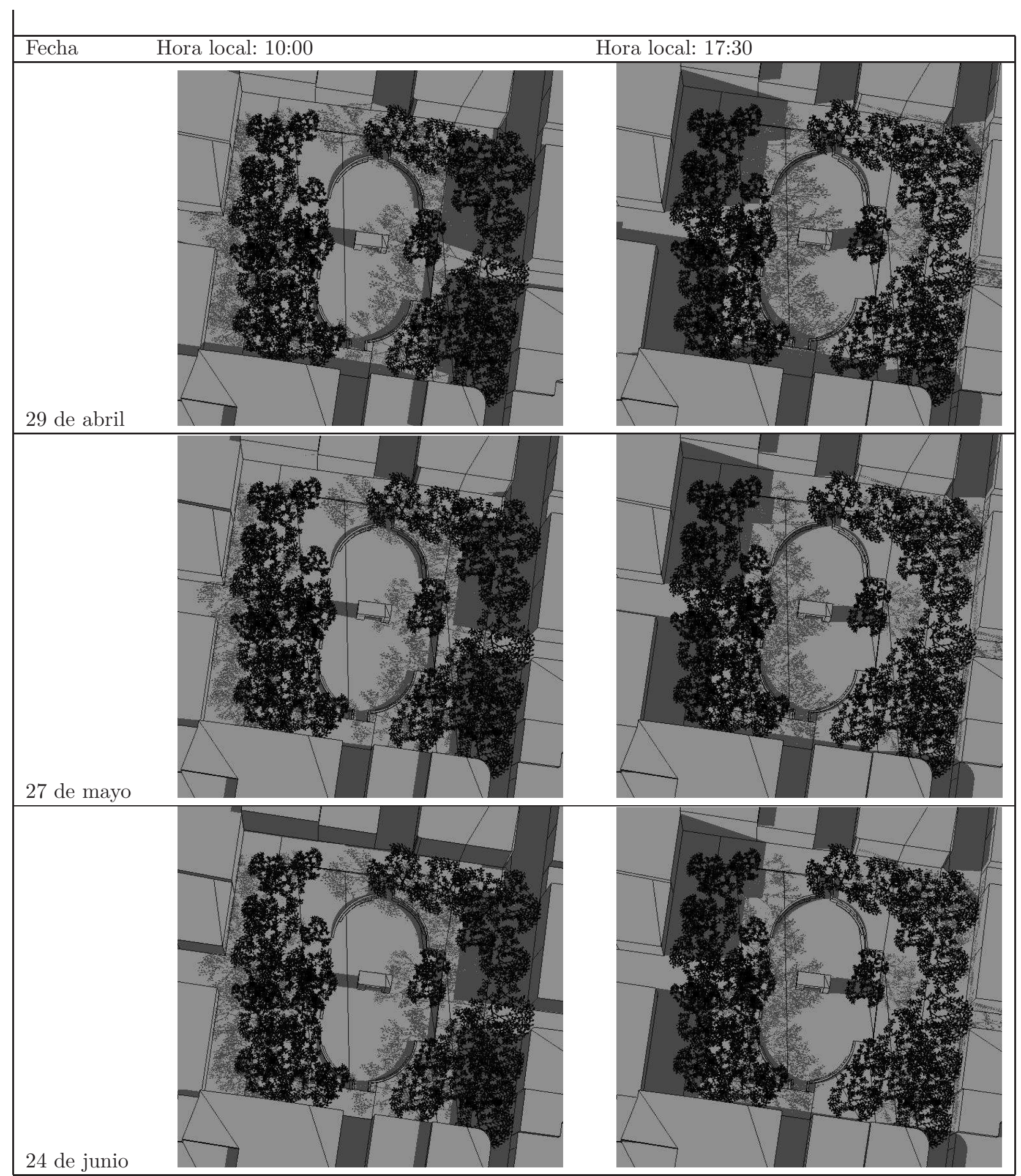


CuAdro 3: Estudio de sombras. Plaza de Vázquez de Mella Fuente: elaboración propia

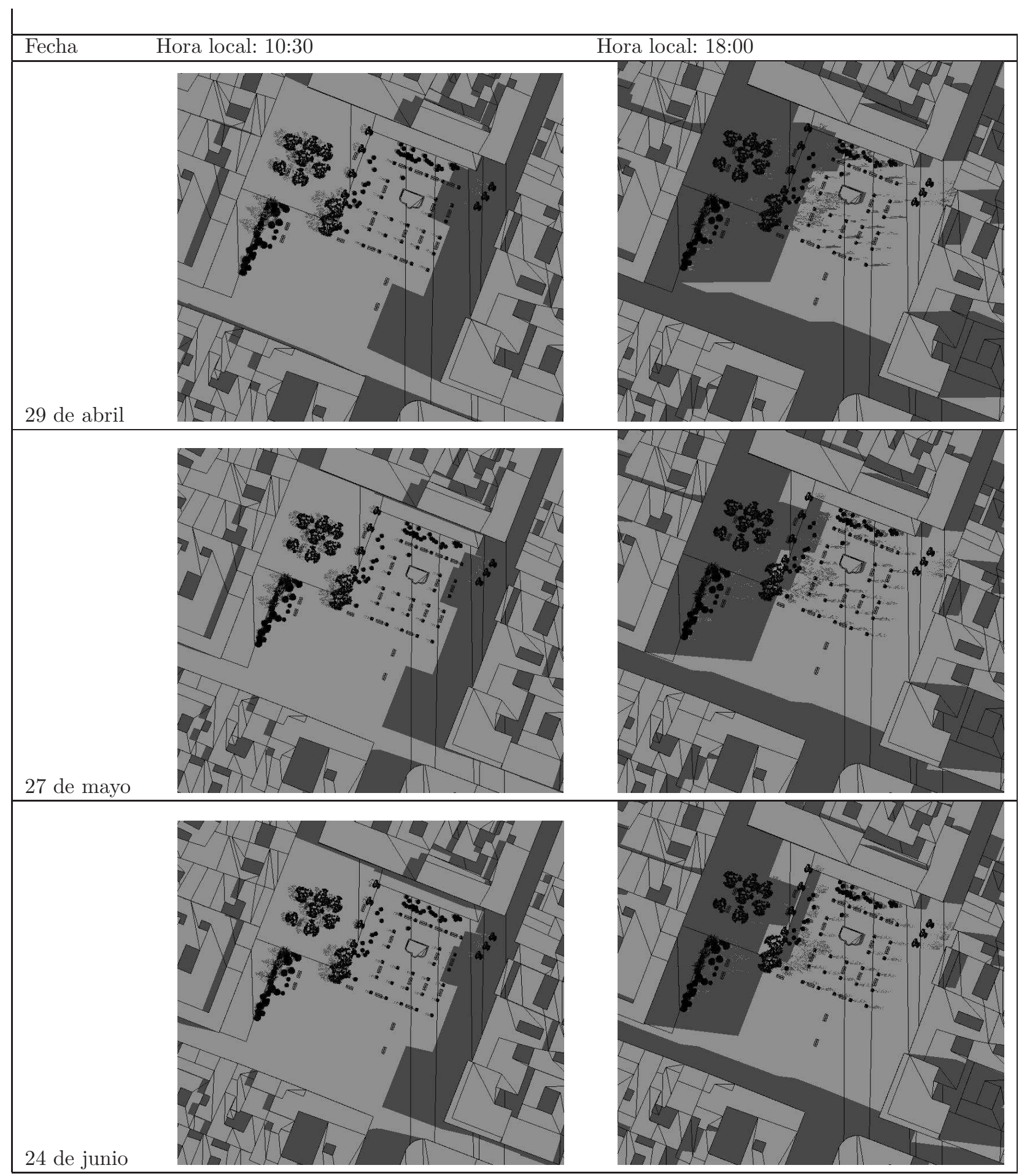


Cundro 4: Estudio de sombras. Plaza de Chamberí

Fuente: elaboración propia

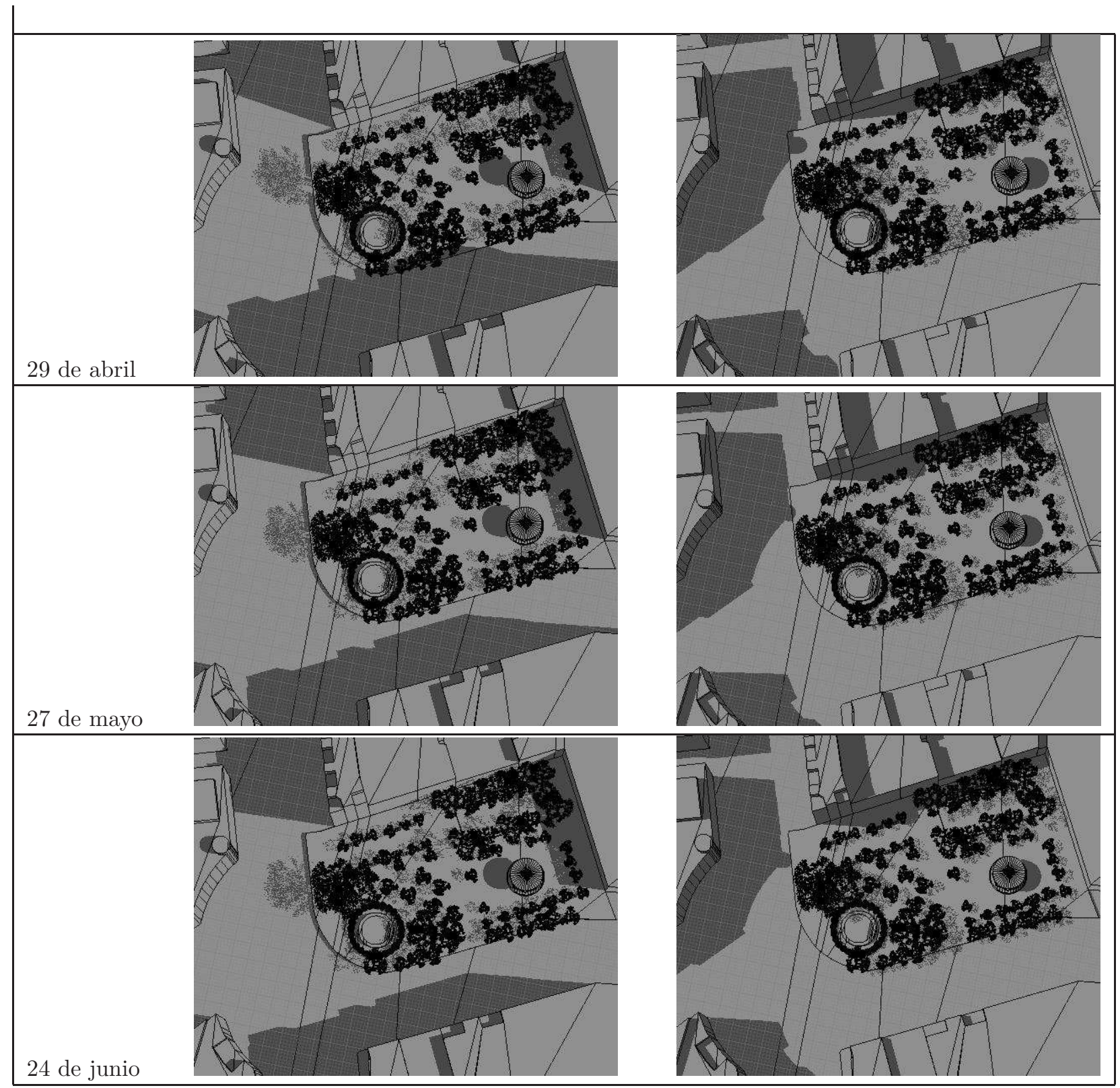




\section{Simulación de iluminación y energía}

La simulación de los niveles de iluminación y de la radiación total que llega a la plaza se ha realizado mediante el software Ecotect v.5.60 de Autodesk. Las bases climáticas empleadas son del programa EnergyPlus del Departamento de Energía de Estados Unidos de América, que las extraen de la World Meteorological Organization.

La simulación se ha realizado para el periodo completo de primavera. Los resultados extraídos en cada una de las plazas se pueden ver en las figuras 16, 17 y 18.

\section{Ruido}

En el distrito centro el $60 \%$ de la población está afectada por exceso de ruido, en el distrito de Chamberí se trata del $65 \%$ de la población, según los documentos de diagnóstico de sostenibilidad de los distritos madrileños realizados por el Área de Gobierno de Medio Ambiente. Todo el Distrito Centro se ha declarado Zona de Actuación Acústica, según lo previsto en el Título V del Plan General de Madrid de 1997. Las actuaciones están siendo llevadas a cabo a través del Plan Espacial de Reducción de la Contaminación Acústica (PERCA).

Sólo en las entradas de las calles que dan a la plaza del 2 de Mayo se superan los $65 \mathrm{dbA}$ durante el día. La zona con valores más altos de ruido es la vía rodada al este de la plaza. Por la noche, gran parte de la plaza se mantiene por debajo de los 50dBa, véase la figura 19.

La plaza de Chamberí tiene unos altos valores de ruido, superando en la mayor parte de la misma los $65 \mathrm{dbA}$, incluso los 70dbA, en las zonas que limitan con la calle Santa Engracia y Eduardo Dato, tanto de día como de noche. Tan sólo la esquina norte se mantiene en valores inferiores a los $65 \mathrm{dbA}$, véase la figura 20.

En la plaza de Vázquez de Mella el ruido se concentra en los viales rodados que circundan la plaza por tres de sus cuatro lados. La zona más al oeste de la plaza es aquella que alcanza mayores niveles de ruido llegando a superar los $70 \mathrm{dbA}$, véase figura 21 .

Los Límites de contaminación acústica para áreas residenciales consolidadas son los de Tipo II (Decreto 78/1999, de 27 de mayo), cuyos valores se pueden consultar en el CuADro 1.

\section{CUADRO 5: Valores Objetivo expresados en LAeq}

\begin{tabular}{|l|l|l|}
\hline Área de sensibilidad acústica & Período diurno & Período nocturno \\
\hline Tipo I (Área de silencio) & 60 & 50 \\
\hline Tipo II (Área levemente ruidosa) & 65 & 50 \\
\hline Tipo III (Área tolerablemente ruidosa) & 70 & 60 \\
\hline Tipo IV (Área ruidosa) & 75 & 70 \\
\hline Tipo V (Área especialmente ruidosa) & 80 & 75 \\
\hline
\end{tabular}

El ruido y la eliminación de la contaminación acústica es una de las principales quejas y demandas por parte de la población del distrito Centro y Chamberí en lo que al espacio público se refiere, junto con la falta de zonas verdes y la rehabilitación de espacios para equipamientos de carácter público, según los documentos de diagnóstico de sostenibilidad de los distritos madrileños realizados por el Área de Gobierno de Medio Ambiente.

\section{Mediciones en las plazas}

\section{Características del equipo}

Las mediciones se realizaron con un equipo Testo 400. Se emplearon tres sensores diferentes que se acoplaron al data logger:

- Una sonda de temperatura seca del aire $\left({ }^{\circ} \mathrm{C}\right)$ con precisión de $\pm 0.01^{\circ} \mathrm{C}$ y humedad relativa $(\%)$.

- Un sensor para la toma de datos de temperaturas de contacto de las diferentes superficies de las plazas $\left({ }^{\circ} \mathrm{C}\right)$.

- Una sonda termoanemométrica para medición de la velocidad del viento $(\mathrm{m} / \mathrm{s})$ y temperatura del aire $\left({ }^{\circ} \mathrm{C}\right)$. 


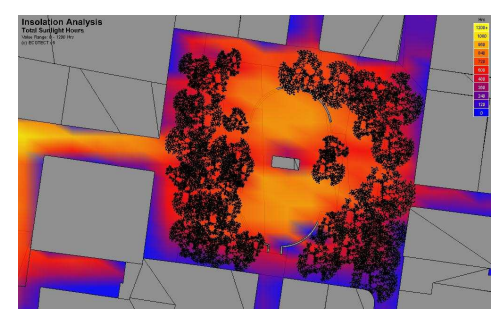

Horas de sol (h):

El rango de horas en las que las diversas partes de la plaza están soleadas durante los meses de primavera va desde las 00:00 horas, en color azul, hasta las 12:00 horas, en amarillo. Existe todo un perímetro de unos 2 metros al sur de la plaza con entre 0 y 120 h de sol, frente a la zona central de la plaza con un mínimo de $600 \mathrm{~h}$ hasta alcanzar más de $1.200 \mathrm{~h}$ soleada.

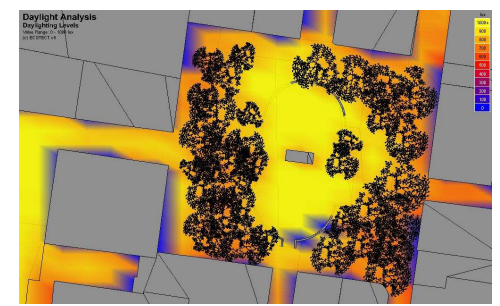

\section{Niveles de iluminación (lux)}

En la zona central de la plaza se alcanza un nivel de iluminación de hasta 1000lux. Las zonas con menor iluminación son los lados este y oeste de la plaza.
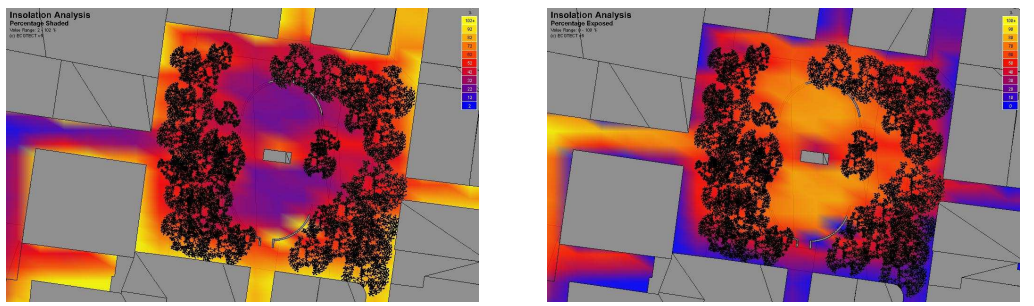

Porcentaje de sombra y porcentaje de sol (\%)

El rango del tiempo que las diversas zonas de la plaza permanecen al sol o a la sombra va del $0 \%$ al $100 \%$. La zona central de la plaza tan sólo permanece a la sombra un $2 \%$ del tiempo a lo largo de los días de primavera. El lao sur de la plaza es el que se encuentra más tiempo en sombra, sin recibir luz directa en ningún momento en zonas muy puntuales.

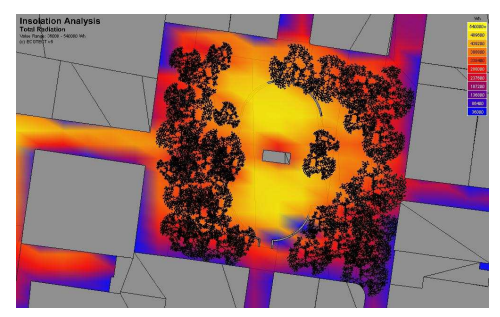

\section{Radiación solar total (Wh)}

En la radiación total está incluida tanto la directa como la difusa. La radiación máxima recibida está en la zona central, a ambos lados de la puerta de Monteleón, alcanzando los 540.000Wh recibidos durante la primavera. Los mínimos se establecen en el perímetro de la plaza con 36.000Wh.

\section{Figura 13: Plaza del 2 de Mayo}




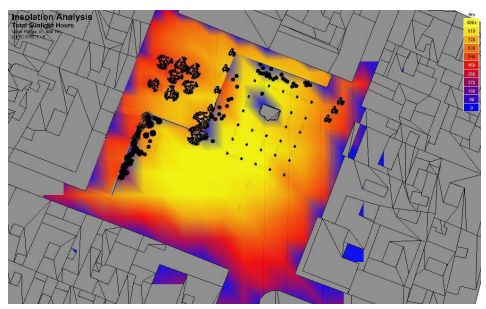

Horas de sol (h):

Parte de la zona central y casi toda la zona con bancos tiene entre $810 \mathrm{~h}$ y $900 \mathrm{~h}$ de sol. La zona alta de la plaza está menos horas soleada, entre 450h y $720 \mathrm{~h}$. Son muy puntuales las zonas con ninguna hora de sol.

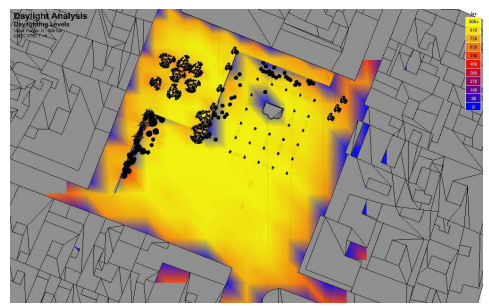

\section{Niveles de iluminación (lux)}

Prácticamente toda la plaza tiene unos niveles de iluminación medios en primavera de entre 810lux y 900lux. Tan sólo en el perímetro de la plaza y en zonas puntuales es de entre 90lux y 180lux.
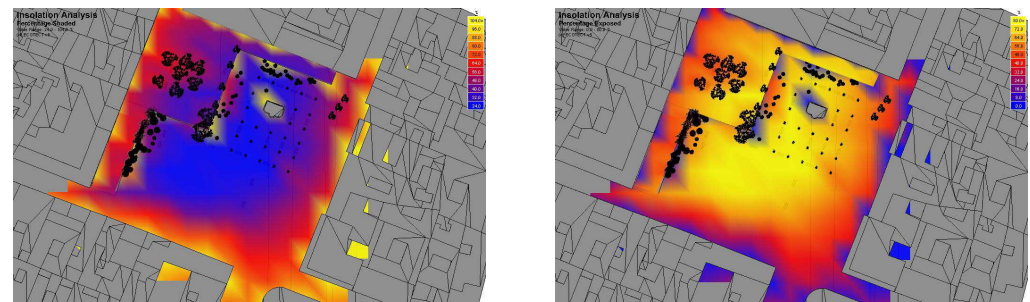

Porcentaje de sombra y porcentaje de sol (\%)

Vázquez de Mella es una plaza con escaso porcentaje de sombra y los puntos sombreados no tienen carácter estancial, ya que se encuentran principalmente en torno a los viales rodados. Tan sólo en la zona alta de la plaza, bajo los árboles, hay una proporción de sombra entre el 64 y $72 \%$.

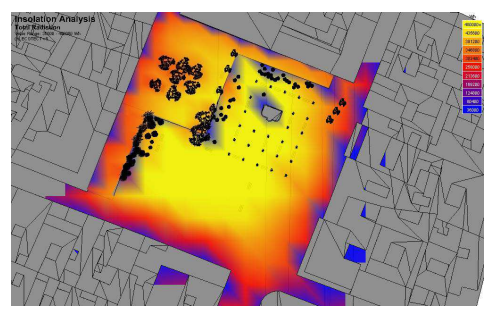

\section{Radiación solar total (Wh)}

Parte de la zona central de la plaza y la zona con bancos son aquellas que reciben una radiación global más elevada, con 480.000Wh durante la primavera. Los puntos con menor radiación solar reciben entre 36.000Wh y 80.400Wh.

Figura 14: Plaza de Vázquez de Mella 


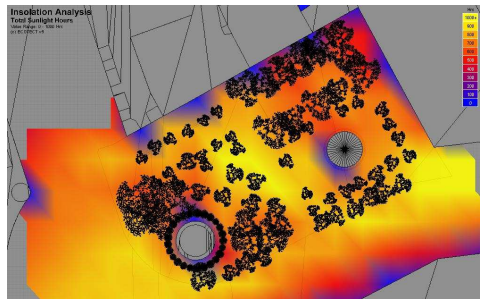

Horas de sol (h):

Tanto en la zona central de la plaza, entre la fuente y el kiosco, donde no existe arbolado, como en la esquina este se reciben más de 1.000h de sol. La zona con menos horas de sol es la esquina norte, que por su orientación debería estar bastante soleada, pero el arbolado existente crea una zona en sombra.

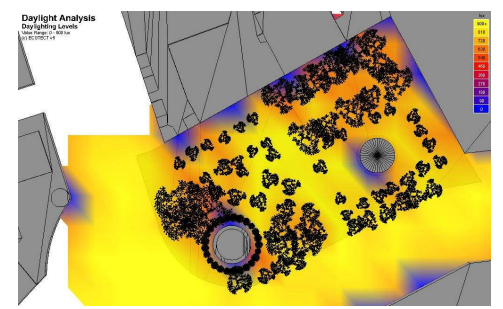

\section{Niveles de iluminación (lux)}

La mayor parte de la plaza tiene unos niveles de iluminación natural de entre 810lux y 900lux.
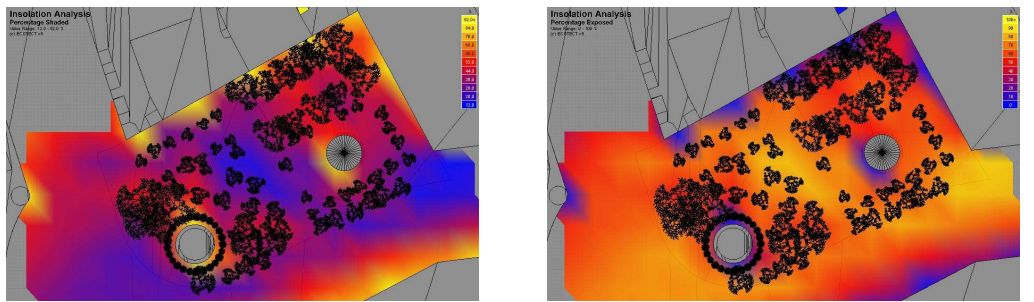

Porcentaje de sombra y porcentaje de sol (\%)

Chamberí es una plaza muy soleada, pocos puntos de la misma tienen un porcentaje de inferior al $70 \%$. El arbolado existente es el que más sombra proporciona, así como el convento de las Siervas de María.

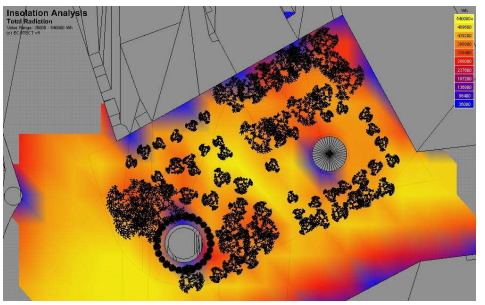

\section{Radiación solar total (Wh)}

En las zonas con más horas de sol se reciben más de $540.000 \mathrm{Wh}$, mientras que en las zonas más sombrías se reciben entre $36.000 \mathrm{Wh}$ y $86400 \mathrm{Wh}$.

\section{Figura 15: Plaza de Chamberí}


Nivel de ruido equivalente diurno

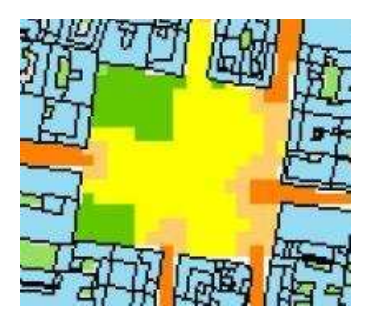

Nivel de ruido equivalente vespertino

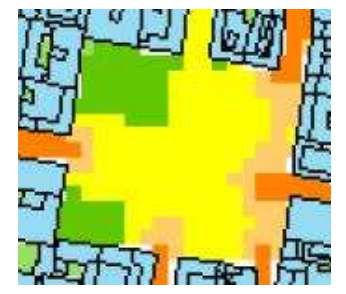

Nivel de ruido equivalente nocturno
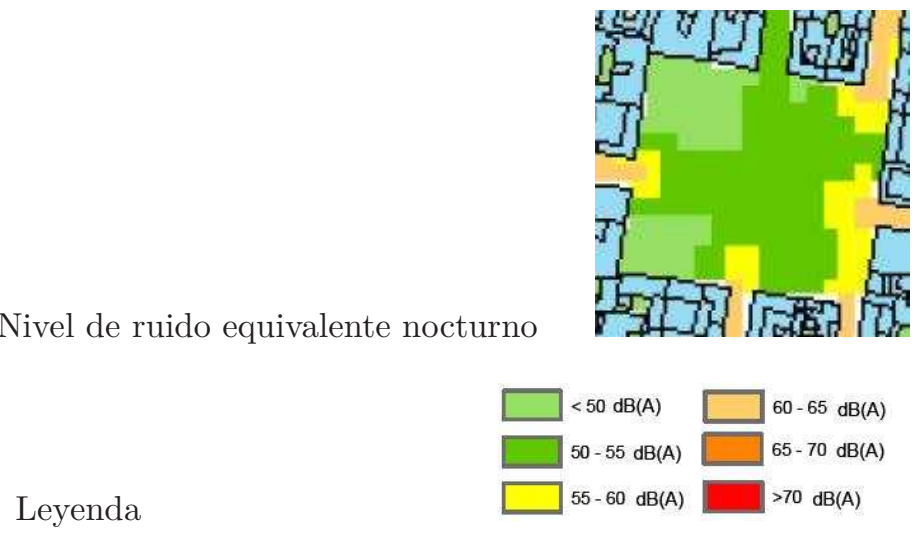

Figura 16: Mapa de ruido de la plaza del 2 de Mayo

Fuente: Mapa de ruido del Área de Gobierno de Medio Ambiente 2006, distrito 01: Centro (Ayuntamiento De MADRID, 2006). 
Nivel de ruido equivalente diurno

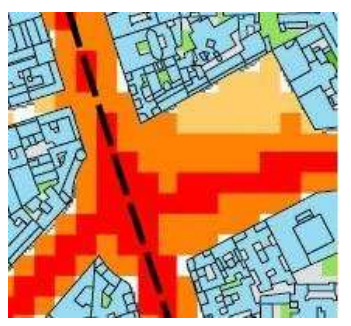

Nivel de ruido equivalente vespertino

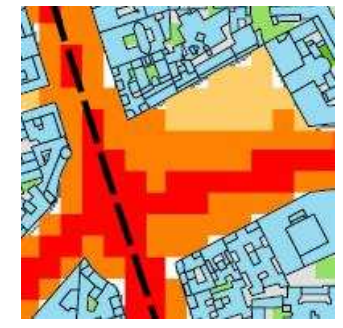

Nivel de ruido equivalente nocturno

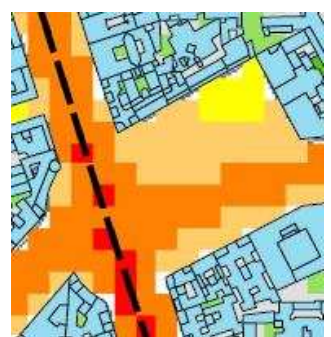

$\square<50 \mathrm{~dB}(\mathrm{~A}) \quad \square \quad 60-65 \mathrm{~dB}(\mathrm{~A})$
$\square 50-55 \mathrm{~dB}(\mathrm{~A}) \quad \square \quad 65-70 \mathrm{~dB}(\mathrm{~A})$
$\square 55-60 \mathrm{~dB}(\mathrm{~A})$
$\square \quad>70 \mathrm{~dB}(\mathrm{~A})$

Figura 17: Mapa de ruido de la plaza de Chamberí

Fuente: Mapa de ruido del Área de Gobierno de Medio Ambiente 2006, distrito 01: Centro. (Ayuntamiento DE MADRID, 2006). 
Nivel de ruido equivalente diurno

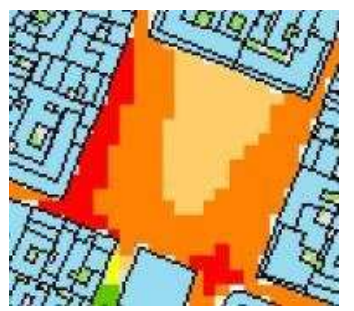

Nivel de ruido equivalente vespertino

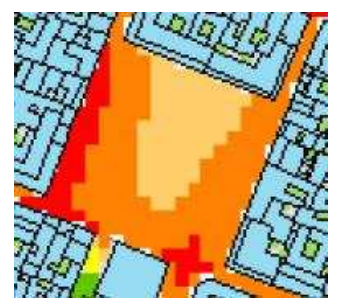

Nivel de ruido equivalente nocturno

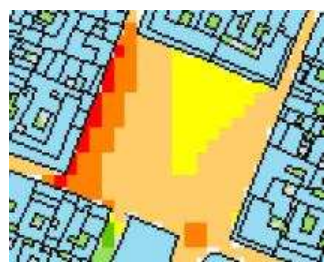

$<50 \mathrm{~dB}(\mathrm{~A}) \quad \square \quad 60-65 \mathrm{~dB}(\mathrm{~A})$
$50-55 \mathrm{~dB}(\mathrm{~A}) \quad \square \quad 65-70 \mathrm{~dB}(\mathrm{~A})$

Leyenda

$55-60 \mathrm{~dB}(\mathrm{~A})$

$>70 \mathrm{~dB}(\mathrm{~A})$

Figura 18: Mapa de ruido de la plaza de Vázquez de Mella

Fuente: Mapa de ruido del Área de Gobierno de Medio Ambiente 2006, distrito 01: Centro (Ayuntamiento De MADRID, 2006). 
Como apoyo se empleó una cámara térmica o termográfica FLIR Systems con una precisión de $\pm 2{ }^{\mathrm{O}} \mathrm{C}$. El objetivo era medir la emisión natural de radiación infrarroja procedente de los objetos y superficies de la plaza, generando una imagen térmica y conociendo así la temperatura a la que se encuentran esas superficies.

La emisividad de los materiales condiciona los datos extraídos de la cámara termográfica, por lo que a la hora de tomar las termografías, la cámara se ha ajustado para una emisividad correspondiente a la del granito y los pavimentos de cemento y ladrillo, esto es, entre 0.9 y 0.93 .

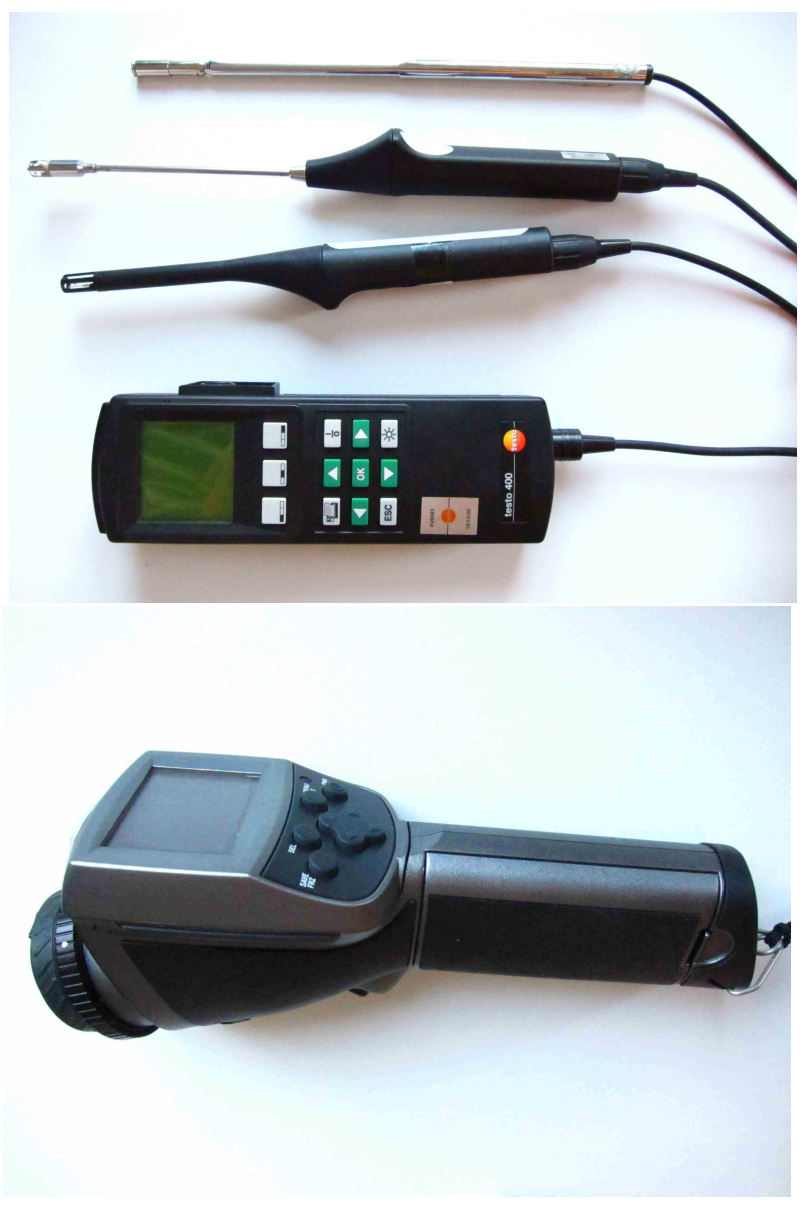

FIGURA 19: Instrumental utilizado

Fuente: elaboración propia

\section{Localización de las medidas}

La toma de datos higrotérmicos se ha llevado a cabo con los siguientes criterios:

- Las temperaturas y humedades al sol se han tomado en los puntos que han permanecido a la sombra durante todo el día o las mayores horas posibles del día.

- El mismo criterio se ha seguido para la toma de datos en los puntos a la sombra, seleccionando aquellos que permanecen sombreados todo el día o la mayor parte de él.

- La lecturas tomadas al sol se han llevado a cabo protegiendo la sonda de la radiación solar directa para no obtener datos falseados.

- En ocasiones puntuales se han realizado medidas de temperaturas de contacto a la sombra también en zonas que habían estado anteriormente soleadas para poder observar las diferencias existentes en los mismos materiales cuando han permanecido totalmente sombreados o cuando han recibido ciertas horas de sol (medidas señaladas en rojo en las tablas de mediciones). 
- Las temperaturas y humedades cerca del agua han sido tomadas siempre al sol protegiendo la sonda de la radiación solar directa.

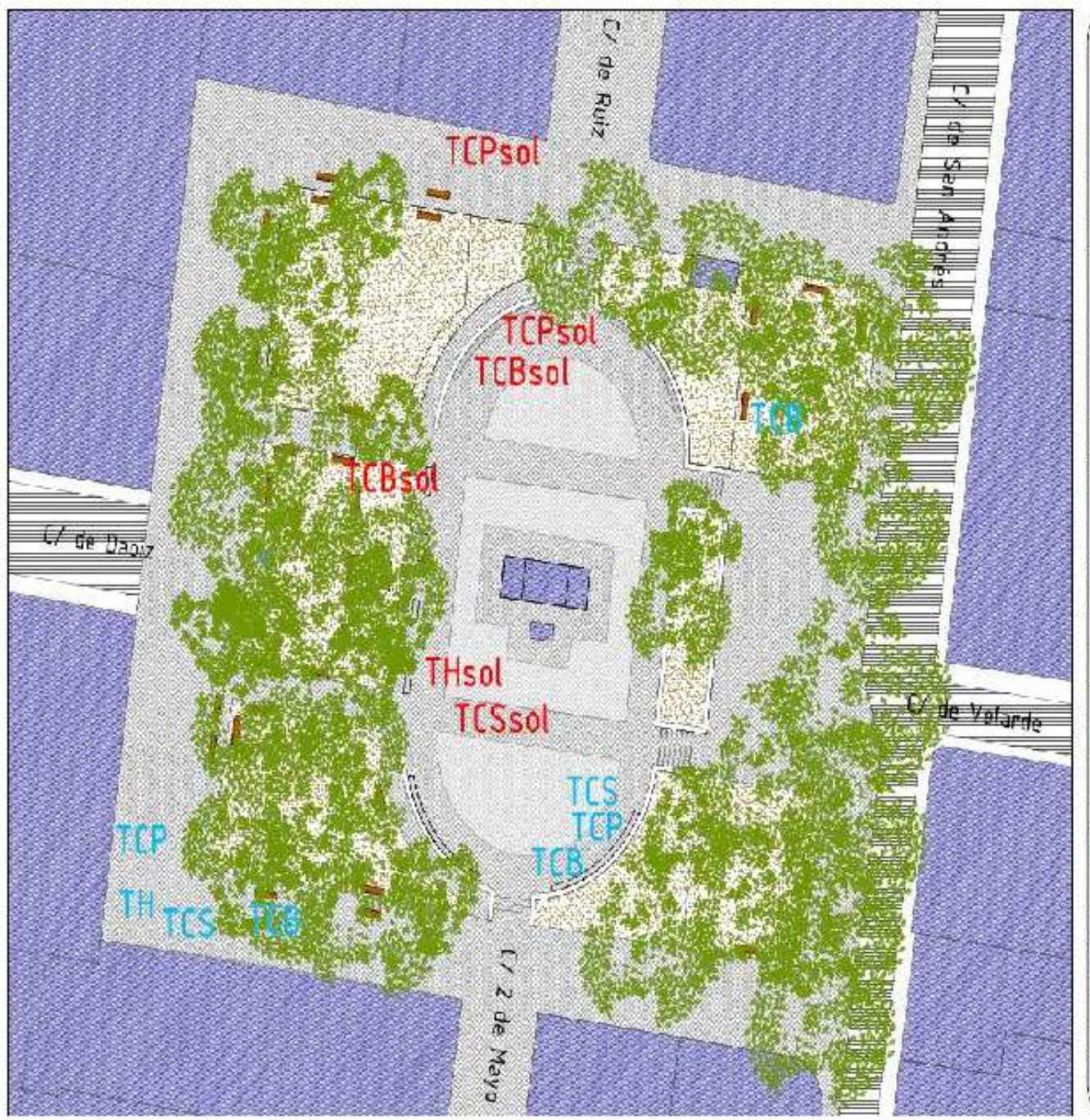

LEYENDA

THsol:

eетperatura y

humecad al sol

Temperatura y

humecad a la

sombra

THagua:

emperatura "

humecad junto al

agua

TCSsol:

Temperatura de

contacto del suelo

al 501

ICPsol:

Temperatura de

contacto de

factiadas al sol

TCBsol:

Temperatura de

contado de bancos

al sol

ics.

Temperatura de

cenracto del suelo

a la sombra

TCF:

Temperatura de

conracto de

fachadas a la

sombra

TCE:

Temperatura de

contacto de benros

a la

Figura 20: Mediciones realizadas en la Plaza del 2 de Mayo

Fuente: elaboración propia

Los planos son correspondientes a este apartado se pueden ver en las figuras 23, 24 y 25.

\section{Planos resumen del estudio climático de las plazas}

Los planos resumen del estudio climático de las plazas analizadas se pueden consultar descargando los archivos correspondientes en la página web de la Biblioteca $\mathrm{CF}+\mathrm{S}$ 


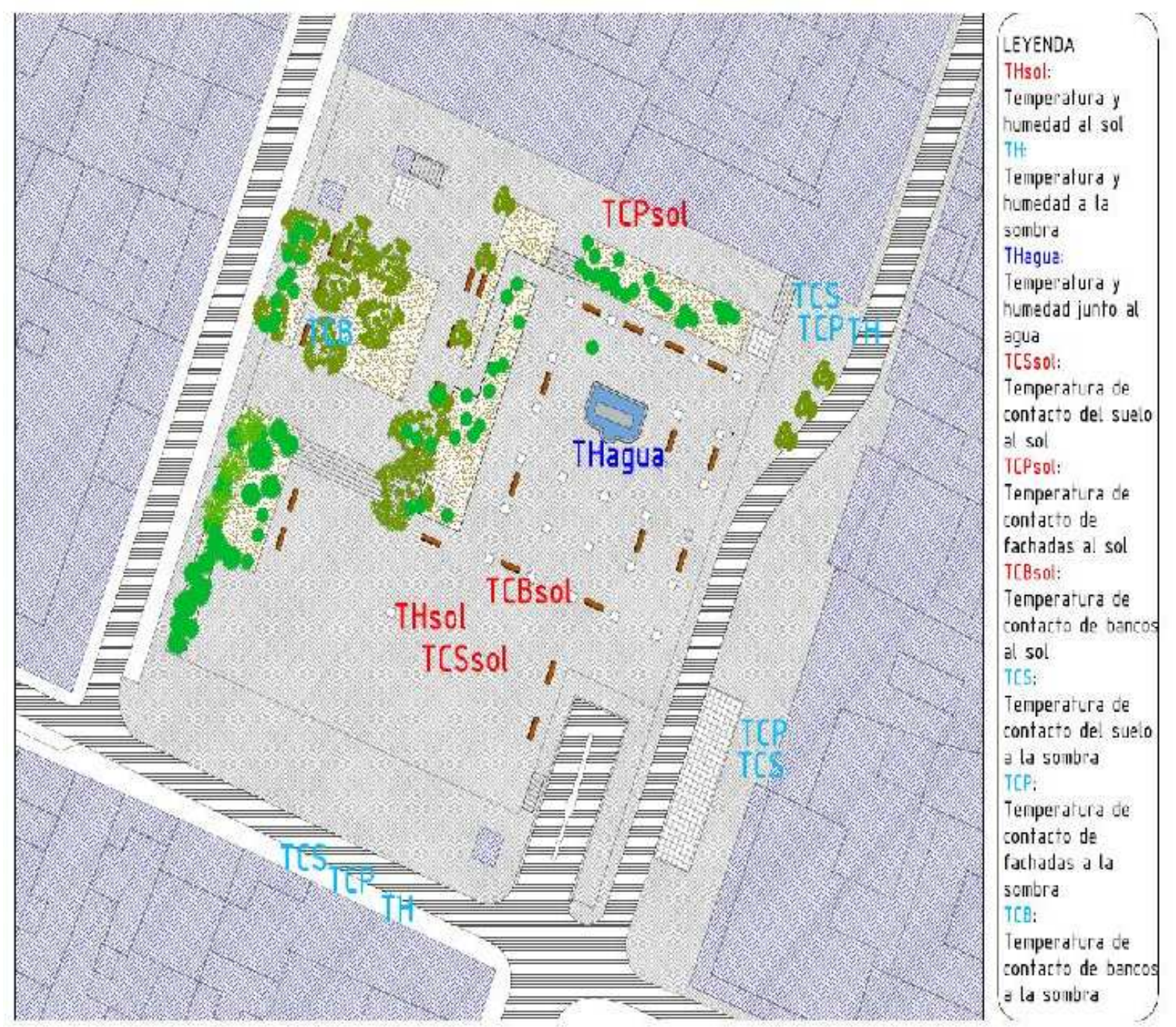

Figura 21: Mediciones realizadas en la plaza de Vázquez de Mella Fuente: elaboración propia 


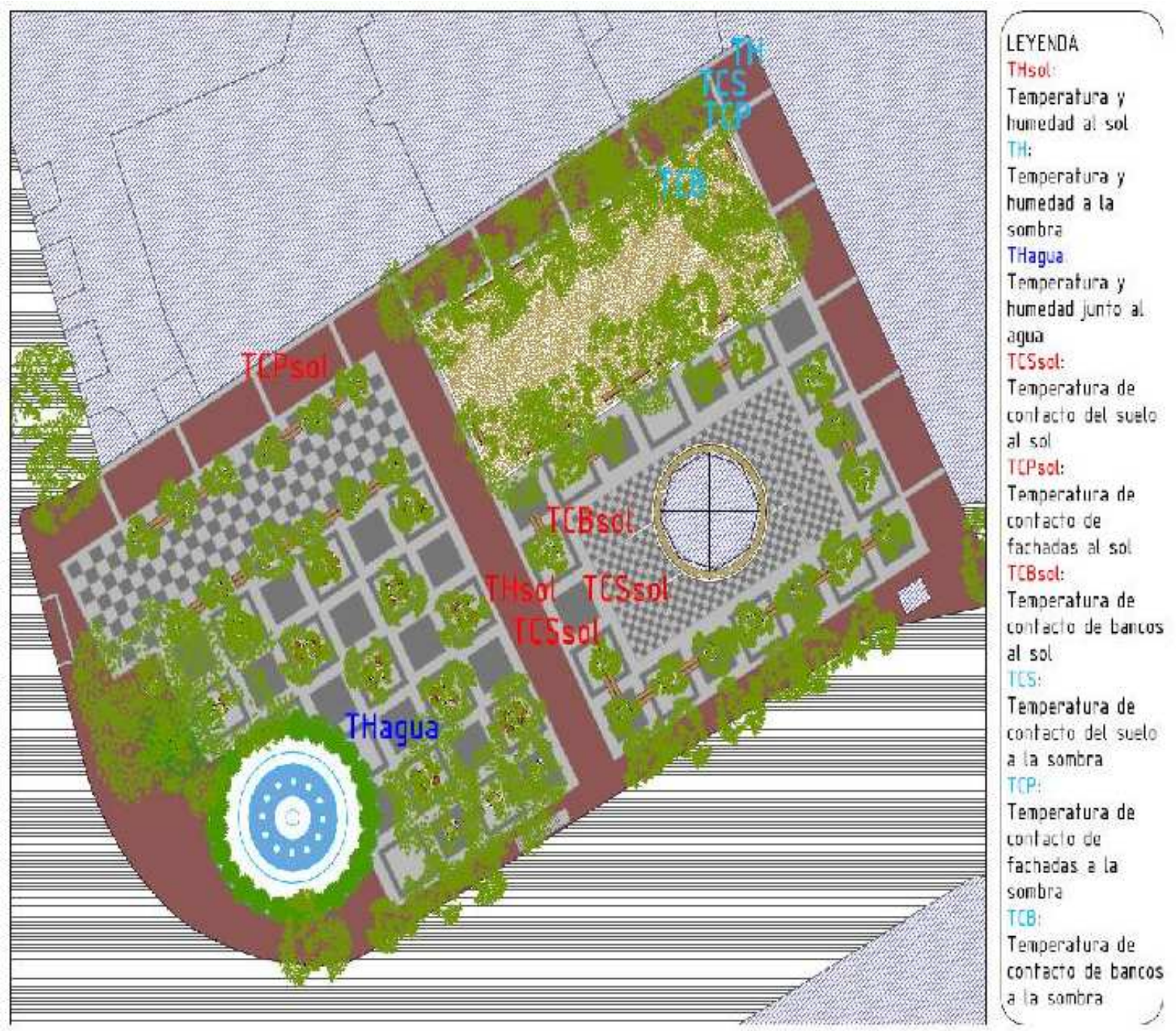

Figura 22: Mediciones realizadas en la plaza de Chamberí Fuente: elaboración propia 


\section{Estudio de las características físico-espaciales de las plazas}

\section{Evolución histórica de las plazas}

\section{Plaza del 2 de Mayo}

La plaza del 2 de Mayo se ubica en el distrito Centro de Madrid, en el barrio de Universidad. El barrio y sus casas se desarrollaron en dos etapas, el siglo XVII y el siglo XIX, aunque la trama es relativamente homogénea.

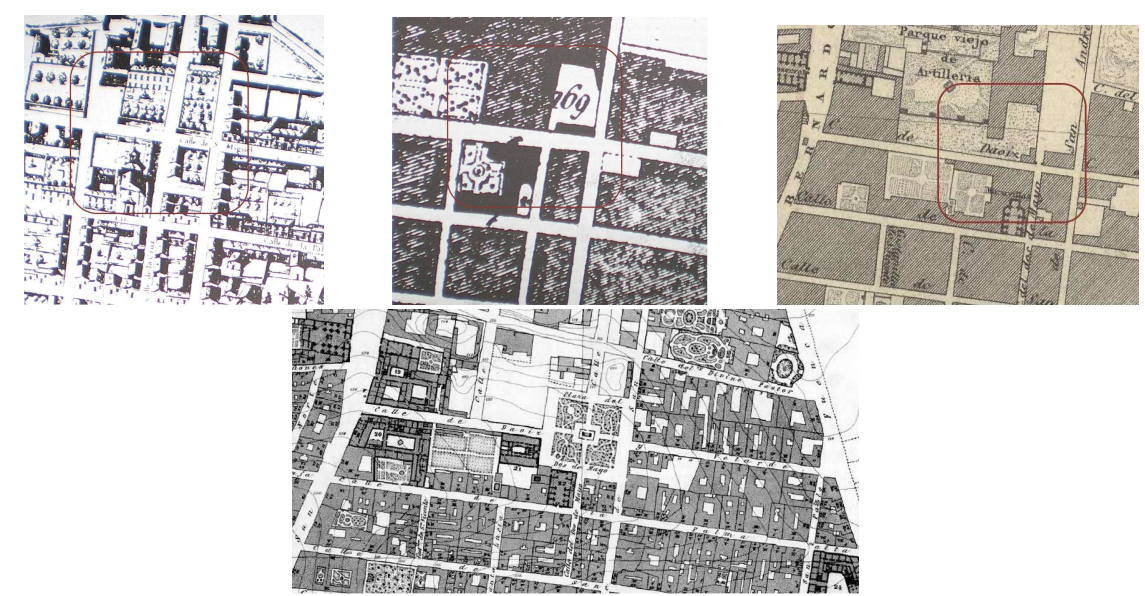

Las imágenes corresponden respectivamente a 1656 (en el plano de Texeira), a 1812 (en el plano de

Juan López), a 1848 y a 1880; pudiendo distinguirse en la primera el Convento de las Maravillas y frente a él una vivienda con jardín que pudo ser el origen del Palacio de Monteleón y siendo la última el estado del proceso de edificación de la zona hacia 1880.

Figura 23: La plaza del 2 de Mayo en distintos momentos

La fuente de las dos primeras es el libro Espacios Públicos en el Centro Histórico de Madrid y la página de la Comunidad de Madrid de las dos últimas

En el solar estuvo el Palacio de Monteleón (1690), que Godoy, en 1807 convirtió en cuartel y que fue derribado en 1868. En la actual plaza, además del cuartel, también estuvo parte del Convento de las Carmelitas Descalzas o de las Maravillas (1616), del que actualmente sólo se conserva su iglesia (1646), la parroquia San Justo y Pastor.

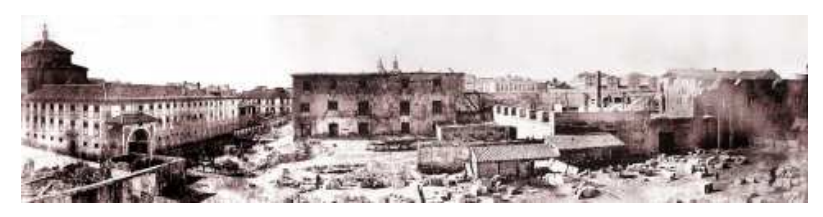

Figura 24: Panorámica del cuartel de Monteleón y alrededores en la fecha de su derribo, 1868

La fotografía fue encargada por el entonces alcalde de Madrid, FERnÁndez DE LOS Ríos

En 1868 FERNÁNDEZ DE LOS Ríos propone la realización de una square en su publicación Futuro Madrid en torno al arco de entrada del desaparecido cuartel de artillería de Monteleón, creándose una placita semicircular. El 1 de mayo de ese año se inaugura la Plaza del Arco y el 5 de mayo el Convento Maravillas cede los terrenos al ayuntamiento que, días después, realizará una propuesta de ampliación de la plaza. El 1 de mayo de 1869 se inaugurará la nueva plaza, que ya tiene una forma rectangular y un tamaño suficiente para considerarse un auténtico espacio público y no sólo un vacío para colocar el arco de Monteleón. El conjunto de Daoíz y Velarde, realizado por AnTonio Solá en 1822, se emplaza en 1869 de manera definitiva en la plaza. Ese mismo año se propone ensanchar las calles circundantes a la plaza a 10 metros, terminándose de realizar las nuevas alineaciones en 1877. 


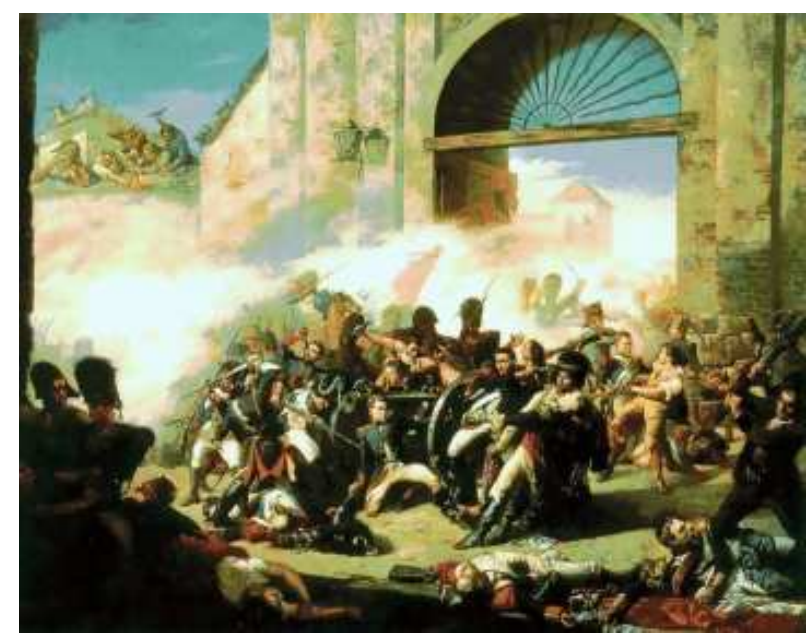

Figura 25: 2 de Mayo de 1808. Se aprecia el arco de entrada al cuartel de Monteleón Fuente: http://urbancidades.wordpress.com

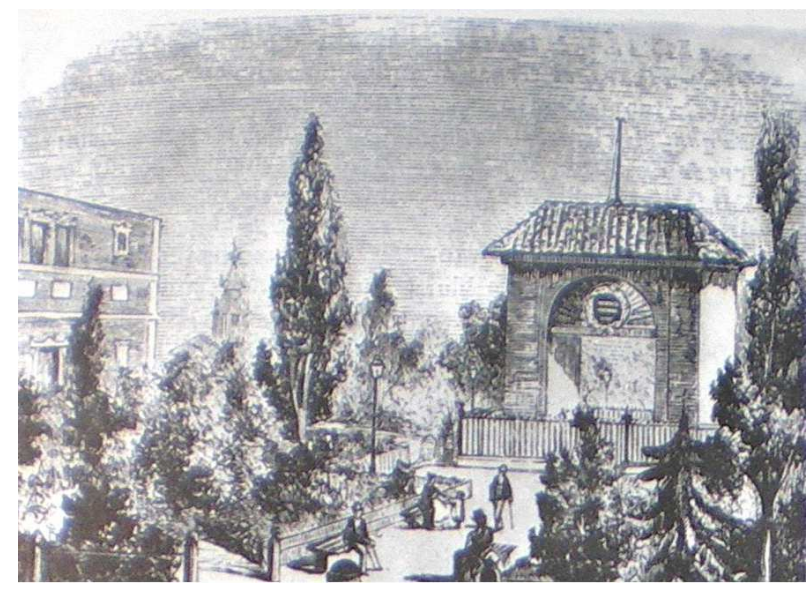

Figura 26: Grabado de la plaza del 2 de Mayo inaugurada. 1869. Los edificios de alrededor están aún sin construir.

Fuente: Espacios Públicos en el Centro Histórico de Madrid 
En 1904, el anteproyecto de reforma interior de Madrid plantea ampliar los límites de la plaza, pero esta propuesta no se llevará a cabo. En 1930 se modifica el ajardinamiento. En 1950 se rediseñó la plaza y en los años 70 se eliminó en tres de los cuatro lados de la plaza el vial rodado con aparcamiento en superficie que existía.

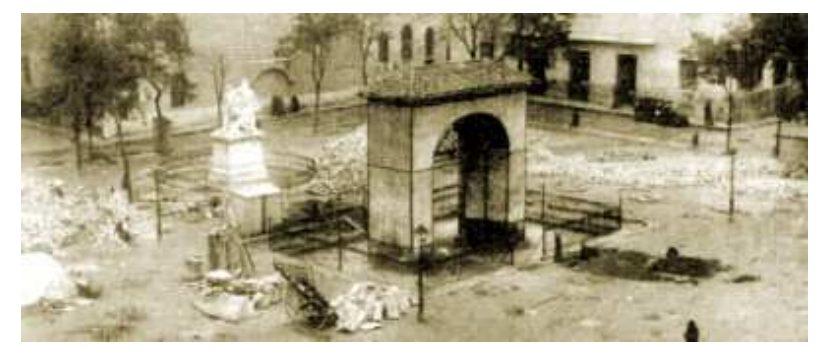

Figura 27: Plaza del 2 de Mayo en 1943

Durante unas obras de remodelación propuestas por PEDRO BIDAGOR para crear un espacio libre de esparcimiento. Fuente: Revista Foros
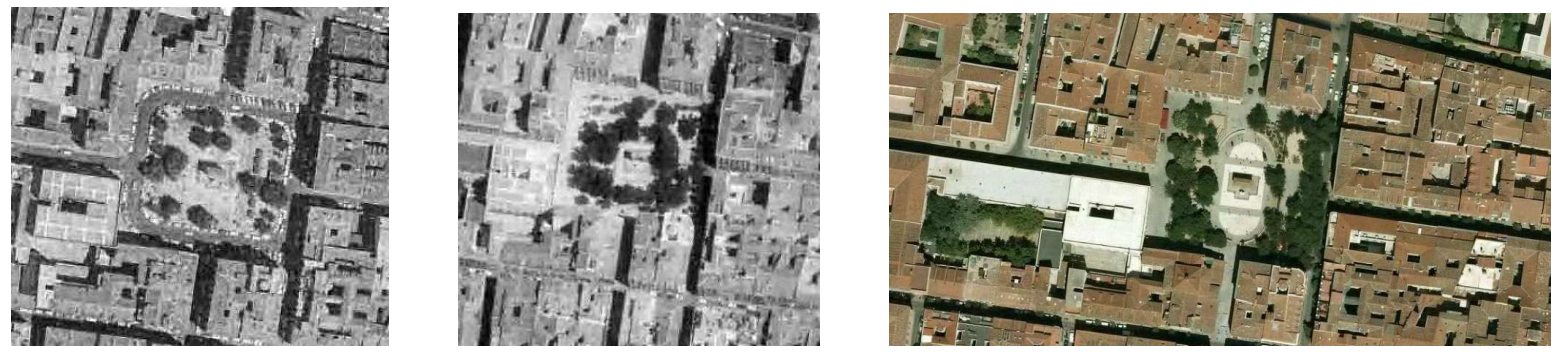

Figura 28: Fotografías aéreas de la plaza del 2 de Mayo

Son imágenes de 1975, 1991 y de la actualidad. Fuente: http://www.madrid.org

La configuración actual de la plaza es muy similar a la original, donde tan sólo se han ido modificando usos del espacio público.

La plaza del 2 de Mayo fue declarada Área de Rehabilitación Preferente: Área I: Plaza del 2 de Mayo. Las Áreas de Rehabilitación Preferente son fruto de la colaboración entre el Ayuntamiento de Madrid, el Ministerio de Obras Públicas (MOPU), actualmente Ministerio de Fomento, y la Comunidad de Madrid. El primero de los convenios de colaboración se suscribió en 1994 y fue objeto de diversos acuerdos posteriores de revisión y ampliación.

El barrio de Universidad fue el primer caso de envergadura en la recuperación integral del Centro Histórico madrileño (Convenio entre el Ayuntamiento, la Comunidad de Madrid y el Ministerio de Fomento), y fue premiado con el galardón Europa Nostra.

\section{Vázquez de Mella}

La plaza de Vázquez de Mella se encuentra en el distrito Centro, en el barrio de Justicia. El nombre original de la plaza era Plaza o Plazuela Bilbao. Este espacio urbano se constituyó tras ser derribada la Iglesia y Convento de los Capuchinos de la Paciencia.

La antigua plaza Bilbao cambió de nombre varias veces, hasta que en 1946, con la colocación de la fuente conmemorativa a Vázquez de Mella el 24 de julio, que actualmente se encuentra en la ubicación original, adquirió el nombre de éste. 32 .

Originalmente era una plaza con jardines y arbolado, como se puede observar en los planos de la figura

En 1950 se construye un aparcamiento en la plaza que no será demolido hasta 1999. En este año la Comunidad de Madrid impulsa la remodelación de la plaza dándole la configuración que tiene en 

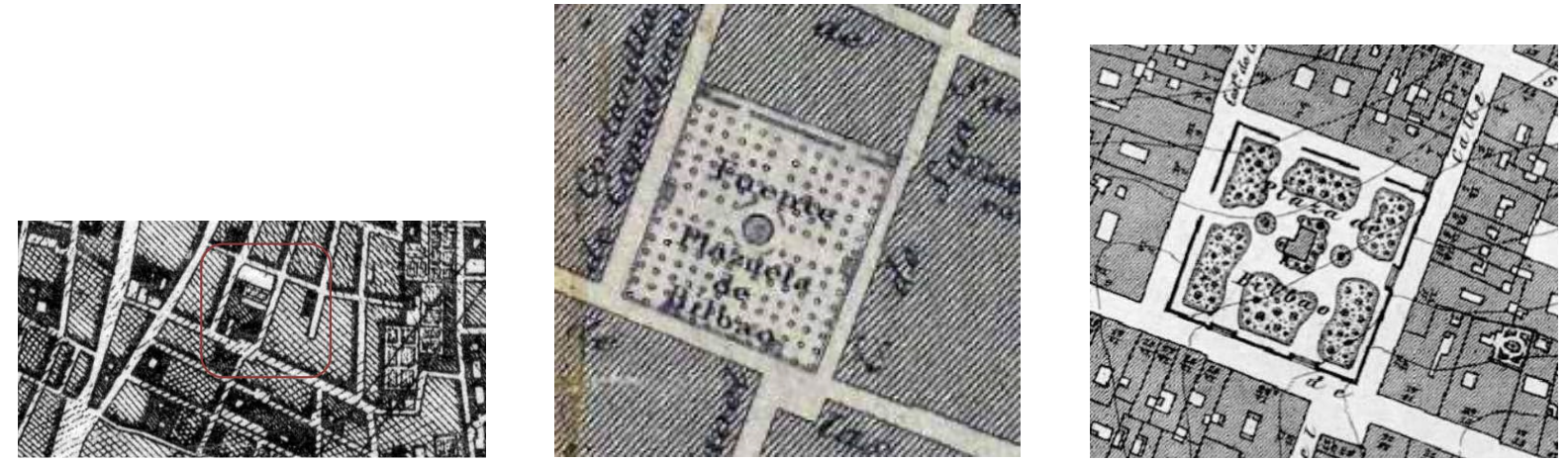

Figura 29: La plaza de Vázquez de Mella en distinos momentos Las imágenes son respectivamente de 1808, 1848 y 1873. Fuente: http://www.madrid.org

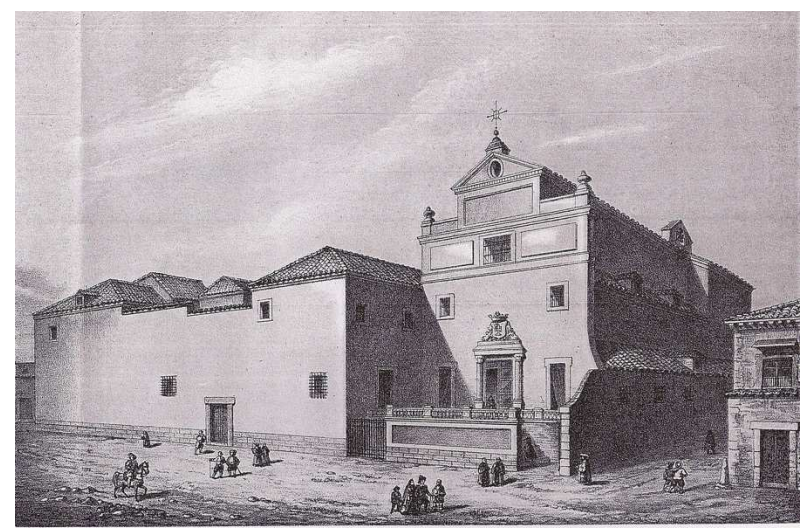

Figura 30: Convento de los Capuchinos de la Paciencia Según litografía de LETRE. Siglo XIX. Fuente: http://www.monumentamadrid.es 
la actualidad y construyendo tres plantas de aparcamiento soterrado. En 2005, se presentó un nuevo proyecto de reacondicionamiento del aparcamiento soterrado redactado por el estudio de arquitectura Teresa SAPEY.

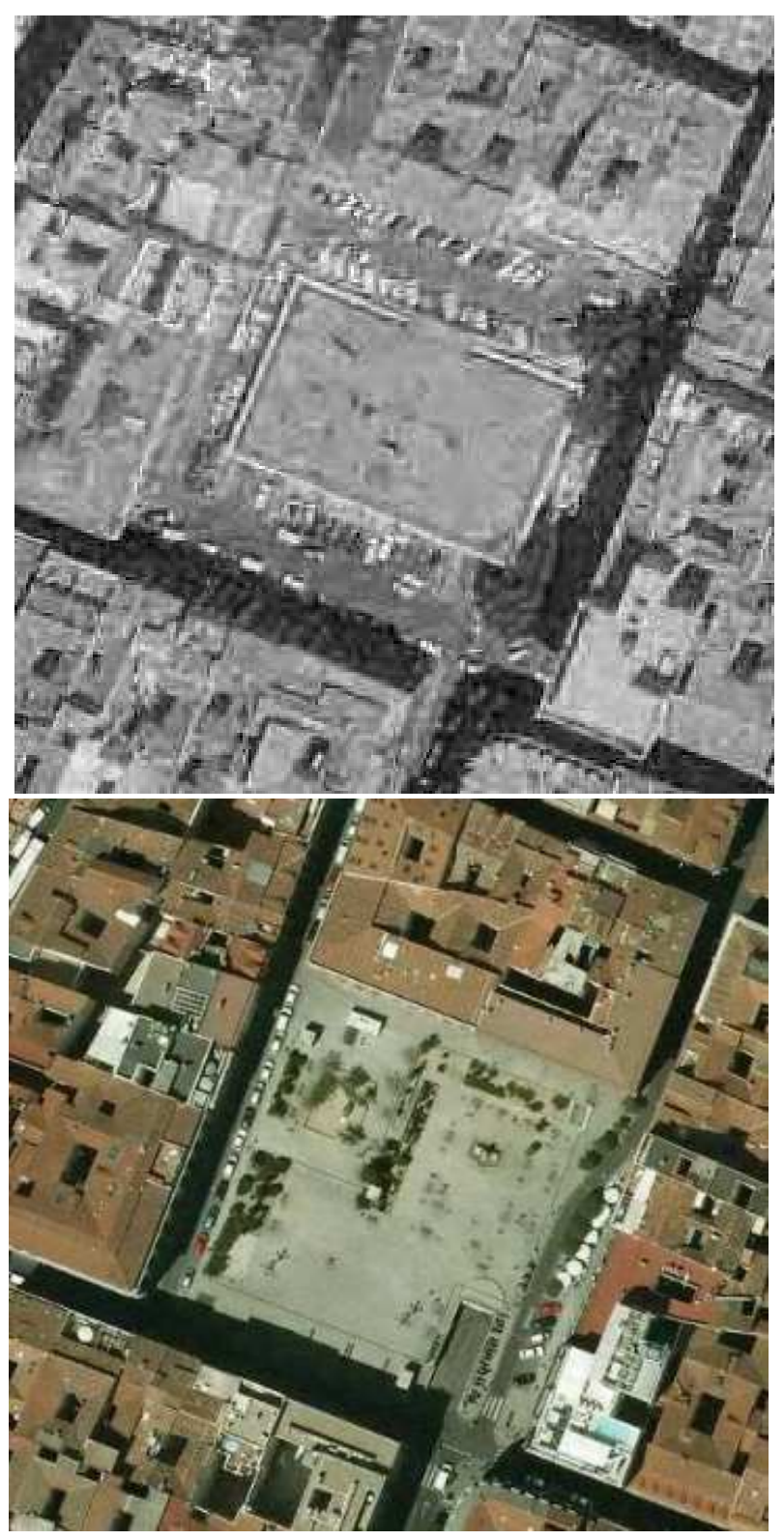

Figura 31: Fotografías aéreas de la plaza de Vázquez de Mella de 1975 y de 2008 Fuente: http://www.madrid.org

\section{Chamberí}

La plaza Chamberí se ubica en el distrito madrileño con el mismo nombre, Chamberí, en el barrio de Almagro. Durante la Edad Media, los actuales terrenos del distrito de Chamberí pertenecían a la Orden del Temple, hasta que, tras su disolución en el siglo XIV, pasaron a formar parte del Consejo de Fuencarral. Esta zona estaba cubierta de bosque que la Corte empleaba para sus cacerías, hasta que CARlos I comienzó a talar esta zona.

La zona de Santa Engracia tenía huertas que fueron explotadas hasta comienzos del siglo XX. La Iglesia, los nobles, la monarquía y los campesinos acomodados se repartieron el $80 \%$ de los terrenos en el siglo XVII. Desde finales del siglo XVIII hasta principios del XIX la agricultura fue perdiendo importancia 
a favor de la industria en esta zona. El Distrito de Chamberí surgió a partir de 1860 en terrenos situados al norte de la recién derribada cerca que había rodeado la ciudad desde tiempos de FELIPE IV.

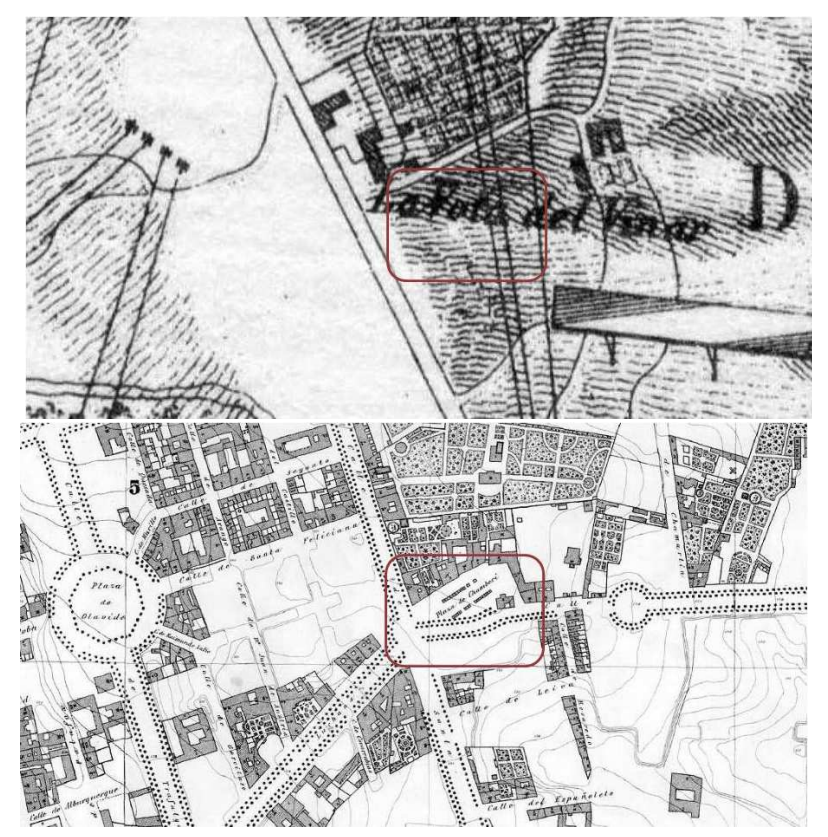

Figura 32: La plaza de Chamberí en distintos momentos

Los planos corresponden a 1808 y a 1873 respectivamente. Fuente: http://www.madrid.org

A principios del siglo XIX se comenzarán a construir las primeras viviendas para los trabajadores, así como los primeros paseos arbolados, como el de Eduardo Dato o la calle Luchana, dos de los viales actuales que configuran la Plaza de Chamberí. Estos viales de esparcimiento propician la aparición de quintas de recreo como la del Marqués de Santiago en la actual plaza Chamberí, antes denominada la plaza vieja, cuya casa, llamada de las 'Columnas', ocupaba el actual emplazamiento de la Junta de Distrito.

Durante la ocupación francesa en España las tropas napoleónicas construyeron un cuartel militar que llamaron Chambèry. Se dice que una pequeña milicia formada por madrileños del barrio, entre la que se encontraban DAoíz y Velarde, durante los sucesos del 2 de Mayo, subieron por la calle Luchana desde Malasaña y Tribunal para enfrentarse a los soldados franceses.

Tras la desamortización de MendizABAL, al pasar la mayor parte de los terrenos a manos privadas y del Estado, durante los siglos XIX y XX comienza a urbanizarse esta zona.

La plaza de Chamberí está situada en el cruce de las calles Eduardo Dato y Santa Engracia y se encuentra al final de la calle Luchana, que une esta plaza con la glorieta de Bilbao. Da nombre a uno de los barrios más castizos de Madrid. En ella nació LARgo CABALlero, ministro de Trabajo durante la II República.

En 1975 la plaza tenía la forma general actual, aunque un vial rodado la rodeaba totalmente y existían aparcamientos entre los edificios que hoy directamente dan a la plaza. Ya a comienzos de los años 90 se eliminaron los aparcamientos y la vía de acceso rodado que rodeaba la plaza. Bajo la plaza está la única estación clausurada del metro de Madrid, la estación de Chamberí.

\section{Características físicas y materiales}

\section{Plaza del 2 de Mayo}

La plaza del 2 de Mayo tiene unas dimensiones generales de $69 \times 77 m^{2}$, con una superficie total de $5.313 m^{2}$. Su forma general, por lo tanto, es prácticamente cuadrada.

Los edificios que la circundan tienen entre 2 y 7 plantas. Los edificios con mayor frente de fachada a la plaza son los de 5 plantas. Tomando esta altura como referencia, la plaza tendría una proporción altura-anchura de entre $1 / 4,8$ y $1 / 4,3$.

En la figura 40 se han identificado los diferentes pavimentos, mobiliario urbano, fuentes y arbolado. 


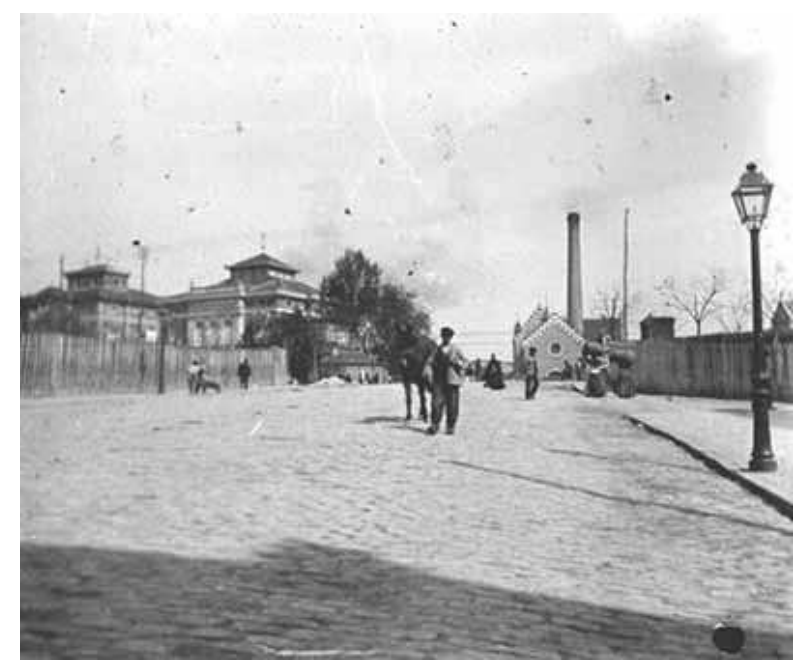

Figura 33: Calle Luchana desde Glorieta Bilbao. 1900

Fuente: http://www.archivofotograficodemadrid.com

El 30,3\% del pavimento de la plaza es permeable, con $1.610 \mathrm{~m}^{2}$ aproximadamente. La calzada rodada tan sólo supone un $8 \%$, con unos $430 \mathrm{~m}^{2}$. Por lo tanto, el $61,7 \%$ del pavimento es de granito, siendo el predominante. Con respecto a mobiliario urbano, hay 15 bancos de madera, 4 de granito y 4 grandes bancos corridos en el centro de la plaza, también de granito. Además, la plaza tiene una fuente de agua potable.

\section{Plaza de Vázquez de Mella}

La plaza Vázquez de Mella tiene unas dimensiones generales de $77 \times 73 m^{2}$, con una superficie total de $5.621 \mathrm{~m}^{2}$, por lo que su forma en planta es prácticamente cuadrada.

La plaza se distribuye en dos niveles, con una plaza de menor dimensión sobrelevada de $30 x 35 \mathrm{~m}^{2}$ en la esquina norte de la plaza.

En la figura 43 se presenta la planta de la plaza, donde se distinguen pavimentos, arbolado, fuentes y bancos.

Los edificios con frente a la plaza de mayor presencia son aquellos de 6 pisos, pudiendo encontrar edificios de 4 a 8 pisos. De modo general, la proporción altura-anchura sería de entre $1 / 4$ y $1 / 3$, 85. En la plaza hay 46 bancos corridos y una fuente ornamental. El pavimento predominante es el de granito gris, con $3.375 \mathrm{~mm}^{2}$, lo que supone el $60 \%$ de la superficie en planta de la plaza. Los pavimentos permeables (arena y jardines) son tan sólo el 8,5\% de la superficie de la plaza. Existen numerosas rejillas de ventilación del garaje bajo la plaza. El resto lo componen viales rodados.

\section{Plaza de Chamberí}

La plaza de Chamberí tiene $48 \times 87 m^{2}$, con una superficie total de $4.176 m^{2}$. Sin embargo, los edificios que configuran el espacio abierto donde se asienta la plaza tienen mayores distancias entre ellos que las señaladas anteriormente, con unas dimensiones generales de $71 \times 121 \mathrm{~m}^{2}$. Así, la plaza ocupa algo menos del $50 \%$ del espacio libre existente, estando el resto ocupado por carriles rodados.

Exceptuando la zona de juegos de niños, cubierta de arena, el resto del pavimento es de terrazo blanco, gris y rojizo. Hay 50 bancos corridos y 54 individuales. En la plaza se encuentra una gran fuente ornamental y un kiosco.

\section{Planos resumen de las características físico-espaciales de las plazas}

Las características físico-espaciales de las plazas se pueden consultar en los correspondientes planos de la plaza del 2 de Mayo, de la plaza de Vázquez de Mella y de la plaza de Chamberí. 


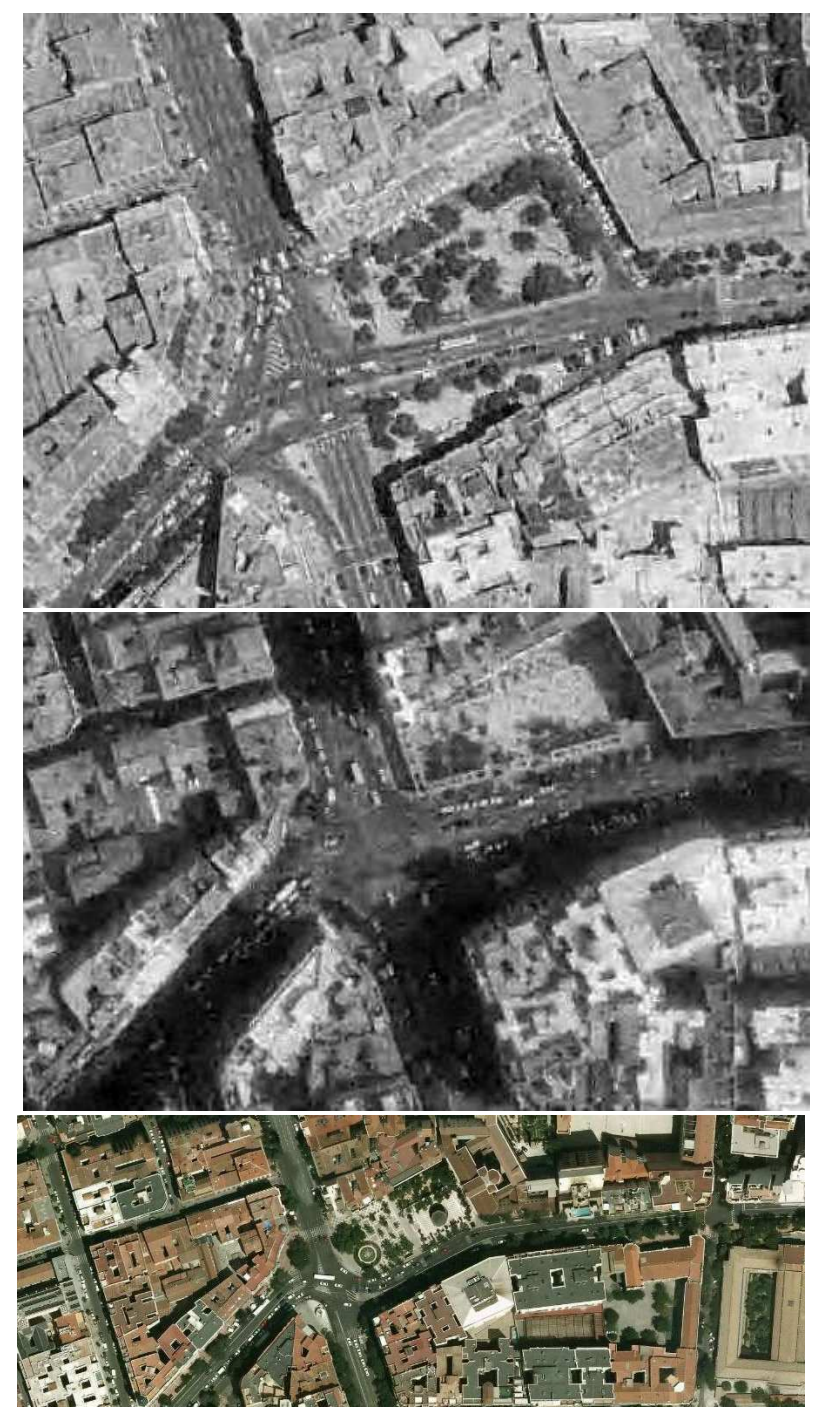

Figura 34: Fotografías aéreas de la plaza de Chamberí de 1975, 1991 y 2008 Fuente: http://www.madrid.org

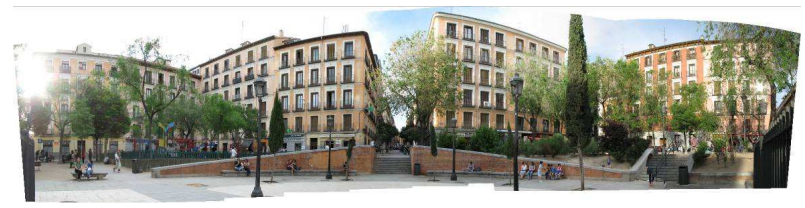

Figura 35: Vista panorámica de la plaza del 2 de Mayo Fuente: Elaboración propia 


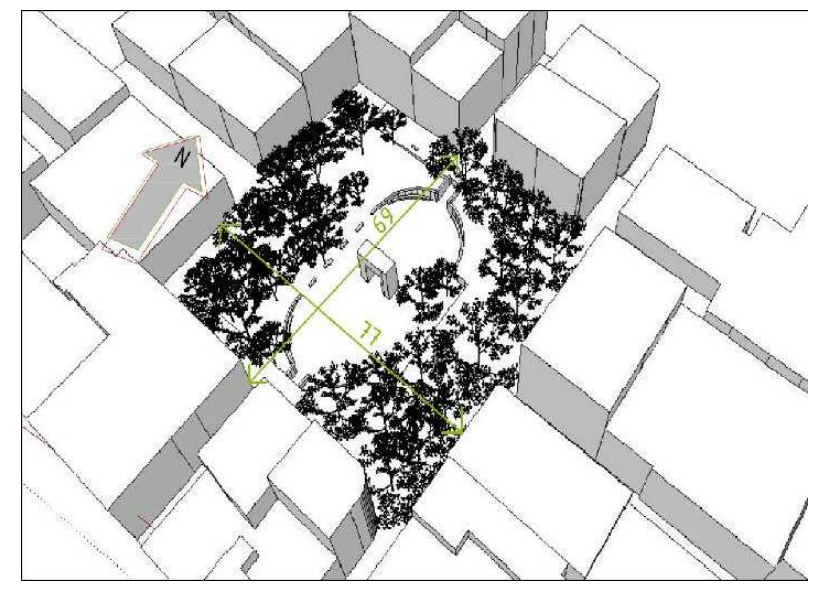

Figura 36: Volumetría y dimensiones de la plaza del 2 de Mayo Fuente: Elaboración propia

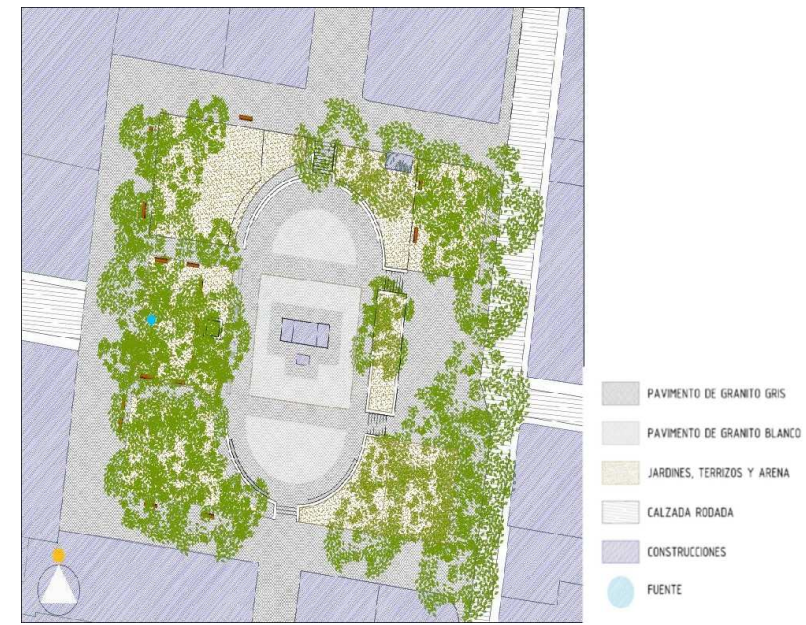

Figura 37: Plano de características físicas y materiales de la plaza del 2 de Mayo Fuente: Elaboración propia

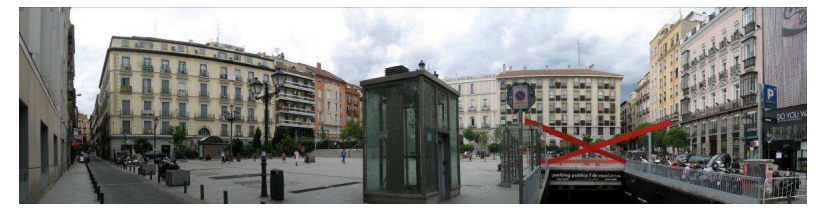

Figura 38: Vista panorámica de la plaza de Vázquez de Mella Fuente: Elaboración propia 


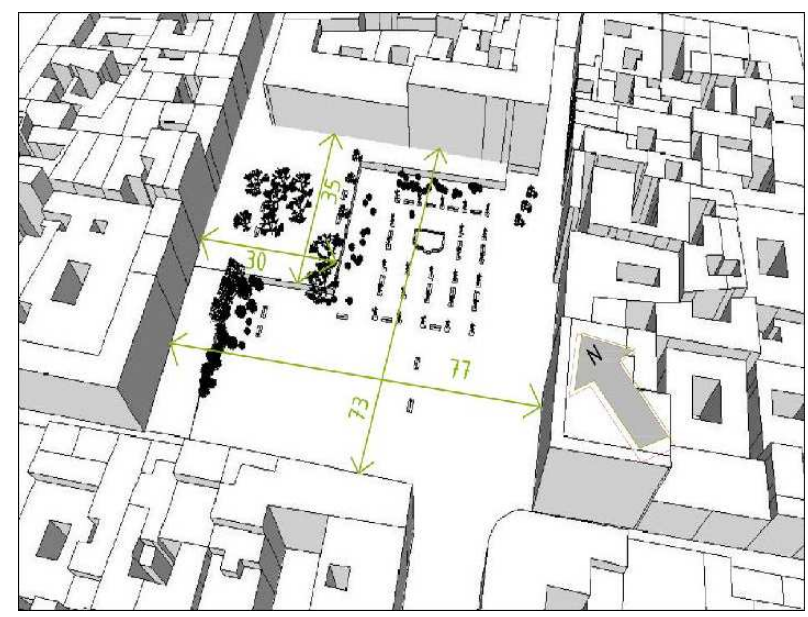

Figura 39: Volumetría y dimensiones de la plaza de Vázquez de Mella Fuente: Elaboración propia

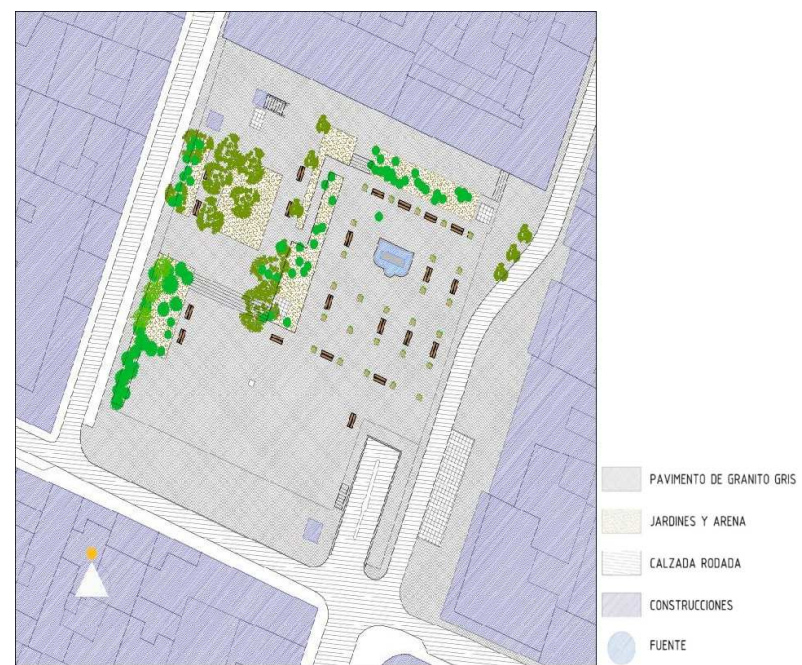

Figura 40: Plano de características físicas y materiales de la plaza de Vázquez de Mella Fuente: Elaboración propia

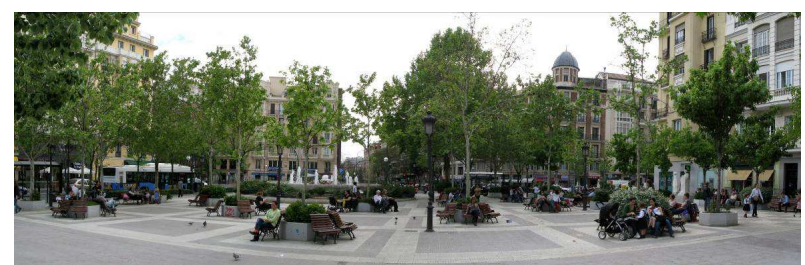

Figura 41: Vista panorámica de la plaza de Chamberí Fuente: Elaboración propia 


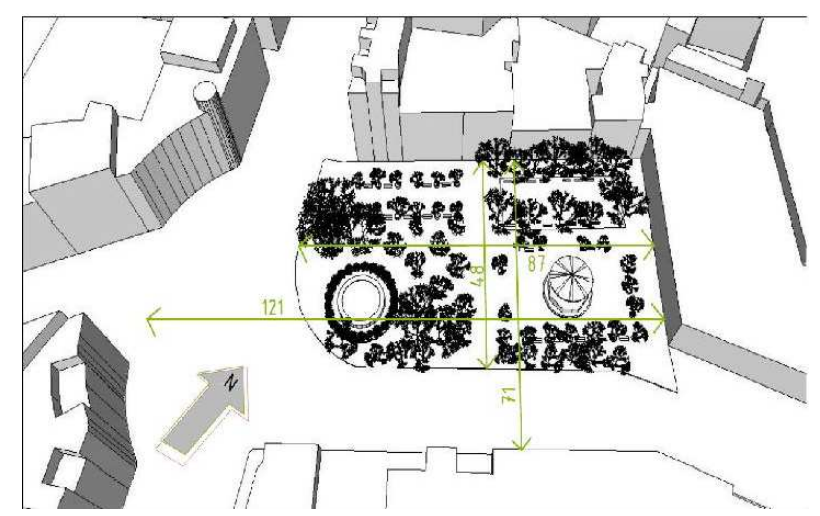

FIgURA 42: Volumetría y dimensiones de la plaza de Chamberí Fuente: Elaboración propia

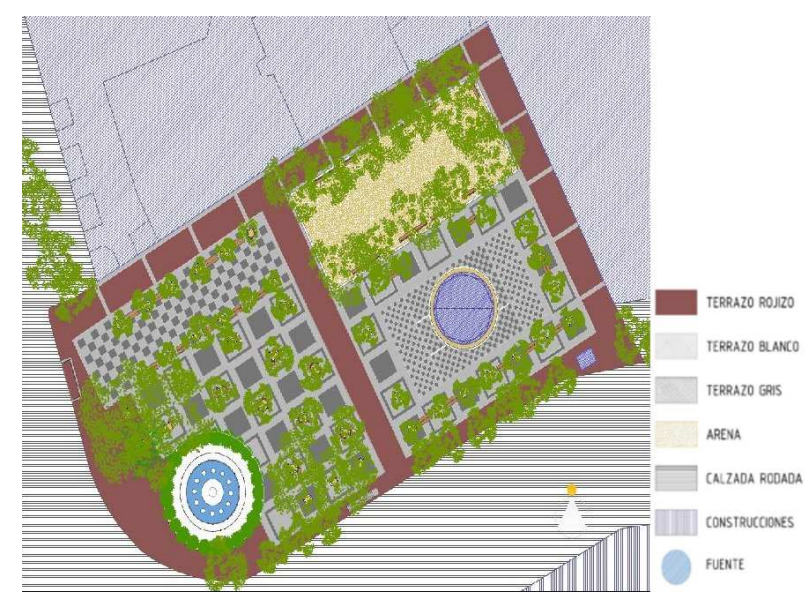

Figura 43: Plano de características físicas y materiales de la Plaza de Chamberí Fuente: Elaboración propia 


\section{Funciones y usos de las plazas}

\section{Función general del espacio}

Los espacios aquí analizados son todos ellos plazas urbanas. La definición que la Real Academia de la Lengua Española hace de plaza es la siguiente:

Plaza

1. f. Lugar ancho y espacioso dentro de un poblado, al que suelen afluir varias calles.

2. f. Aquel donde se venden los mantenimientos y se tiene el trato común de los vecinos, y donde se celebran las ferias, los mercados y fiestas públicas.

En la segunda acepción se puede observar que al propio significado de la palabra van asociadas ciertas funciones como la de espacio que sirve para la relación entre vecinos, lugar donde se celebran eventos o donde se venden servicios.

Las tres plazas seleccionadas son espacios característicos de cada uno de los barrios en los que se encuentran, teniendo además asociados a ellos valores históricos y políticos como es el caso de Chamberí y la Plaza del 2 de Mayo.

Tanto la Plaza del 2 de Mayo y como la de Vázquez de Mella se tratan de los mayores espacios urbanos abiertos que se pueden encontrar en cada uno de sus barrios.

\section{Equipamientos y servicios privados}

Las tres plazas están circundadas de edificios en los que se desarrollan diversas actividades y se ofrecen servicios tanto públicos como privados.

\section{Plaza del 2 de Mayo}

En la plaza del 2 de Mayo destaca el edificio del colegio y convento Maravillas. El resto de construcciones son viviendas en las que se desarrollan diversas actividades privadas en planta baja, encontrando comercios, locales de hostelería, una ONG o el acceso a un aparcamiento.

Todos estos servicios son accesibles desde la propia plaza. En general no ocupan el espacio público, a excepción de un par de comercios. La transparencia de sus fachadas es elevada, superando el $50 \%$, lo que permite una visión del interior de estos comercios desde el espacio público y viceversa.

Los bares a partir del mediodía suelen sacar mesas y sillas a la plaza, creando terrazas para sus usuarios.

\section{Plaza de Vázquez de Mella}

En esta plaza existen dos edificios de gran entidad como son el hotel Room Mate en la esquina sur de la plaza y el Centro de Rehabilitación Psicosocial en la esquina noreste. El resto de edificios tienen un uso principal de vivienda con bajos comerciales como bares, restaurantes, comercio textil y electrónica, así como bajos con actividades sociales.

Tan sólo uno de los bares saca una pequeña terraza a la plaza, dado que por delante de los bajos comerciales pasan viales rodados y que la escasa anchura de la acera no lo permite.

Los bajos de las fachadas norte y sur tienen una transparencia baja, no alcanzando el $50 \%$ de superficie acristalada, mientras que las otras dos fachadas lo superan.

\section{Plaza de Chamberí}

Los límites de esta plaza son de diferente carácter al de las dos plazas anteriores. La plaza está limitada en dos de sus lados (norte y este) por edificios, tal y como ocurre en las otras plazas, pero al sur y al oeste limita con dos grandes viales como la calle Santa Engracia y la calle Eduardo Dato, así como con el cruce de ambas con una tercera calle, Luchana.

Los edificios que dan a la plaza se tratan de viviendas con bajos comerciales, la Junta Municipal de Chamberí y el colegio y convento de las Siervas de Jesús.

En los bajos comerciales de la plaza se pueden encontrar dos bares, dos pequeños comercios y una entidad bancaria. Los bares en ciertos momentos del día sacan a la plaza terrazas. 


\section{Actividades espontáneas y colectivas}

Respecto a las actividades espontáneas como podrían ser los músicos callejeros, pintores, o teatro de calle, etcétera, en los días en los que se llevaron a cabo los trabajos de campo no se identificó ninguna actividad de este tipo.

Sin embargo, cada una de las plazas ha servido y sirve como lugar para el desarrollo de diversas actividades colectivas.

En la Plaza del 2 de Mayo se celebran:

- Las fiestas del 2 de Mayo

- Mercadillo al aire libre

- Conciertos al aire libre

- Encuentros organizados.

En la Plaza de Vázquez de Mella se llevan a cabo:

- Las fiestas del Día del Orgullo Gay

- Teatro de calle de la Noche en Blanco

- Teatro de calle de la Noche de los Teatros

- Encuentros organizados

- Mercadillo al aire libre

Y finalmente, en la Plaza de Chamberí se organizan:

- Las fiestas del Carmen

- Encuentros organizados

- Visitas al Anden 0

- Conciertos en el Templete de la Música

\section{Planos resumen de funciones y usos en las plazas}

A continuación se adjunta un plano resumen de cada una de las plazas analizadas (de la plaza del 2 de Mayo, de la plaza de Vázquez de Mella y de la plaza de Chamberí) en los que se indican las funciones y usos de cada una de las zonas y construcciones que componen la plaza, identificando:

- El uso de cada uno de los edificios de la plaza

- Los equipamientos y servicios

- Usos definidos del espacio

- Hitos y referencias urbanas

- Y mobiliario urbano existente.

\section{El empleo de las plazas}

Se ha estudiado el empleo que la gente hace de las plazas en los mismos días de abril, mayo y de junio, en los que se han realizado lecturas de temperaturas, humedad y viento. De este modo, se podrán establecer las posibles relaciones entre las condiciones ambientales y el uso que hacen los ciudadanos de los espacios urbanos estudiados. 


\section{Actividades desarrolladas en las plazas}

Se han identificado aquellas actividades que suponen una estancia en el espacio público, esto es, aquellas en las que las personas permanecen en ese espacio, están paradas.

Por otra parte, se han descartado aquellas personas que tan sólo 'pasan' por las plazas, así como aquellas que desarrollan actividades estanciales que tan sólo están ligadas a espacios de carácter privado como pueden ser las terrazas de bares y restaurantes.

Las actividades identificadas son las siguientes:

- Mirar lo que sucede alrededor;

- hablar con otras personas;

- leer;

- dormir;

- comer o beber en las plazas;

- hablar por teléfono;

- esperar a alguien;

- jugar;

- pasear al perro.

\section{Usuarios}

En las plazas seleccionadas prevalece el carácter doméstico, esto es, un uso de este espacio por parte de los ciudadanos de Madrid, un uso cotidiano por parte de los vecinos.

Las plazas se emplean por ciudadanos de todas las edades y sexos. En la localización de personas en las plazas se han distinguido los niños (menores de 18 años), los adultos (entre 18 y 65 años) y ancianos (personas mayores de 65 años).

Las relaciones que se dan en los espacios estudiados son tanto personales (familias, amigos o cuidadoras con niños) como no personales (público en general o grupos específicos como los escolares).

\section{Localización de las personas en las plazas}

La localización de las personas se ha realizado en los mismos días en los que se han realizado las mediciones ambientales, esto es, un día de los meses de abril, mayo y junio, tres veces al día, por la mañana, por la tarde y por la noche.

Para ello, se han realizado alrededor de 1.000 fotografías que han sido revisadas y a través de las cuales se han localizado las personas usuarias de las plazas.

Los criterios básicos que se han empleado en la localización de las personas son los siguientes:

- Tan sólo se han identificado las personas que están realizando una actividad estancial en las plazas, sin identificar las personas que tan sólo pasan por estos espacios.

- Se han señalado sólo las personas que están en espacios de carácter público, sin contabilizar los ciudadanos que hacen uso de las terrazas de bares y restaurantes, ya que su utilización del espacio urbano está más condicionada por los equipamientos que por los condicionantes climáticos.

- Se han distinguido las personas que están de pie de aquellas que están sentadas, dado que la actividad metabólica varía y por lo tanto podría variar la situación de confort.

- Al mismo tiempo se han identificado las personas en base a su edad, ya que el confort también depende de esta variable.

- Se han diferenciado aquellas personas que se encuentran al sol y a la sombra para poder contrastar estos resultados con las necesidades para alcanzar el confort identificadas en el estudio climático teórico. Se han considerado a la sombra tanto las personas que se encuentran a la sombra arrojada por edificios o elementos constructivos, como aquellas que se encuentran a la sombra de los árboles.

Todos estos criterios se han representado gráficamente como aparece en la figura 47. 


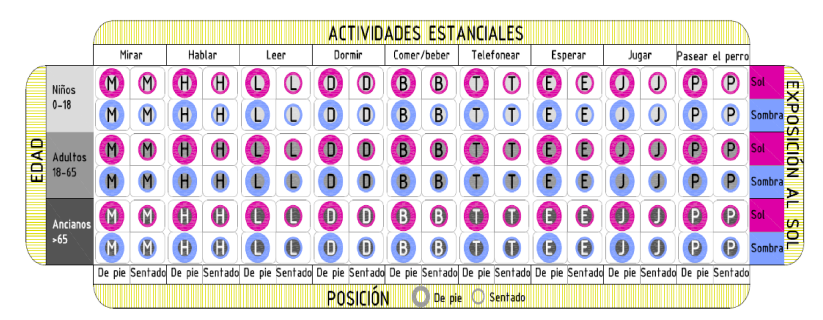

Figura 44: Actividades estanciales

Fuente: elaboración propia

\section{Plaza del 2 de Mayo}

Este apartado consta de los planos en los que se describe la plaza del 2 de Mayo en función de las actividades de las personas y su localización, que pueden verse en las figuras 48 a 56 .

\section{Plaza de Vázquez de Mella}

Este apartado consta de los planos en los que se describe la plaza de Vázquez de Mella en función de las actividades de las personas y su localización, que pueden verse en las figuras 57 a 65 . 


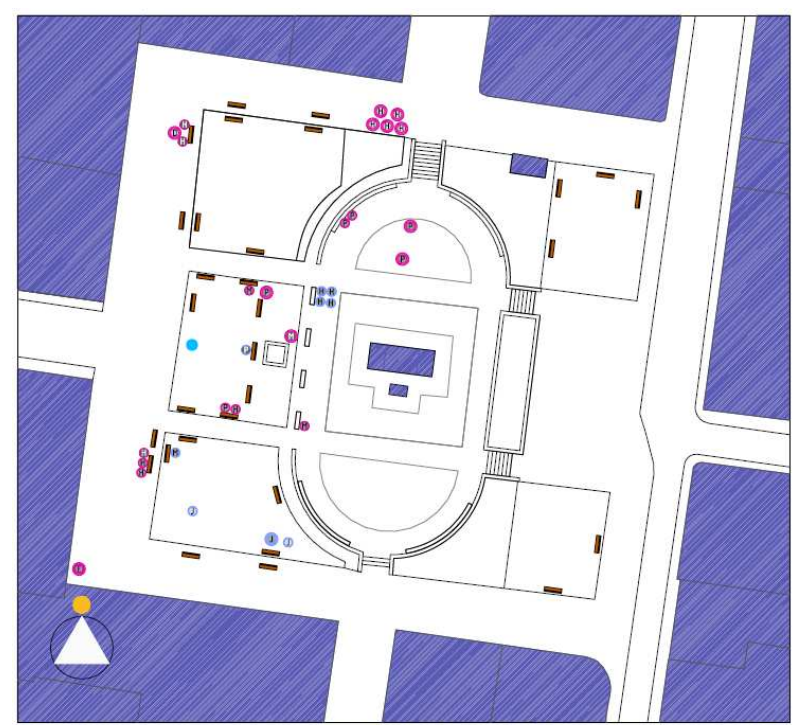

LOCALIZACIÓN DE PERSONAS: PLAZA DEL 2 DE MAYO, 29 DE ABRIL_10:00h

\begin{tabular}{|l|c|c|c|c|}
\multicolumn{2}{|l|}{ Número de personas } & Niños & Adultos & Ancianos \\
\hline Total & $31(100 \%)$ & $8(25.8 \%)$ & $18(58 \%)$ & $5(16.2 \%)$ \\
\hline Al sol & $22(70.9 \%)$ & 6 & 12 & 4 \\
\hline A la sombra & $9(29.1 \%)$ & 2 & 6 & 1 \\
\hline De pie & $12(38.7 \%)$ & 5 & 5 & 2 \\
\hline Sentados & $19(61.3 \%)$ & 3 & 13 & 3 \\
\hline
\end{tabular}

ACTIVIDADES PRINCIPALES: PLAZA DEL 2 DE MAYO, 29 DE ABRIL_10:00h Hablar: 15 personas / Paseando perro: 7 personas / Mirar: 4 personas

FigURA 45: 29 de abril, 10:00h

Fuente: elaboración propia 


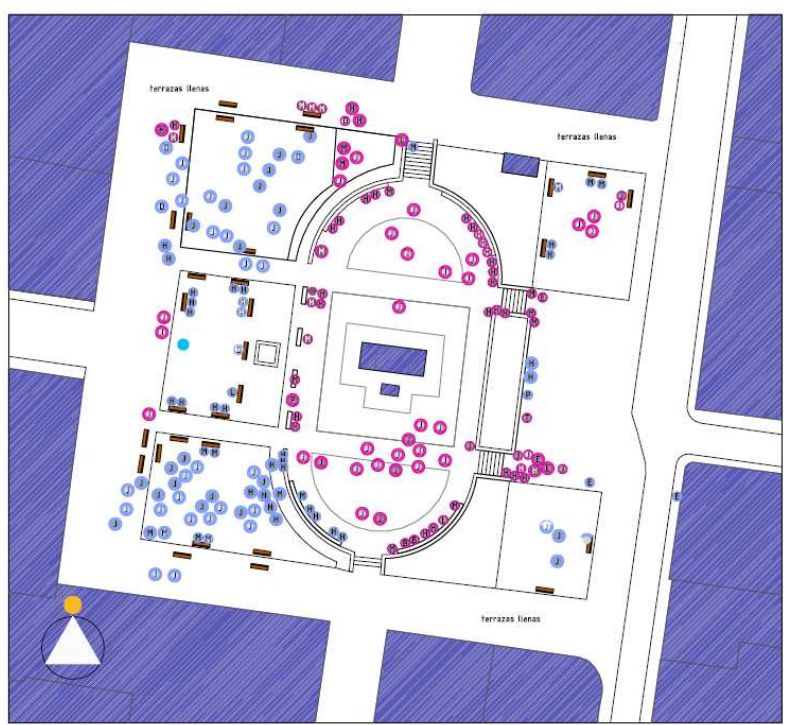

LOCALIZACIÓN DE PERSONAS: PLAZA DEL 2 DE MAYO, 29 DE ABRIL_17:30h

\begin{tabular}{|l|c|c|c|c|}
\hline \multicolumn{2}{|l|}{ Número de personas } & Niños & Adultos & Ancianos \\
\hline Total & $196(100 \%)$ & $67(34.2 \%)$ & $116(59.2 \%)$ & $13(6.6 \%)$ \\
\hline Al sol & $95(48.5 \%)$ & 32 & 53 & 10 \\
\hline A la sombra & $101(51.5 \%)$ & 35 & 63 & 3 \\
\hline De pie & $111(56.6 \%)$ & 60 & 49 & 2 \\
\hline Sentados & $85(43.3 \%)$ & 7 & 67 & 11 \\
\hline
\end{tabular}

ACTIVIDADES PRINCIPALES: PLAZA DEL 2 DE MAYO, 29 DE ABRIL_17:30h

Jugar: 89 personas / Hablar: 65 personas / Mirar: 31 personas

FIgURA 46: 29 de abril, 17:30h

Fuente: elaboración propia 


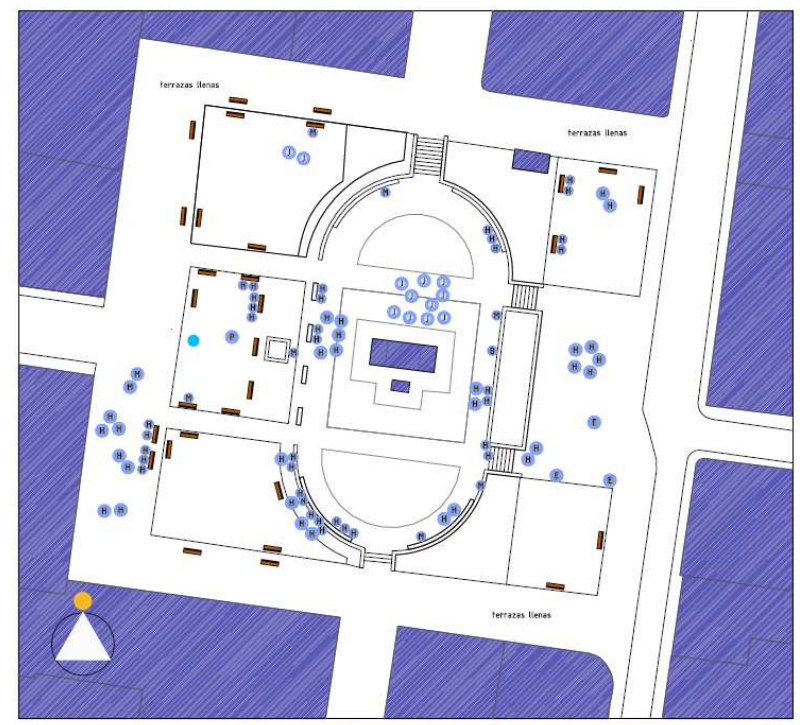

LOCALIZACIÓN DE PERSONAS: PLAZA DEL 2 DE MAYO, 29 DE ABRIL_23:00h
\begin{tabular}{|l|c|c|c|c|}
\hline Número de personas & Niños & Adultos & Ancianos \\
\hline Total & $89(100 \%)$ & $12(13.5 \%)$ & $77(86.5 \%)$ & $0(0 \%)$ \\
\hline De pie & $47(52.8 \%)$ & 12 & 35 & 0 \\
\hline Sentados & $42(47.2 \%)$ & 0 & 42 & 0 \\
\hline
\end{tabular}

ACTIVIDADES PRINCIPALES: PLAZA DEL 2 DE MAYO, 29 DE ABRIL_23:00h

Hablar: 64 personas / Jugar: 12 personas / Mirar: 9 personas

FigurA 47: 29 de abril, 23:00h

Fuente: elaboración propia 


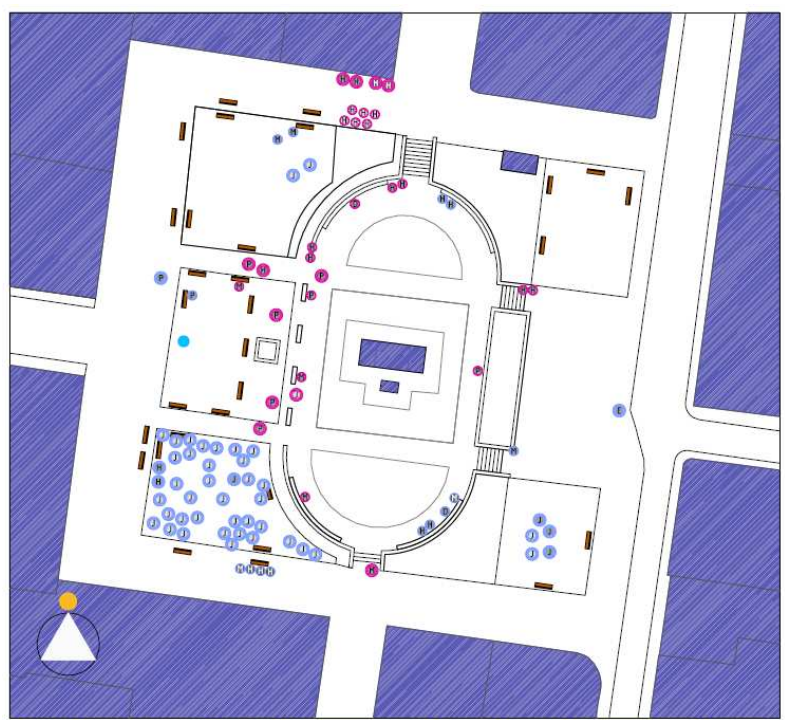

LOCALIZACIÓN DE PERSONAS: PLAZA DEL 2 DE MAYO, 27 DE MAYO_10:00h

\begin{tabular}{|l|c|c|c|c|}
\hline \multicolumn{2}{|l|}{ Número de personas } & Niños & Adultos & Ancianos \\
\hline Total & $91(100 \%)$ & $46(50.5 \%)$ & $38(41.8 \%)$ & $7(7.7 \%)$ \\
\hline Al sol & $30(49.2 \%)$ & 7 & 21 & 2 \\
\hline A la sombra & $61(50.8 \%)$ & 39 & 17 & 5 \\
\hline De pie & $57(62.6 \%)$ & 40 & 15 & 2 \\
\hline Sentados & $34(37.4 \%)$ & 6 & 23 & 5 \\
\hline
\end{tabular}

ACTIVIDADES PRINCIPALES: PLAZA DEL 2 DE MAYO, 27 DE MAYO_10:00h

Jugar: 44 personas / Hablar: 26 personas / Mirar/ pasear perro: 9 personas

Figura 48: 27 de mayo, 10:00h

Fuente: elaboración propia 


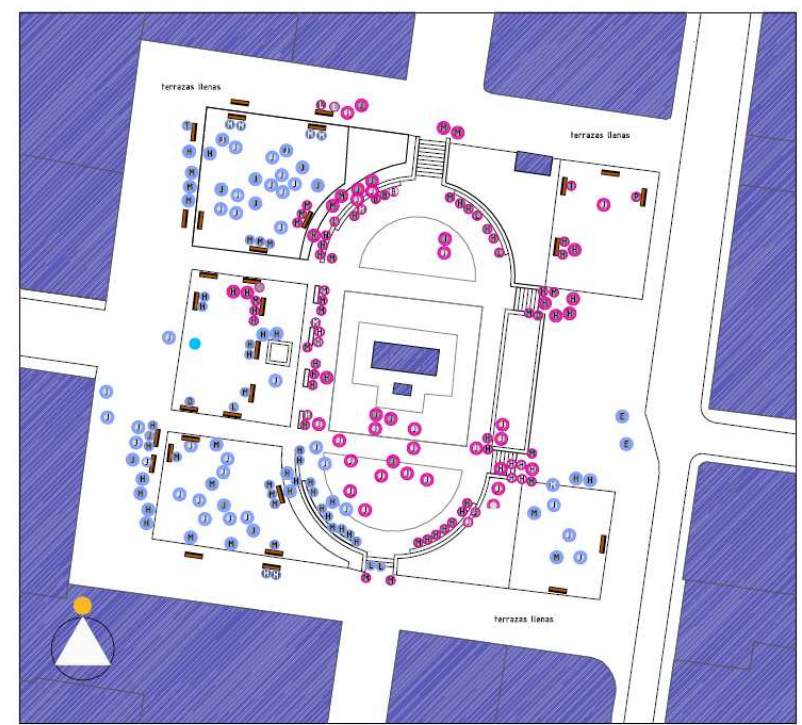

LOCALIZACIÓN DE PERSONAS: PLAZA DEL 2 DE MAYO, 27 DE MAYO_17:30h

\begin{tabular}{|l|c|c|c|c|}
\hline \multicolumn{2}{|l|}{ Número de personas } & Niños & Adultos & Ancianos \\
\hline Total & $216(100 \%)$ & $62(28.7 \%)$ & $141(58.3 \%)$ & $13(6 \%)$ \\
\hline Al sol & $113(52.3 \%)$ & 33 & 76 & 4 \\
\hline A la sombra & $103(47.7 \%)$ & 29 & 65 & 9 \\
\hline De pie & $109(50.5 \%)$ & 54 & 52 & 3 \\
\hline Sentados & $107(49.5 \%)$ & 8 & 89 & 10 \\
\hline
\end{tabular}

ACTIVIDADES PRINCIPALES: PLAZA DEL 2 DE MAYO, 27 DE MAYO_17:30h

Hablar: 79 personas / Jugar: 75 personas / Mirar: 50 personas

FigURA 49: 27 de mayo, 17:30h

Fuente: elaboración propia 


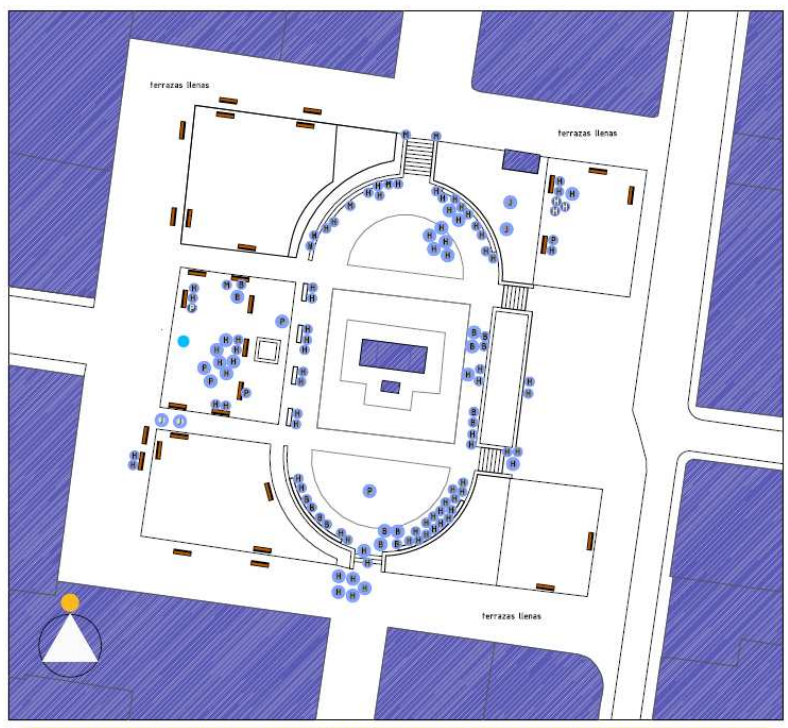

LOCALIZACIÓN DE PERSONAS: PLAZA DEL 2 DE MAYO, 27 DE MAYO_23:00h

\begin{tabular}{|l|c|c|c|c|}
\hline \multicolumn{2}{|l|}{ Número de personas } & Niños & Adultos & Ancianos \\
\hline Total & $122(100 \%)$ & $2(1.6 \%)$ & $116(95.2 \%)$ & $4(3.2 \%)$ \\
\hline De pie & $35(28.7 \%)$ & 2 & 33 & 0 \\
\hline Sentados & $87(71.3 \%)$ & 0 & 83 & 4 \\
\hline
\end{tabular}

ACTIVIDADES PRINCIPALES: PLAZA DEL 2 DE MAYO, 27 DE MAYO_23:00h

Hablar: 91 personas / Bebiendo: 16 personas / Paseando perro: 7 personas

Figura 50: 27 de mayo, 23:00h

Fuente: elaboración propia 


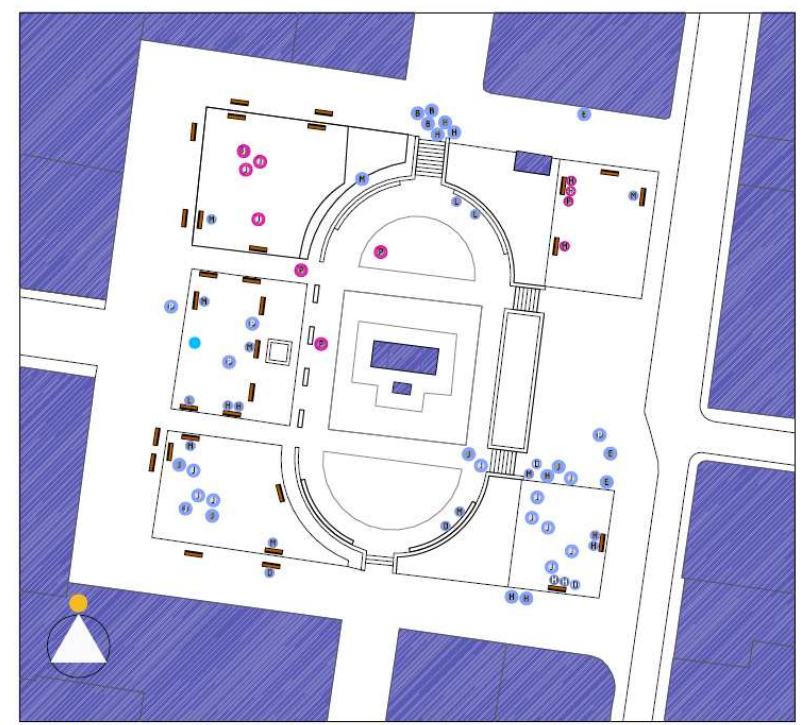

LOCALIZACIÓN DE PERSONAS: PLAZA DEL 2 DE MAYO, 24 DE JUNIO_10:00h

\begin{tabular}{|l|c|c|c|c|}
\multicolumn{2}{|l|}{ Número de personas } & Niños & Adultos & Ancianos \\
\hline Total & $64(100 \%)$ & $16(25 \%)$ & $40(62.5 \%)$ & $8(12.5 \%)$ \\
\hline Al sol & $11(17.2 \%)$ & 4 & 6 & 1 \\
\hline A la sombra & $53(82.8 \%)$ & 12 & 34 & 7 \\
\hline De pie & $24(37.5 \%)$ & 13 & 5 & 6 \\
\hline Sentados & $40(62.5 \%)$ & 3 & 35 & 2 \\
\hline
\end{tabular}

ACTIVIDADES PRINCIPALES: PLAZA DEL 2 DE MAYO, 24 DE JUNIO_10:00h

Jugar: 19 personas / Hablar: 14 personas / Mirar: 10 personas

FIGURA 51: 24 de junio, 10:00h

Fuente: elaboración propia 


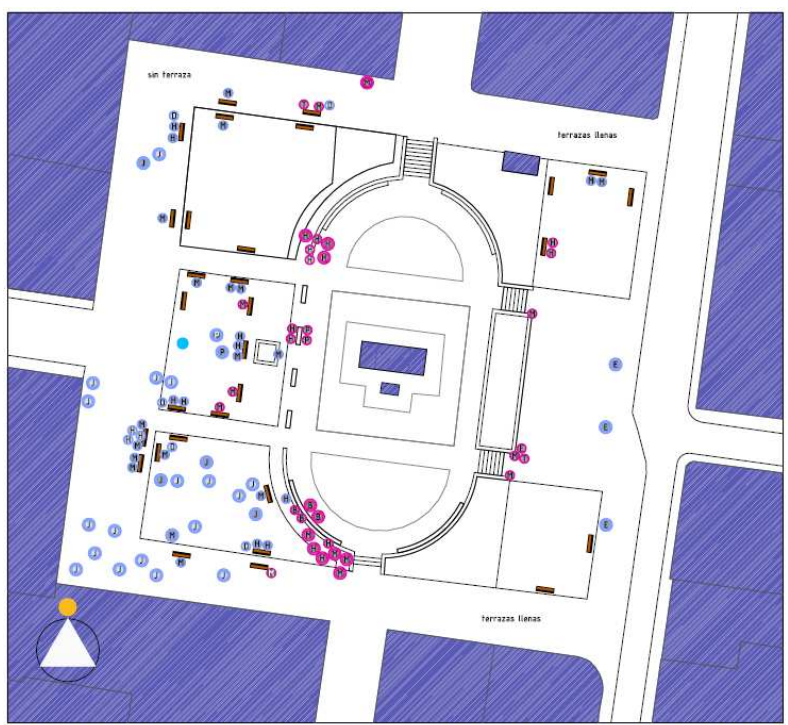

LOCALIZACIÓN DE PERSONAS: PLAZA DEL 2 DE MAYO, 24 DE JUNIO_17:30h

\begin{tabular}{|l|c|c|c|c|}
\hline \multicolumn{2}{|l|}{ Número de personas } & Niños & Adultos & Ancianos \\
\hline Total & $97(100 \%)$ & $28(28.9 \%)$ & $67(69 \%)$ & $2(2.1 \%)$ \\
\hline Al sol & $35(36.1 \%)$ & 2 & 32 & 1 \\
\hline A la sombra & $62(63.9 \%)$ & 26 & 35 & 1 \\
\hline De pie & $40(41.2 \%)$ & 18 & 21 & 1 \\
\hline Sentados & $57(58.8 \%)$ & 10 & 46 & 1 \\
\hline
\end{tabular}

ACTIVIDADES PRINCIPALES: PLAZA DEL 2 DE MAYO, 24 DE JUNIO_17:30h

Hablar: 26 personas / Mirar: 34 personas / Jugar: 24 personas

Figura 52: 24 de junio, 17:30h

Fuente: elaboración propia 


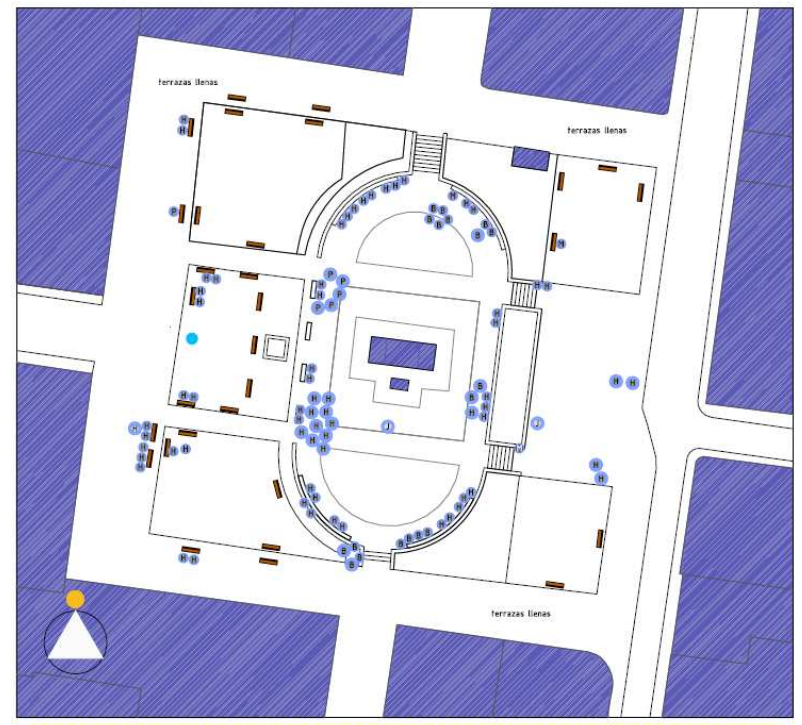

LOCALIZACIÓN DE PERSONAS: PLAZA DEL 2 DE MAYO, 24 DE JUNIO_23:00h

\begin{tabular}{|l|c|c|c|c|}
\hline \multicolumn{2}{|l|}{ Número de personas } & Niños & Adultos & Ancianos \\
\hline Total & $96(100 \%)$ & $3(3.1 \%)$ & $92(95.9 \%)$ & $1(1 \%)$ \\
\hline De pie & $28(29.2 \%)$ & 3 & 25 & 0 \\
\hline Sentados & $68(70.8 \%)$ & 0 & 67 & 1 \\
\hline
\end{tabular}

ACTIVIDADES PRINCIPALES: PLAZA DEL 2 DE MAYO, 24 DE JUNIO_23:00h

Hablar: 67 personas / Bebiendo: 18 personas / Paseando perro: 6 personas

Figura 53: 24 de junio, 23:00h

Fuente: elaboración propia 


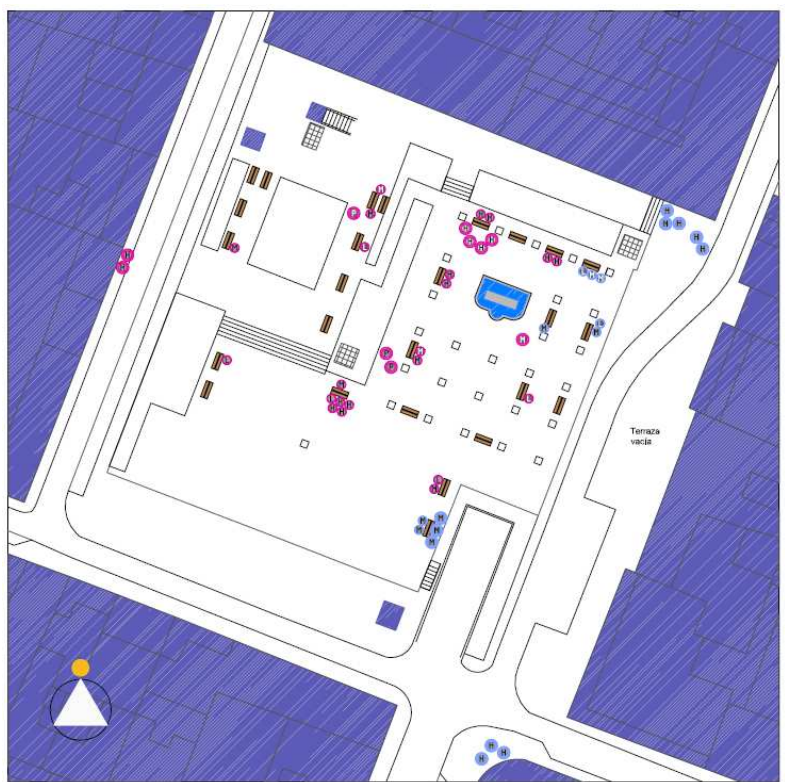

LOCALIZACIÓN DE PERSONAS: PLAZA VÁZQUEZ DE MELLA, 29 DE ABRIL_10:30h

\begin{tabular}{|l|l|c|c|c|}
\hline \multicolumn{2}{|l|}{ Número de personas } & Niños & Adultos & Ancianos \\
\hline Total & $51(100 \%)$ & $4(7.8 \%)$ & $37(72.6 \%)$ & $10(19.6 \%)$ \\
\hline Al sol & $19(37.2 \%)$ & 4 & 9 & 6 \\
\hline A la sombra & $32(62.8 \%)$ & 0 & 28 & 4 \\
\hline De pie & $21(41.2 \%)$ & 4 & 15 & 2 \\
\hline Sentados & $30(58.8 \%)$ & 0 & 22 & 8 \\
\hline
\end{tabular}

ACTIVIDADES PRINCIPALES: PLAZA DEL 2 DE MAYO, 29 DE ABRIL_10:30h

Hablar: 24 personas / Mirar: 19 personas / Leer: 7 personas

Figura 54: 29 de abril, 10:30h

Fuente: elaboración propia 


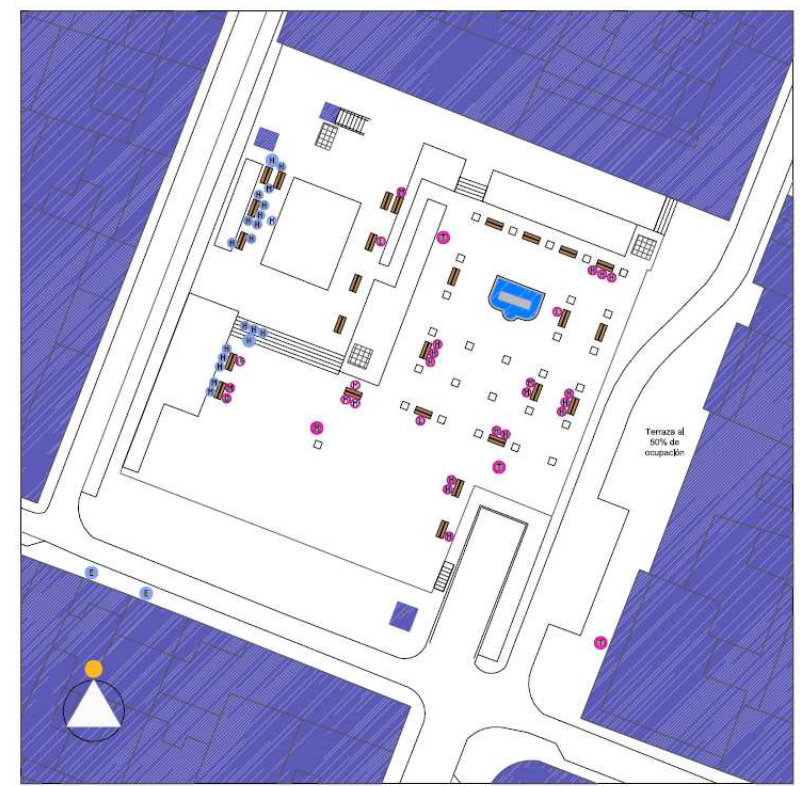

LOCALIZACIÓN DE PERSONAS: PLAZA VÁZQUEZ DE MELLA, 29 DE ABRIL_18:00h

\begin{tabular}{|l|l|c|c|c|}
\hline \multicolumn{2}{|l|}{ Número de personas } & Niños & Adultos & Ancianos \\
\hline Total & $52(100 \%)$ & $4(7.7 \%)$ & $47(90.4 \%)$ & $1(1.9 \%)$ \\
\hline Al sol & $30(57.7 \%)$ & 3 & 26 & 1 \\
\hline A la sombra & $22(42.3 \%)$ & 1 & 21 & 0 \\
\hline De pie & $8(15.4 \%)$ & 0 & 8 & 0 \\
\hline Sentados & $44(84.6 \%)$ & 4 & 39 & 1 \\
\hline
\end{tabular}

ACTIVIDADES PRINCIPALES: PLAZA DEL 2 DE MAYO, 29 DE ABRIL_18:00h

Hablar: 29 personas / Mirar: 14 personas / Leer: 4 personas

FigurA 55: 29 de abril, 18:00h

Fuente: elaboración propia 


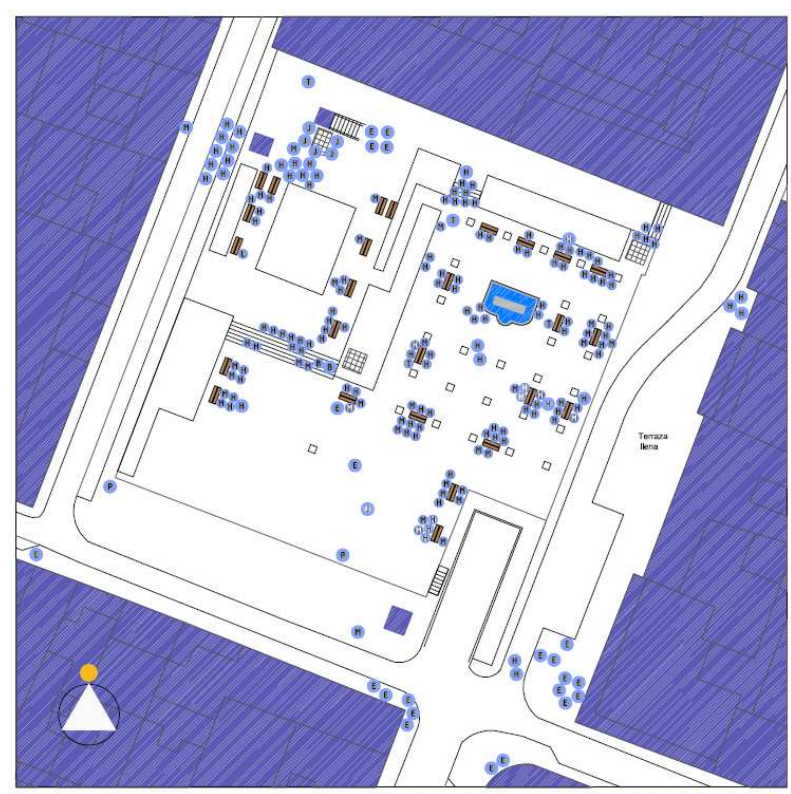

LOCALIZACIÓN DE PERSONAS: PLAZA VÁZQUEZ DE MELLA, 29 DE ABRIL_23:30h

\begin{tabular}{|l|c|c|c|c|}
\hline \multicolumn{2}{|l|}{ Número de personas } & Niños & Adultos & Ancianos \\
\hline Total & $206(100 \%)$ & $5(2.4 \%)$ & $195(94.7 \%)$ & $6(2.9 \%)$ \\
\hline De pie & $64(31.1 \%)$ & 2 & 61 & 1 \\
\hline Sentados & $142(68.9 \%)$ & 3 & 134 & 5 \\
\hline
\end{tabular}

ACTIVIDADES PRINCIPALES: PLAZA DEL 2 DE MAYO, 29 DE ABRIL_23:30h Hablar: 135 personas / Mirar: 34 personas / Jugar: 6 personas

Figura 56: 29 de abril, 23:30h

Fuente: elaboración propia 


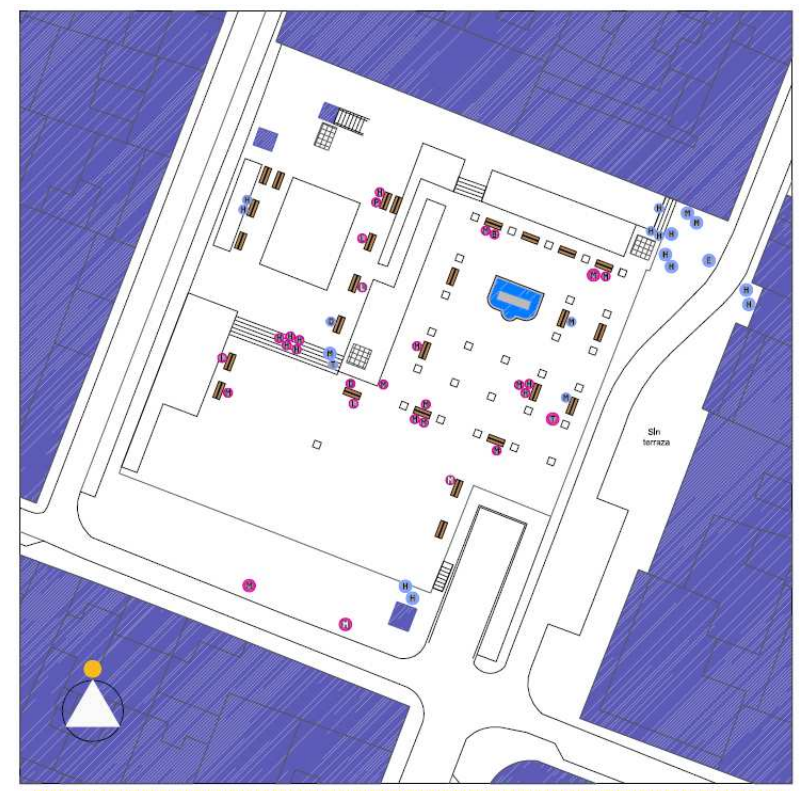

LOCALIZACIÓN DE PERSONAS: PLAZA VÁZQUEZ DE MELLA, 27 DE MAYO_10:30h

\begin{tabular}{|l|c|c|c|c|}
\hline \multicolumn{2}{|l|}{ Número de personas } & Niños & Adultos & Ancianos \\
\hline Total & $50(100 \%)$ & $0(0 \%)$ & $47(94 \%)$ & $3(6 \%)$ \\
\hline Al sol & $30(60 \%)$ & 0 & 27 & 3 \\
\hline A la sombra & $20(40 \%)$ & 0 & 20 & 0 \\
\hline De pie & $15(30 \%)$ & 0 & 14 & 1 \\
\hline Sentados & $35(70 \%)$ & 0 & 33 & 2 \\
\hline
\end{tabular}

ACTIVIDADES PRINCIPALES: PLAZA DEL 2 DE MAYO, 27 DE MAYO_10:30h

Hablar: 20 personas / Mirar: 20 personas / Leer: 4 personas

FiguRA 57: 27 de mayo, 10:30h

Fuente: elaboración propia 


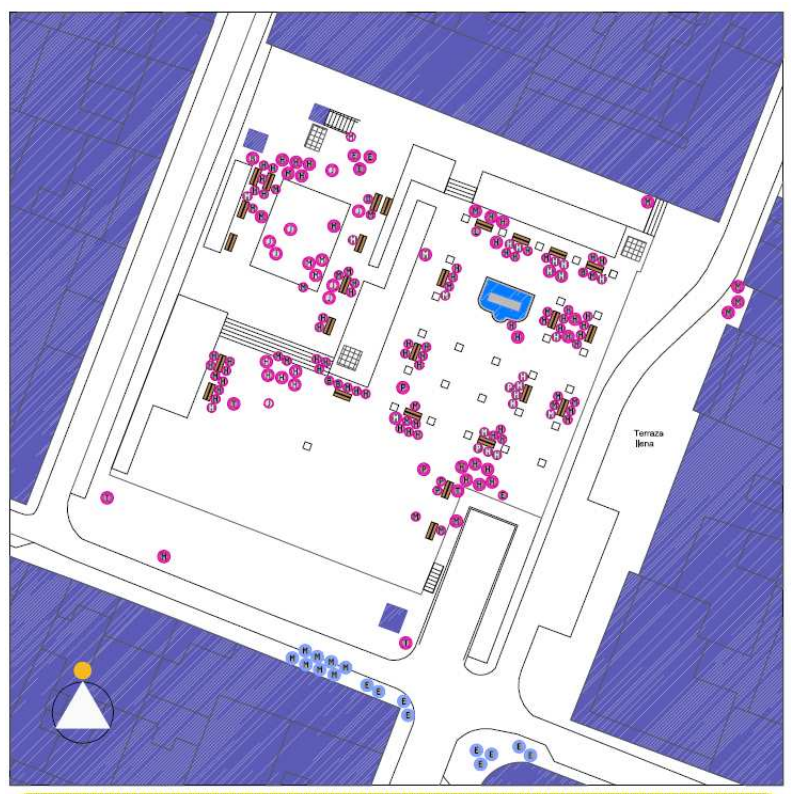

LOCALIZACIÓN DE PERSONAS: PLAZA VÁZQUEZZ DE MELLA, 27 DE MAYO_18:00h
\begin{tabular}{|l|l|c|c|c|}
\hline Número de personas & Niños & Adultos & Ancianos \\
\hline Total & $174(100 \%)$ & $18(10.3 \%)$ & $132(75.9 \%)$ & $24(13.8 \%)$ \\
\hline Al sol & $157(190.2 \%)$ & 18 & 115 & 24 \\
\hline A la sombra & $17(9.8 \%)$ & 0 & 17 & 0 \\
\hline De pie & $72(41.4 \%)$ & 16 & 52 & 4 \\
\hline Sentados & $102(58.6 \%)$ & 2 & 80 & 20 \\
\hline
\end{tabular}

ACTIVIDADES PRINCIPALES: PLAZA DEL 2 DE MAYO, 27 DE MAYO_18:00h

Hablar: 83 personas / Mirar: 59 personas / Jugar: 8 personas

FigurA 58: 27 de mayo, 18:00h

Fuente: elaboración propia 


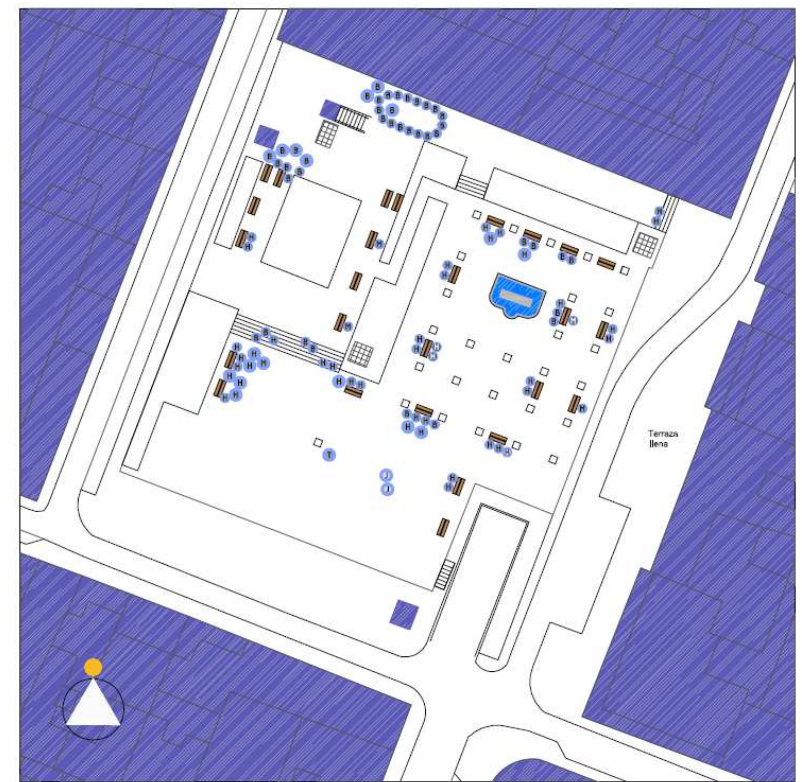

LOCALIZACIÓN DE PERSONAS: PLAZA VÁZQUEZ DE MELLA, 27 DE MAYO_23:30h

\begin{tabular}{|l|c|c|c|c|}
\multicolumn{2}{|l|}{ Número de personas } & Niños & Adultos & Ancianos \\
\hline Total & $90(100 \%)$ & $3(3.3 \%)$ & $84(93.4 \%)$ & $3(3.3 \%)$ \\
\hline De pie & $21(23.3 \%)$ & 2 & 19 & 0 \\
\hline Sentados & $69(76.7 \%)$ & 1 & 65 & 3 \\
\hline
\end{tabular}

ACTIVIDADES PRINCIPALES: PLAZA DEL 2 DE MAYO, 27 DE MAYO_23:30h

Hablar: 43 personas / Beber: 40 personas / Mirar: 5 personas

FigurA 59: 27 de mayo, 23:30h

Fuente: elaboración propia 


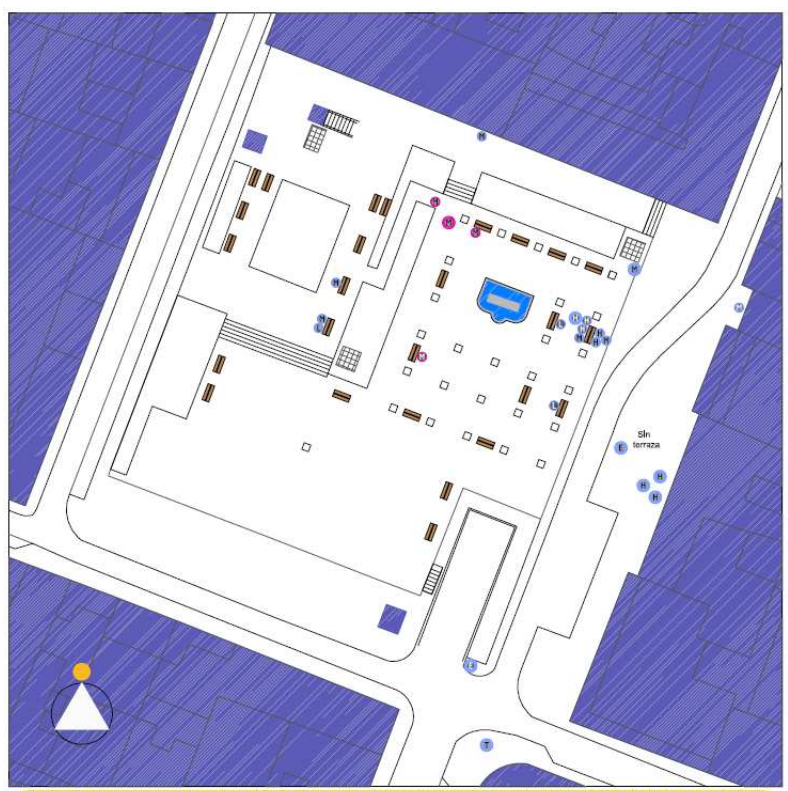

LOCALIZACIÓN DE PERSONAS: PLAZA VÁZqueZ dE MELLA, 24 DE JUNIO 10:30h

\begin{tabular}{|l|l|c|c|c|}
\hline \multicolumn{2}{|l|}{ Número de personas } & Niños & Adultos & Ancianos \\
\hline Total & $25(100 \%)$ & $0(0 \%)$ & $17(68 \%)$ & $8(32 \%)$ \\
\hline Al sol & $4(16 \%)$ & 0 & 3 & 1 \\
\hline A la sombra & $21(84 \%)$ & 0 & 14 & 7 \\
\hline De pie & $9(36 \%)$ & 0 & 7 & 2 \\
\hline Sentados & $16(64 \%)$ & 0 & 10 & 6 \\
\hline
\end{tabular}

ACTIVIDADES PRINCIPALES: PLAZA DEL 2 DE MAYO, 24 DE JUNIO_10:30h

Mirar: 12 personas / Hablar: 8 personas / Leer: 3 personas

Figura 60: 24 de junio, 10:30h

Fuente: elaboración propia 


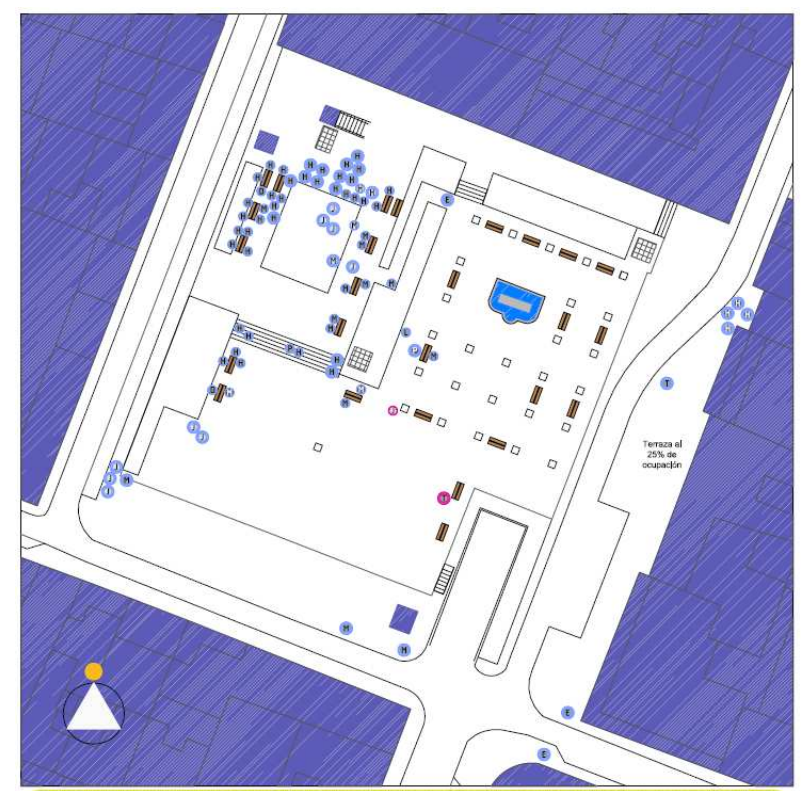

LOCALIZACIÓN DE PERSONAS: PLAZA VÁZQUEZ DE MELLA, 24 DE JUNIO_18:00h

\begin{tabular}{|l|c|c|c|}
\hline Número de personas & Niños & Adultos & Ancianos \\
\hline
\end{tabular}

\begin{tabular}{|l|l|l|l|l|}
\hline Total & $80(100 \%)$ & $14(17.6 \%)$ & $59(73.6 \%)$ & $7(8.8 \%)$ \\
\hline
\end{tabular}

Al so

A la sombra $78197.5 \%$

\begin{tabular}{|l|l|l|l|l|}
\hline De pie & $38(47.5 \%)$ & 11 & 22 & 5 \\
\hline Sentados & $42(52.5 \%)$ & 3 & 37 & 2 \\
\hline
\end{tabular}

ACTIVIDADES PRINCIPALES: PLAZA DEL 2 DE MAYO, 24 DE JUNIO_18:00h

Hablar: 44 personas / Mirar: 17 personas / Jugar: 10 personas

Figura 61: 24 de junio, 18:00h

Fuente: elaboración propia 


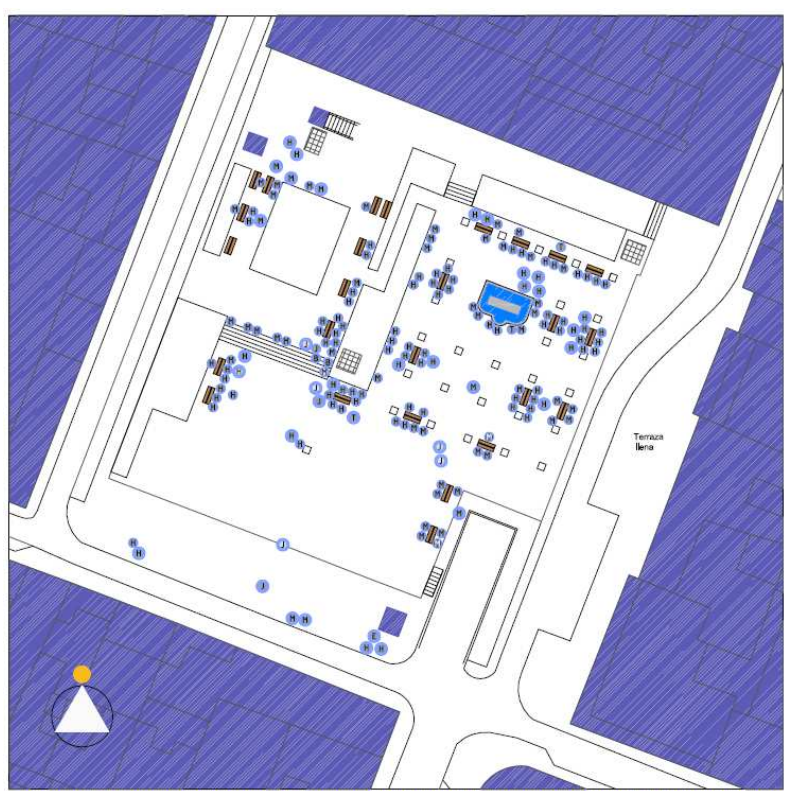

LOCALIZACIÓN DE PERSONAS: PLAZA VÁZQUEZ DE MELLA, 24 DE JUNIO_23:30h
\begin{tabular}{|l|c|c|c|c|}
\hline Número de personas & Niños & Adultos & Ancianos \\
\hline Total & $164(100 \%)$ & $7(4.3 \%)$ & $155(94.5 \%)$ & $2(1.2 \%)$ \\
\hline De pie & $38(30.2 \%)$ & 6 & 32 & 0 \\
\hline Sentados & $126(69.8 \%)$ & 1 & 123 & 2 \\
\hline
\end{tabular}

ACTIVIDADES PRINCIPALES: PLAZA DEL 2 DE MAYO, 24 DE JUNIO_23:30h

Hablar: 95 personas / Mirar: 55 personas / Jugar: 8 personas

FigurA 62: 24 de junio, 23:30h

Fuente: elaboración propia

\section{Plaza de Chamberí}

Este apartado consta de los planos en los que se describe la plaza de Chamberí en función de las actividades de las personas y su localización, que pueden verse en las figuras 66 a 74 .

\section{Planos resumen de la utilización de las plazas por parte de las personas en primavera}

Los planos se pueden descargar en los archivos de la plaza del 2 de Mayo, de la plaza de Vázquez de Mella y de la plaza de Chamberí.

\section{Resultados}

\section{Resultados del estudio climático}

Estudio de necesidades y estrategias y adecuación de las plazas a las mismas

Del estudio teórico de clima realizado para tres actividades metabólicas diversas y dos tipos de arropamiento diverso, se puede concluir que:

- Durante el mes de abril, con un arropamiento de 1clo e independientemente de la actividad estancial que se esté realizando (caminar, estar de pie parado o estar sentado) será necesaria una aportación de calor para alcanzar el bienestar higrotérmico.

- Durante el mes de mayo, seguirá siendo necesaria la aportación solar para alcanzar el bienestar hasta las 16:00h si se está sentado, las 15:00h si se está de pie o hasta las 13:00h si se camina. 


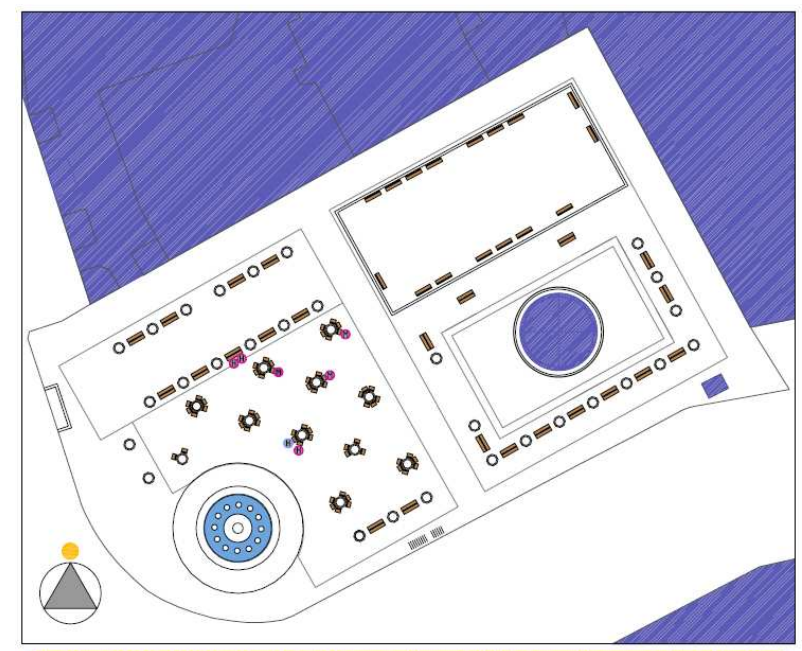

LOCALIZACIÓN DE PERSONAS: PLAZA CHAMBERÍ, 29 DE ABRIL_9:00h
\begin{tabular}{|l|l|c|c|c|}
\hline Número de personas & Niños & Adultos & Ancianos \\
\hline Total & $7(100 \%)$ & $0(0 \%)$ & $6(85.7 \%)$ & $1(14.3 \%)$ \\
\hline Al sol & $6(85.7 \%)$ & 0 & 5 & 1 \\
\hline A la sombra & $1(14.3 \%)$ & 0 & 1 & 0 \\
\hline De pie & $0(0 \%)$ & 0 & 0 & 0 \\
\hline Sentados & $7(100 \%)$ & 0 & 6 & 1 \\
\hline
\end{tabular}

ACTIVIDADES PRINCIPALES: PLAZA CHAMBERI, 29 DE ABRIL_9:00h

Hablar: 4 personas / Mirar: 3 personas

Figura 63: 29 de abril, 9:00h

Fuente: elaboración propia 


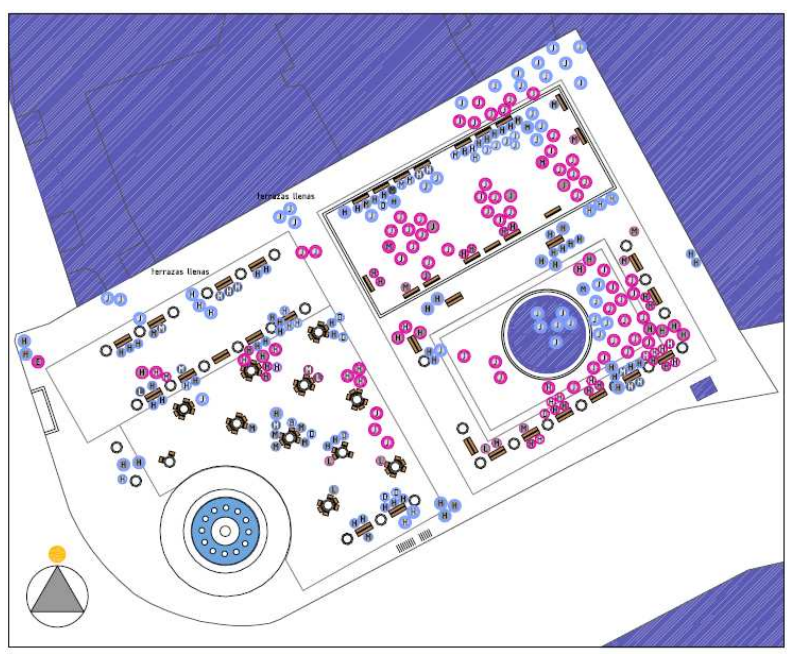

LOCALIZACIÓN DE PERSONAS: PLAZA CHAMBERÍ, 29 DE ABRIL_16:30h

\begin{tabular}{|l|c|c|c|c|}
\hline \multicolumn{2}{|l|}{ Número de personas } & Niños & Adultos & Ancianos \\
\hline Total & $271(100 \%)$ & $136(50 \%)$ & $118(43.7 \%)$ & $17(6.3 \%)$ \\
\hline Al sol & $117(43.2 \%)$ & 70 & 43 & 4 \\
\hline A la sombra & $154(56.8 \%)$ & 66 & 75 & 13 \\
\hline De pie & $138(50.9 \%)$ & 103 & 35 & 0 \\
\hline Sentados & $133(49.1 \%)$ & 33 & 83 & 17 \\
\hline
\end{tabular}

ACTIVIDADES PRINCIPALES: PLAZA CHAMBERÍ, 29 DE ABRIL_16:30h Hablar: 130 personas / Jugar: 96 personas / Mirar: 29 personas

Figura 64: 29 de abril, 16:30h

Fuente: elaboración propia

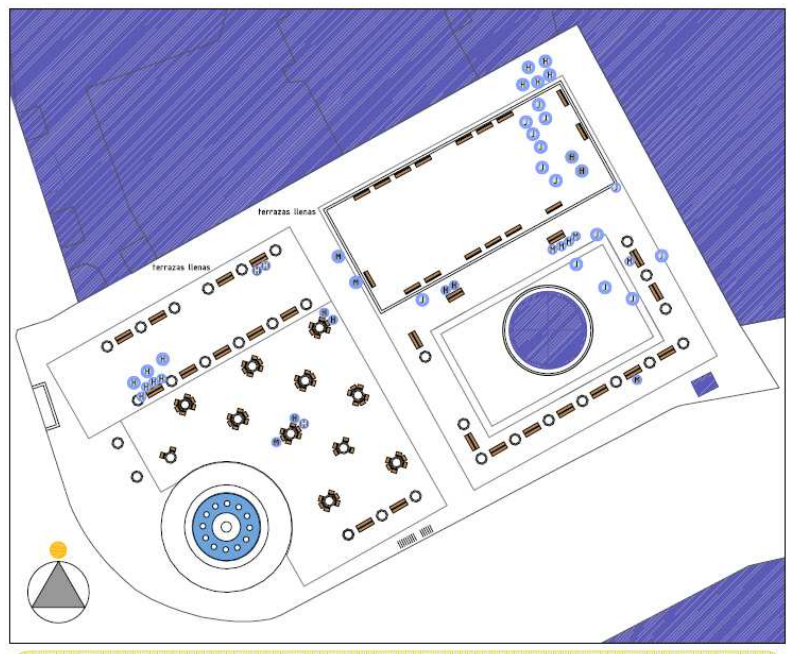

LOCALIZACIÓN DE PERSONAS: PLAZA CHAMBERÍ, 29 DE ABRIL_22:00h

\begin{tabular}{|l|c|c|c|c|}
\hline \multicolumn{2}{|l|}{ Número de personas } & Niños & Adultos & Ancianos \\
\hline Total & $45(100 \%)$ & $31(68.9 \%)$ & $11(24.4 \%)$ & $3(6.7 \%)$ \\
\hline De pie & $25(55.6 \%)$ & 21 & 4 & 0 \\
\hline Sentados & $20(44.4 \%)$ & 10 & 7 & 3 \\
\hline
\end{tabular}

ACTIVIDADES PRINCIPALES: PLAZA CHAMBERÍ, 29 DE ABRIL_22:00h

Hablar: 22 personas / Jugar: 14 personas / Mirar: 9 personas

Figura 65: 29 de abril, 22:00h

Fuente: elaboración propia 


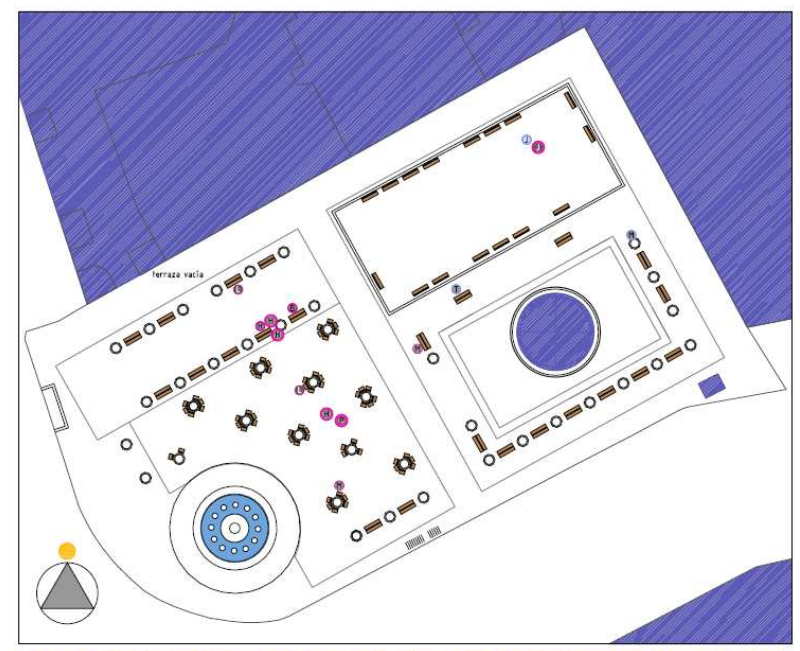

LOCALIZACIÓN DE PERSONAS: PLAZA CHAMBERí, 27 DE MAYO_9:00h
\begin{tabular}{|l|l|c|c|c|}
\hline Número de personas & Niños & Adultos & Ancianos \\
\hline Total & $13(100 \%)$ & $1(7.7 \%)$ & $9(69.2 \%)$ & $3(23.1 \%)$ \\
\hline Al sol & $10(76.9 \%)$ & 0 & 7 & 3 \\
\hline A la sombra & $3(23.1 \%)$ & 1 & 2 & 0 \\
\hline De pie & $5(38.5 \%)$ & 0 & 4 & 1 \\
\hline Sentados & $8(61.5 \%$ & 1 & 5 & 2 \\
\hline
\end{tabular}

ACTIVIDADES PRINCIPALES: PLAZA CHAMBERÍ, 27 DE MAYO_9:00h

Hablar: 4 personas / Mirar: 3 personas / Jugar: 2 personas

Figura 66: 27 de mayo, 9:00h

Fuente: elaboración propia 


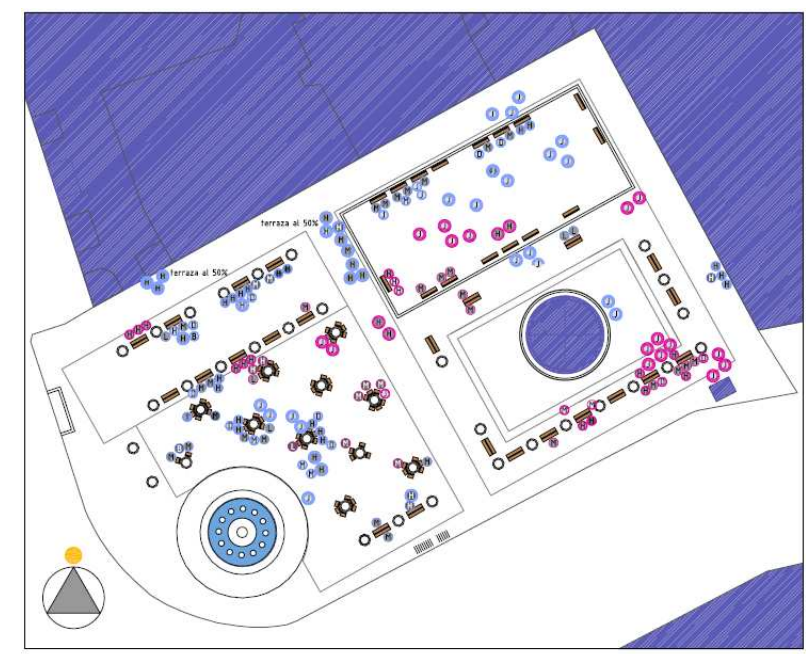

LOCALIZACIÓN DE PERSONAS: PLAZA CHAMBERÍ, 27 DE MAYO_16:30h

\begin{tabular}{|l|l|c|c|c|}
\hline \multicolumn{2}{|l|}{ Número de personas } & Niños & Adultos & Ancianos \\
\hline Total & $162(100 \%)$ & $62(38.3 \%)$ & $80(49.4 \%)$ & $20(12.3 \%)$ \\
\hline Al sol & $63(38.9 \%)$ & 23 & 30 & 10 \\
\hline A la sombra & $99(61.1 \%)$ & 39 & 50 & 10 \\
\hline De pie & $59(36.4 \%)$ & 38 & 18 & 3 \\
\hline Sentados & $103(63.6 \%)$ & 24 & 62 & 17 \\
\hline
\end{tabular}

ACTIVIDADES PRINCIPALES: PLAZA CHAMBERÍ, 27 DE MAYO_16:30h

Hablar: 59 personas / Mirar: 49 personas / Jugar: 41 personas

FIGURA 67: 27 de mayo, 16:30h

Fuente: elaboración propia

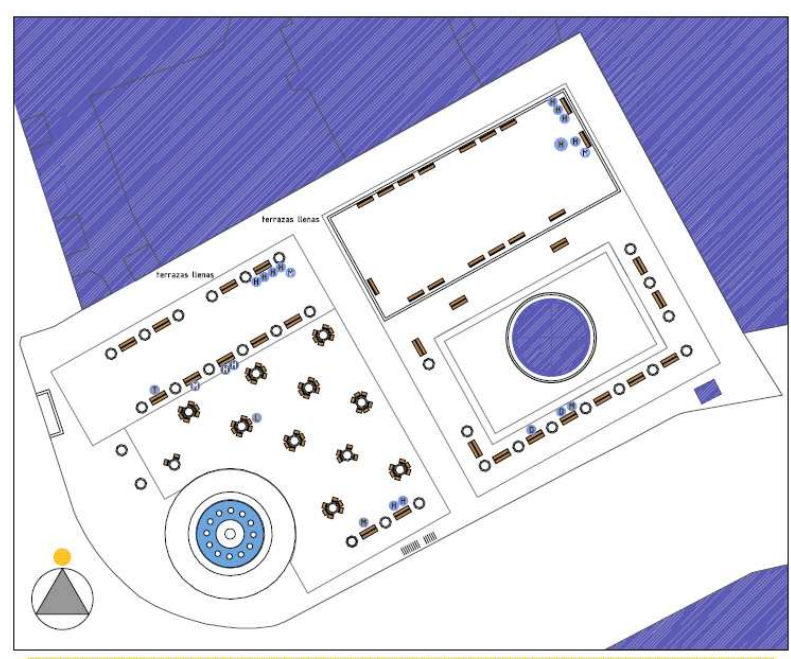

LOCALIZACIÓN DE PERSONAS: PLAZA VÁZQUEZ DE MELLA, 27 DE MAYO_22:00h

\begin{tabular}{|l|l|c|c|c|}
\hline \multicolumn{2}{|l|}{ Número de personas } & Niños & Adultos & Ancianos \\
\hline Total & $22(100 \%)$ & $2(9.1 \%)$ & $17(49.4 \%)$ & $3(13.6 \%)$ \\
\hline De pie & $1(4.5 \%)$ & 0 & 1 & 0 \\
\hline Sentados & $21(95.5 \%)$ & 2 & 16 & 3 \\
\hline
\end{tabular}

ACTIVIDADES PRINCIPALES: PLAZA CHAMBERÍ, 27 DE MAYO_22:00h

Hablar: 13 personas / Mirar: 5 personas

FIGURA 68: 27 de mayo, 22:00h

Fuente: elaboración propia 


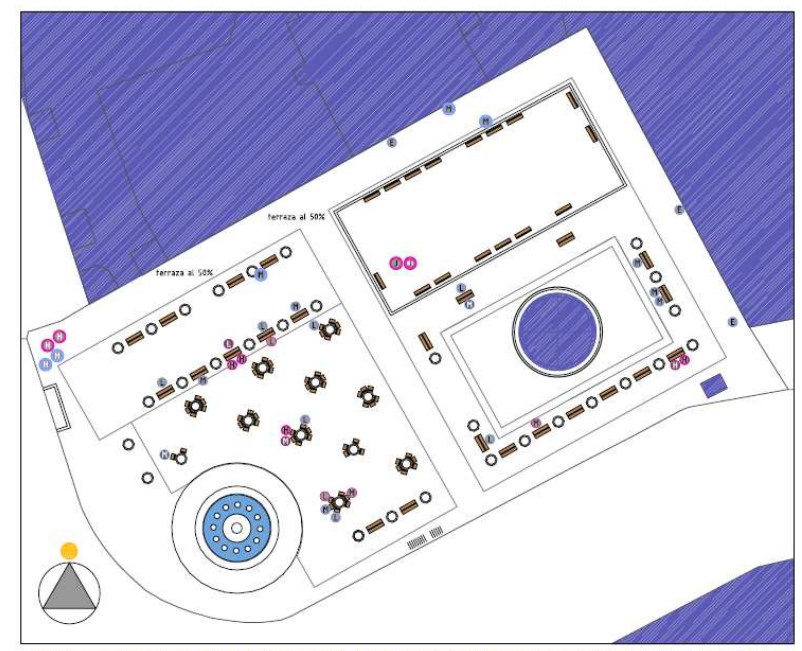

LOCALIZACIÓN DE PERSONAS: PLAZA CHAMBERÍ, 24 DE JUNIO_9:00h
\begin{tabular}{|l|l|c|c|c|}
\hline Número de personas & Niños & Adultos & Ancianos \\
\hline Total & $38(100 \%)$ & $1(2.6 \%)$ & $32(84.2 \%)$ & $5(13.2 \%)$ \\
\hline Al sol & $12(31.6 \%)$ & 1 & 8 & 3 \\
\hline A la sombra & $26(68.4 \%)$ & 0 & 24 & 2 \\
\hline De pie & $9(23.7 \%)$ & 1 & 8 & 0 \\
\hline Sentados & $29(76.3 \%)$ & 0 & 24 & 5 \\
\hline
\end{tabular}

ACTIVIDADES PRINCIPALES: PLAZA CHAMBERÍ, 24 DE JUNI0_9:00h

Mirar: 15 personas / Hablar: 8 personas / Jugar: 2 personas

Figura 69: 24 de junio, 9:00h

Fuente: elaboración propia 


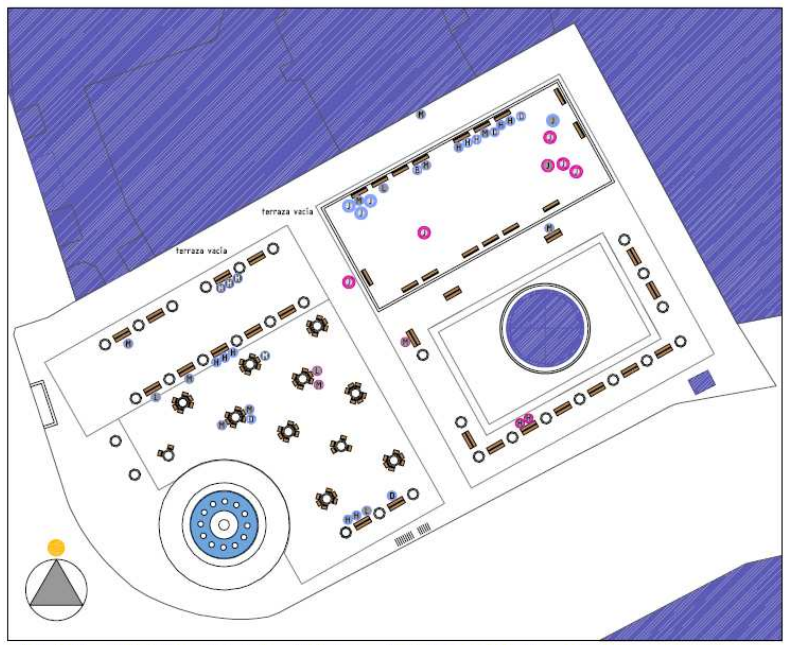

LOCALIZACIÓN DE PERSONAS: PLAZA CHAMBERÍ, 24 DE JUNIO_16:30h

\begin{tabular}{|l|c|c|c|c|}
\hline \multicolumn{2}{|l|}{ Número de personas } & Niños & Adultos & Ancianos \\
\hline Total & $45(100 \%)$ & $15(33.3 \%)$ & $26(57.8 \%)$ & $4(8.9 \%)$ \\
\hline Al sol & $10(22.2 \%)$ & 6 & 4 & 0 \\
\hline A la sombra & $35(77.8 \%)$ & 9 & 22 & 4 \\
\hline De pie & $10(22.2 \%)$ & 8 & 2 & 0 \\
\hline Sentados & $35(77.8 \%)$ & 7 & 24 & 4 \\
\hline
\end{tabular}

ACTIVIDADES PRINCIPALES: PLAZA CHAMBERÍ, 24 DE JUNIO_16:30h

Hablar: 15 personas / Mirar: 12 personas/ Jugar: 10 personas

Figura 70: 24 de junio, 16:30h

Fuente: elaboración propia

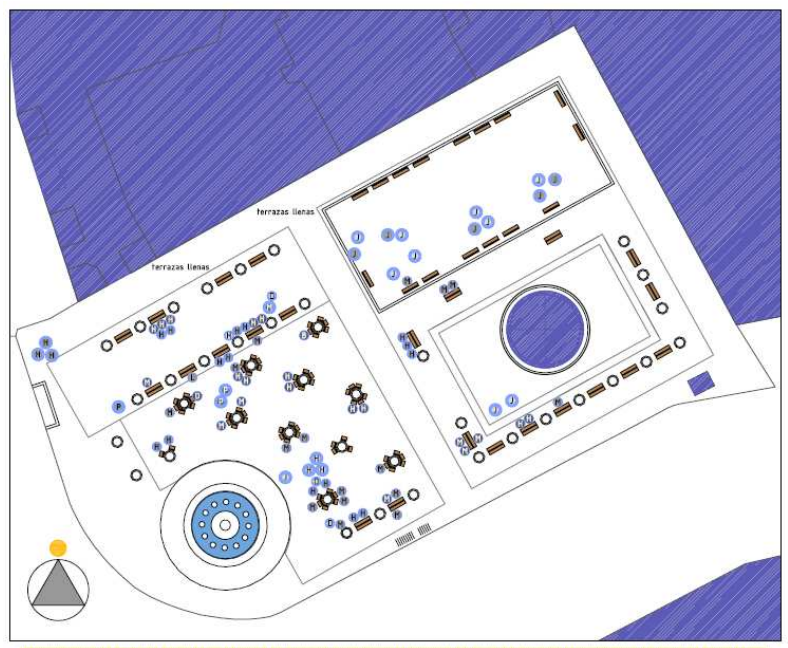

LOCALIZACIÓN DE PERSONAS: PLAZA CHAMBERII, 24 DE JUNIO_22:00h

\begin{tabular}{|l|c|c|c|c|}
\hline \multicolumn{2}{|l|}{ Número de personas } & Niños & Adultos & Ancianos \\
\hline Total & $83(100 \%)$ & $17(20.5 \%)$ & $41(49.4 \%)$ & $25(30.1 \%)$ \\
\hline De pie & $25(30.1 \%)$ & 13 & 9 & 3 \\
\hline Sentados & $58(69.9 \%)$ & 4 & 32 & 22 \\
\hline
\end{tabular}

ACTIVIDADES PRINCIPALES: PLAZA CHAMBERII, 24 DE JUNIO_22:00h

Hablar: 35 personas / Mirar: 24 personas / Jugar: 15 personas

Figura 71: 24 de junio, 22:00h

Fuente: elaboración propia 
- En mayo se alcanzarán ciertas horas de bienestar a primeras horas de la tarde, con entre 3 y 4 horas de confort si se está sentado o de pie, y 2 horas a primera y última hora de la tarde, si se camina.

- En mayo comenzará a resultar necesario disponer de espacios sombreados por los que se pueda caminar para la mayor parte de las horas de la tarde.

- Durante el mes de junio la estrategia de sombreamiento, esto es, de disponer de espacios a la sombra, resultará necesaria a partir del mediodía y durante toda la tarde, aún y cuando se ha reducido el nivel de arropamiento de 1clo a 0.7clo. Además, puntualmente, a media tarde, será necesario el viento para alcanzar el confort caminando o jugando.

- A primera hora del mes de junio, hasta mediodía si se está sentado o de pie y hasta las 10:00h si se camina, resulta necesaria una aportación solar para encontrarse confortable. Existe una hora en la que se alcanza el bienestar ampliado entre las 12:00h y las 13:00h si se está sentado o de pie y entre las 10:00h y las 11:00h si se está caminando.

- En ninguno de los meses se desciende por debajo del $20 \%$ de humedad relativa, que es el límite inferior de humedad relativa para encontrarse confortable (OLGYAY, 1963) por lo que en principio, no resulta necesaria la aportación de humedad al ambiente, aún y cuando la humedad relativa en estos meses es baja.

Cabe señalar, que en los estudios teóricos de clima se tiene en cuenta que siempre existirá un número de personas que no se encuentren en confort, por ello, al hablar de bienestar se contempla entre un $10 \%$ y un $20 \%$ de personas que no se encuentran confortables (NEILA, 2004).

\section{Mediciones en las plazas}

\section{Diferencia entre medidas in situ y medidas teóricas}

En las mediciones realizadas en las plazas se hace patente la diferencia existente entre los valores obtenidos in situ y los valores teóricos de las temperaturas y humedades medias con las que se debe trabajar en las herramientas de caracterización climática de un lugar.

La dificultad de caracterización climática de los espacios exteriores urbanos reside en que las condiciones microclimáticas de estos espacios son difícilmente generalizables, careciendo en muchas ocasiones de datos climáticos en puntos cercanos a la zona de estudio. Scudo (Scudo, Dessi y RogorA, 2004) señala que un espacio público en el que se dan gran variedad de variables los datos provenientes de las estaciones meteorológicas difícilmente podrán caracterizar sus condiciones microclimáticas.

Se han realizado comparativas de los valores de temperatura y humedad registrados en las tres plazas. Sin embargo, no se ha realizado una comparativa entre las temperaturas registradas en las plazas durante las mañanas, dado que cada una de ellas se ha medido en horas diferentes y esta es la hora del día en la que más varían estos datos, por lo que las conclusiones extraídas de esta comparativa no resultarían representativas.

\section{Temperaturas del aire}

Analizando las mediciones de temperatura del aire de las tres plazas se observa que la de Vázquez de Mella es la que alcanza unas temperaturas más elevadas durante las tardes de los meses estudiados, aunque en ocasiones es superada por la plaza de Chamberí. La plaza del 2 de Mayo es la que tiene unas temperaturas más bajas durante las tardes.

Sin embargo, por las noches la plaza Vázquez de Mella es aquella que ha registrado unas temperaturas del aire más bajas, pudiendo deberse a que tiene una mayor proporción de cielo visto (sky view factor $\left.(\mathrm{SVF})^{3}\right)$ que las otras. Chamberí es la plaza que registra mayores temperaturas por las noches, pudiendo deberse a que se encuentra junto al cruce de tres grandes viales asfaltados, siendo estos los pavimentos que mayor calor acumulan y los que más lentamente se enfrían por tener un albedo ${ }^{4}$ muy bajo (FARIÑN, 1990).

Las temperaturas del aire registradas al sol tienen la mayor diferencia con las registradas a la sombra durante el mes de abril, siendo a la sombra de entre $1.5^{\mathrm{O}} \mathrm{C}$ y $4^{\mathrm{O}} \mathrm{C}$ menores. Durante mayo y junio esas diferencias se reducen, siendo las temperaturas a la sombra entre $1^{\mathrm{O}} \mathrm{C}$ y $2.5^{\mathrm{O}} \mathrm{C}$ inferiores a las registradas al sol.

\footnotetext{
${ }^{3}$ Es la relación entre la radiación recibida (o emitida) por una superficie plana y la radiación emitida (o recibida) por todo el globo celeste (WATSON Y Johnson, 1987). Es una medida adimensional entre cero y uno, siendo cero un cielo totalmente obstruido y uno un espacio totalmente libre (OKe, 1988).

${ }^{4}$ Relación, expresada en porcentaje, de la radiación que cualquier superficie refleja sobre la radiación que incide sobre la misma. Las superficies claras tienen valores de albedo superior a las oscuras, y las brillantes más que las mates. Fuente: http://www.wikipedia.org
} 
Las temperaturas del aire registradas cerca de zonas en las que se hace uso del agua, como son las fuentes existentes en Vázquez de Mella y en Chamberí, también son inferiores a las registradas lejos del agua. Durante las tardes la reducción es de entre $1^{\mathrm{O}} \mathrm{C}$ y $3.5^{\mathrm{O}} \mathrm{C}$. Esa reducción de la temperatura será inferior durante la noche, que será de $0.5^{\mathrm{O}} \mathrm{C}$.

\section{Humedad relativa}

Las humedades relativas más bajas registradas durante el día, tanto al sol como a la sombra, son aquellas de la plaza Chamberí, que varían entre el $26 \% \mathrm{HR}$ y el $31 \% \mathrm{HR}$.

Según van subiendo las temperaturas de abril a junio, la plaza Vázquez de Mella es aquella que tiene unos valores de humedad relativa mayores por la noche y Chamberí es aquella con unos valores más bajos. En abril los valores nocturnos de humedad relativa son similares en todas las plazas.

De modo general, la humedad relativa a la sombra es un $4 \%$ mayor a la sombra que al sol durante las mañanas. Ese valor se reduce por las tardes, pasando a ser de un $2 \%$.

El uso de agua en las fuentes hace que en torno a ellas la humedad relativa se vea incrementada un $3.5 \%$ en Vázquez de Mella y el $8 \%$ en Chamberí.

\section{Viento}

En la plaza del 2 de Mayo las lecturas de viento han variado desde la calma hasta una velocidad máxima de $4 \mathrm{~m} / \mathrm{s}$. La dirección del viento y su intensidad han variado a lo largo de los meses e incluso a lo largo de los propios días en los que se ha realizado el estudio. Los vientos provenientes del noreste y del este provocaban mayores velocidades en la parte alta de la plaza, aquella que queda precisamente al este, mientras que la parte baja de la plaza quedaba protegida. Sin embargo, cuando los vientos provenían del norte, sur o suroeste, era en la parte baja de la plaza donde se registraron velocidades mayores.

El viento en la plaza Vázquez de Mella seguía el eje NE-SO, direcciones predominantes del viento en Madrid. En abril los vientos provenían del NE, mientras que en mayo y junio lo hacían desde el SO. La intensidad de los mismos ha variado tanto a lo largo de los días como a lo largo de los meses, con velocidades mínimas de $0.08 \mathrm{~m} / \mathrm{s}$ y máximas de $3.2 \mathrm{~m} / \mathrm{s}$.

En la plaza Chamberí tanto la intensidad como la dirección del viento ha sido muy variable, ya que es la plaza más expuesta. La velocidad del viento ha variado desde los $0.07 \mathrm{~m} / \mathrm{s}$ hasta $\operatorname{los} 3.3 \mathrm{~m} / \mathrm{s}$.

En ninguna de las tres plazas se ha superado la velocidad de $4 \mathrm{~m} / \mathrm{s}$, que comienza a tener efectos mecánicos.

\section{Materiales de las plazas}

Las temperaturas a las que se encuentran los materiales condicionan el intercambio radiante que se da entre estos y los usuarios, condicionando el confort en estos espacios. Este intercambio de energía se da a escala de microclima (CABALlERo, 2004), esto es, a una altura del suelo de entre 1.5 y 2 metros.

Existe un comportamiento diferenciado en cada tipo de superficie y elementos de la ciudad.

Las zonas verdes son en general frescas o templadas, dependiendo de la densidad y acabados superficiales. Además, a mayor cantidad de arbolado menor almacenamiento de calor, ya que sus hojas se mantienen a temperatura ambiente y proporcionan sombra al resto de elementos. Principalmente la plaza del 2 de Mayo tiene un arbolado de gran porte y muy tupido, y junto con las zonas ajardinadas o de pavimentos permeables ocupan prácticamente la mitad de la superficie de la plaza, por lo que, en principio, debería ser una plaza más fresca que Vázquez de Mella, prácticamente sin arbolado, e incluso que la plaza Chamberí. En las mediciones de temperatura realizadas se ha comprobado que es así durante el día.

De las mediciones realizadas se ha observado que los pavimentos de tierra se mantienen a la temperatura del aire aún y cuando están soleados.

Por otra parte, los materiales como la madera, con una baja inercia térmica ${ }^{5}$, se comprueba a través de las mediciones que se calientan muy rápidamente por la mañana, estando superficialmente más calientes que materiales más densos, pero a lo largo del día esa temperatura se mantiene y prácticamente no varía. Por la noche se enfrían muy rápidamente, cogiendo la misma temperatura que el aire, al igual que ocurre con los bancos de madera que se encuentran a la sombra.

Los materiales pétreos tienen una alta inercia térmica, por lo que almacenan mucho calor y lo emiten lentamente por la noche. Su capacidad de almacenamiento también depende de sus colores, siendo inferior la de los materiales claros, ya que reflejan una alta proporción de la radiación solar incidente sobre ellos (albedo alto).

A excepción de la plaza del 2 de Mayo que tiene una elevada proporción de pavimentos permeables (el $30.3 \%$ de los pavimentos) el resto de plazas tienen pavimentos de una alta inercia térmica, tratándose de granitos o materiales cementosos, al igual que ocurre también con el resto de pavimentos de la plaza del

\footnotetext{
${ }^{5}$ La inercia térmica es la capacidad que tiene la masa de conservar la energía térmica recibida e ir liberándola progresivamente (NEILA, 2004).
} 
2 de Mayo, por lo que el almacenamiento de energía en ellos será elevado, aumentando la temperatura de contacto de las superficies.

Analizando las mediciones realizadas en las plazas se observa que estos materiales pétreos y cementosos, por la noche, vuelven prácticamente a alcanzar las temperaturas que tenían en las mediciones realizadas por la mañana, por lo que han perdido la mayor parte del calor almacenado. En junio, por la noche, aún tienen una temperatura algo superior a aquella que tenían por la mañana.

La plaza de Chamberí se encuentra en el cruce de tres grandes viales asfaltados. Las superficies asfaltadas son las que más calor almacenan y lo emiten lentamente por la noche, hecho que influirá en la plaza.

Las temperaturas de contacto de los materiales pétreos y cementosos van incrementando de la mañana a la tarde. Esto ocurre tanto al sol como en los lugares a la sombra.

Los materiales cementosos de color claro incrementan entre $11^{\mathrm{O}} \mathrm{C}$ en abril y $18^{\mathrm{O}} \mathrm{C}$ en junio, mientras que los rojizos lo hacen entre $13^{\mathrm{O}} \mathrm{C}$ y $20.5^{\mathrm{O}} \mathrm{C}$, alcanzando una temperatura máxima de $50.6^{\mathrm{O}} \mathrm{C}$ la tarde de junio.

Los ladrillos rojizos suben aproximadamente unos $6^{\mathrm{O}} \mathrm{C}$ desde la mañana a la tarde.

Los granitos de color gris claro incrementan su temperatura de la mañana a la tarde entre $8^{\circ}$ en abril y $11^{\circ} \mathrm{C}$ en junio. Los granitos de color gris oscuro, sin embargo, lo hacen entre $9^{\mathrm{O}} \mathrm{C}$ y $16^{\mathrm{O}} \mathrm{C}$, alcanzando una temperatura máxima registrada de $50.5^{\mathrm{O}} \mathrm{C}$.

Los incrementos de temperatura de los materiales pétreos y cementosos de las plazas que se encuentran a la sombra son de entre $2^{\mathrm{O}} \mathrm{C}$ y $8^{\mathrm{O}} \mathrm{C}$ desde la mañana a la tarde. Además, la diferencia de temperatura entre aquellos que se encuentran al sol y aquellos que están a la sombra es de alrededor de $5^{\mathrm{O}} \mathrm{C}$ por las mañanas y $9^{\mathrm{O}} \mathrm{C}$ por las tardes de abril, hasta alcanzar una diferencia de temperatura máxima en junio, donde aquellos materiales que se encuentran al sol tienen hasta $16^{\circ} \mathrm{C}$ más.

La temperatura que alcanzan los materiales más densos al sol llega a ser en abril de $9^{\mathrm{O}} \mathrm{C}$ y en junio de $15^{\circ} \mathrm{C}$ superior a la temperatura del aire. Los menos densos alcanzan una diferencia máxima de $8^{\circ} \mathrm{C}$.

Los bancos de materiales con menor inercia térmica como es la madera, en los días analizados han alcanzado una temperatura de contacto máxima de $43^{\circ} \mathrm{C}$, mientras que los bancos de granito han alcanzado una temperatura de contacto máxima de $50.5^{\circ} \mathrm{C}$. La diferencia entre ambos materiales es que los bancos de madera una vez que el usuario se siente en ellos, perderán rápidamente ese calor almacenado, mientras que en los bancos de granito no ocurrirá lo mismo, manteniéndose a temperatura muy elevada durante largo tiempo. Por esta razón, los bancos de granito o materiales muy densos con una alta inercia térmica se convierten en fuentes de calor para las personas que se encuentran en las plazas.

No es recomendable el uso de bancos de materiales con una alta inercia térmica situados en zonas que durante el verano se encuentren continuamente al sol, aunque sí podrían ser empleados en zonas que estén soleadas tan sólo durante los momentos más fríos del año.

Esta misma lógica podrá ser empleada para el uso de pavimentos, empleando preferiblemente materiales con una baja inercia térmica en aquellas zonas continuamente soleadas durante los meses más cálidos en los que resulta necesario estar en zonas lo más frescas posible.

Las tres plazas en estudio tienen pavimentos e incluso bancos de materiales con una alta inercia térmica que se encuentran continuamente soleados durante los días de primavera. Estos espacios alcanzan unas altas temperaturas, por lo que a partir de mediados de mayo, que resulta necesario el sombreamiento, serán espacios aún más calurosos por el intercambio radiante que habrá de estos materiales hacia el ambiente más cercano a los usuarios de las plazas.

\section{Zonificación climática de las plazas}

Partiendo de este acercamiento teórico de la situación climática de las plazas, de las simulaciones de iluminación, radiación solar y estudios de sombras realizados con el software Ecotect y de las mediciones y observaciones realizadas en los trabajos de campo, se han identificado las zonas con mayor disponibilidad de sombra y menor acumulación solar en pavimentos y las zonas con menor disponibilidad de sombra o más soleadas y mayor acumulación de energía en pavimentos durante los meses de abril, mayo y junio. A continuación se van a explicar los criterios que se han seguido, se puede ver el código de colores utilizado en la figura 75 y los planos correspondientes a la plaza del 2 de Mayo en la figura 76, a la plaza de Vázquez de Mella en la figura 77 y a la plaza de Chamberí en la figura 78.

Las características que se han tenido en cuenta para definir los espacios cálidos y frescos se basan en la capacidad de captación y almacenamiento de energía que tiene cada una de las zonas, y son las siguientes:

- Disponibilidad de sombra;

- existencia de arbolado; 
- Inercia térmica de los pavimentos.

Los tonos cálidos hacen referencia a las zonas de las plazas sin acceso a sombra durante los meses de primavera. Por otra parte, las zonas de tonos azulados son las zonas con acceso a sombra, ya sea por estar en zonas con sombra arrojada de los edificios como por la sombra de los árboles de gran porte.

Dado que en las mediciones de temperaturas realizadas durante los trabajos de campo se ha detectado que los pavimentos de alta inercia térmica van acumulando energía térmica en ellos elevando su temperatura tanto al sol como a la sombra y, por otra parte, se ha detectado un incremento de humedad en zonas vegetadas, se han elaborado dos gamas de colores tanto para las zonas sombreadas como para las soleadas incluyendo estos parámetros.

Así, los tonos rojizos más claros son, dentro de las zonas al sol, los menos cálidos por ser zonas con pavimentos de baja inercia térmica, y los rojos más oscuros son aquellas zonas más cálidas de la plaza soleados y con pavimentos de alta inercia térmica.

Los tonos azules más claros, son, dentro de las zonas a la sombra, aquellos que corresponden a los espacios menos frescos, por tener pavimentos pesados o no disponer de árboles, y los azules más oscuros son aquellos puntos sombreados más frescos, con pavimentos ligeros y arbolado, además de disponer de sombra arrojada por los edificios.

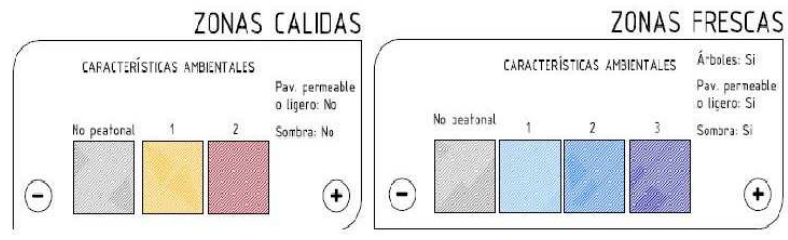

FIGURA 72: Código de colores utilizado en los planos de zonificación climática Fuente: elaboración propia

Plaza del 2 de Mayo

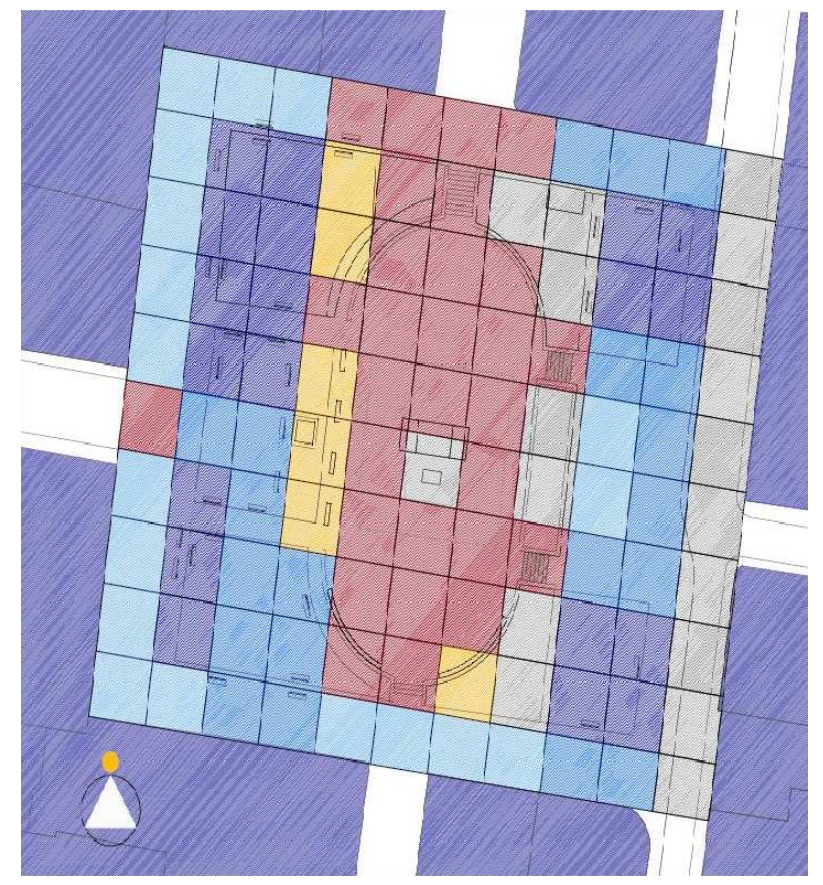

Figura 73: Zonificación climática de la plaza del 2 de Mayo

Fuente: elaboración propia 
La plaza del 2 de Mayo ofrece diversas posibilidades de situarse en el espacio público con diferentes grados de soleamiento y de sombra. Esto la convierte en una plaza confortable, al ofrecer al ciudadano la posibilidad de seleccionar el espacio en el que se encuentre mejor.

Durante la primavera existen más espacios sombreados con un $62 \%$ del total de lugares peatonales, frente a espacios soleados o sin acceso a sombra, que suponen el $38 \%$ restante.

El espacio abierto sin arbolado en el centro de la plaza se convierte en un buen lugar estancial durante los meses más fríos, aunque durante los meses más cálidos estará continuamente soleado y se alcanzarán altas temperaturas.

Los árboles son de hoja caduca, por lo que permitirán la entrada del sol durante el invierno.

La plaza del 2 de Mayo, por tanto, tiene espacios diferenciados dependiendo de la necesidad de radiación solar o sombreamiento, algo imprescindible en un clima como el madrileño. El plano que hace referencia a todas estas características se puede consultar en la figura 76 .

Plaza de Vázquez de Mella

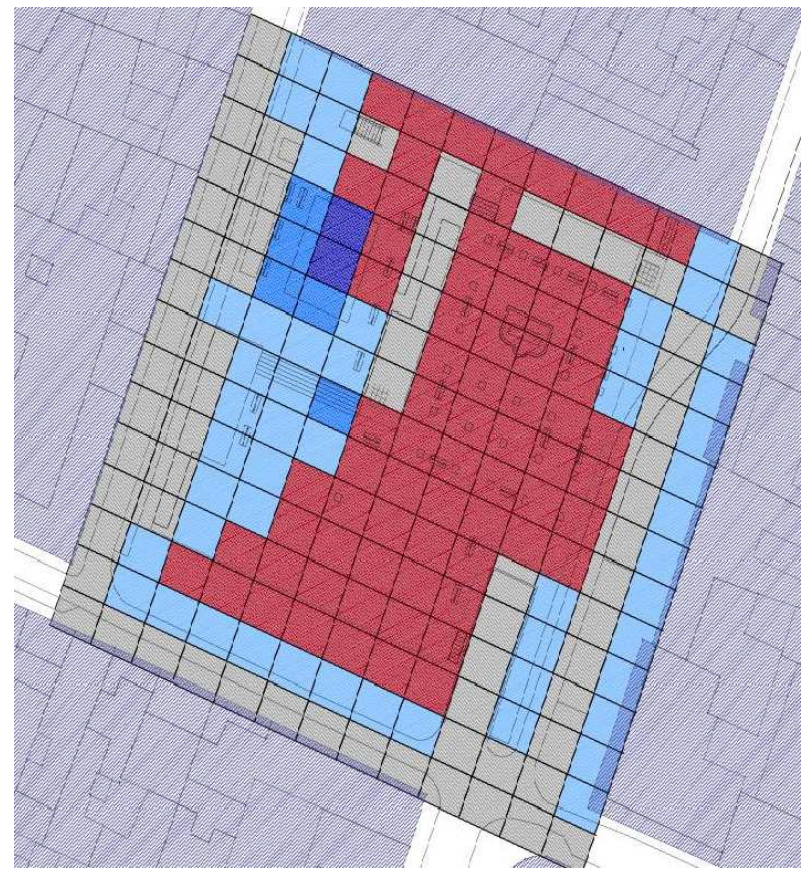

FIGURA 74: Zonificación climática de la plaza Vázquez de Mella

Fuente: elaboración propia

En la plaza Vázquez de Mella durante la primavera se puede tener acceso tanto a zonas soleadas como en sombra, pero carece de variedad en cuanto a tipos de espacios a la sombra o soleados. Las zonas al sol tienen un carácter muy cálido, con pavimentos muy densos y soleamiento a lo largo de todo el día. Las zonas de sombra por otra parte, sólo tienen sombra durante algunas horas al día y carecen prácticamente de arbolado o de pavimentos permeables.

Cabe señalar que es una plaza muy soleada durante la primavera, con el $55 \%$ de la superficie peatonal totalmente al sol y con pavimentos densos. El resto de la superficie tan sólo tiene sombra durante algunas horas del día, a excepción de una pequeña zona en la parte alta de la plaza, en torno a la zona de juegos de niños, donde existen unos árboles con porte suficiente para crear sombra. La zona con mayor número de horas de sombra se sitúa fuera de la zona de uso de la gente, pues está en el vial rodado, al sur de la plaza.

El escaso porte del arbolado reduce notablemente las zonas confortables en la plaza para los momentos más cálidos. Los pavimentos, además, al ser pétreos, tienen una alta inercia térmica y acumulan mucha energía, lo que dificulta aún más alcanzar el confort durante los momentos más cálidos de la primavera, principalmente en junio, donde se han alcanzado por la tarde temperaturas de contacto de los materiales de más de $50^{\circ} \mathrm{C}$.

Por otra parte, la mayoría de los bancos se encuentran al sol durante los meses de primavera, y la mayor parte de los espacios que están sombrados en algún momento del día no dan opción al ciudadano a 
sentarse, por lo que ésta es una plaza que ofrece pocas posibilidades al usuario de seleccionar la posición que le sea más confortable. El plano que hace referencia a todas estas características se puede consultar en la figura 77.

\section{Plaza de Chamberí}

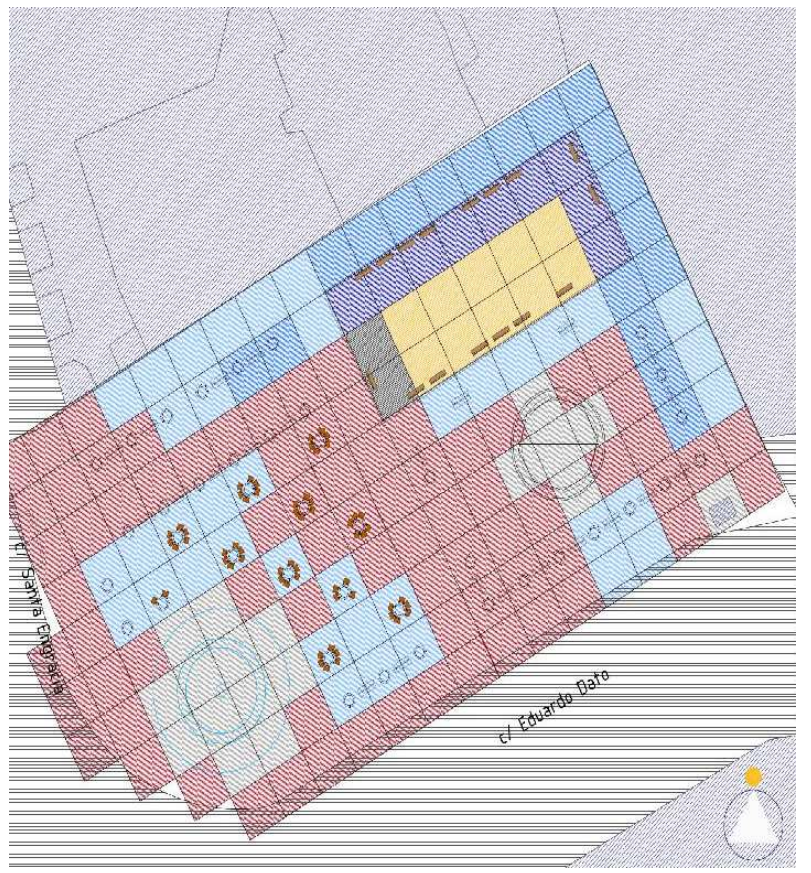

Figura 75: Zonificación climática de la plaza de Chamberí

Fuente: elaboración propia

Chamberí es en principio una plaza muy soleada, pero el arbolado existente la convierte en un espacio urbano con accesibilidad a sombra. Existe variedad de espacios diversos a la sombra, por lo que el ciudadano tiene opción a elegir diferentes zonas.

La necesidad de radiación solar está perfectamente cubierta los meses con necesidad de aportación de calor, siendo los espacios soleados de carácter cálido, totalmente expuestos al sol durante la primavera y con pavimentos con una gran capacidad de acumular energía.

Los espacios totalmente soleados durante la primavera suponen el $54 \%$ de la superficie peatonal.

La zona más sombreada es la esquina norte de la plaza, además de tener un pavimento permeable y arbolado de gran porte. El resto de las zonas tan sólo están a la sombra durante algunas horas del día.

En Chamberí la accesibilidad a espacios soleados será más sencilla que a zonas sombreadas, pero aún así es una plaza que ofrece posibilidades de selección de zonas estanciales a sus usuarios. El plano que hace referencia a todas estas características se puede consultar en la figura 78 .

\section{Resultados del estudio físico espacial de las plazas}

\section{Dimensiones en planta}

KEVIn Lynch establece un máximo para las plazas de 110 metros de anchura y longitud, señalando que históricamente, ningún espacio que haya triunfado como zona de encuentro y de relación ha superado esta dimensión (LYNCH, 1998). Además, señala los 25 metros como distancia máxima para ver lo que sucede alrededor.

Por otra parte, JAN GEHL establece un radio de acción de los sentidos de entre 20-100 metros (GHEL, 2001).

Teniendo en cuenta estos parámetros se puede concluir que todas las plazas analizadas tienen unas dimensiones apropiadas para funcionar correctamente como zona de encuentro y de relación entre individuos. Cabe destacar que la plaza Chamberí, no como plaza peatonal, sino como hueco urbano, supera estas dimensiones, al alcanzar los 121 metros de longitud en la dirección este-oeste, por lo que se pierde el carácter de recinto cerrado. 


\section{Altura de los edificios}

Las calles y espacios más vivos suelen ser aquellos con edificios de entre 3 y 4 plantas, pues permiten una comunicación interior-exterior, entre espacio privado y público (GHEL, 2001). En todas las plazas existen edificios de estas características. En Chamberí, la altura media de los edificios que dan directamente a la plaza es de tres pisos, en las otras dos plazas son de cinco y seis pisos.

Cabe señalar que la altura de los edificios no supone una obstrucción solar total del espacio público, al contrario, pues existen tanto zonas soleadas como zonas en sombra, creándose espacios diferenciados para poder estar en confort tanto en invierno como en verano. Las plazas rodeadas de edificios de mayor altura tendrán una dificultad mayor en enfriarse durante la noche, dado que su proporción de cielo visible es menor.

\section{El empleo del agua, vegetación y pavimentos en las plazas}

El empleo de agua como sistema de acondicionamiento climático en las plazas 2 de Mayo y Vázquez de Mella es muy escaso.

En la plaza del 2 de Mayo tan sólo hay una fuente de agua potable, pero no hay un uso del agua como regulador microclimático. Sin embargo, el arbolado de gran porte que cubre más de la mitad de la plaza aportará humedad al ambiente. Además, más del $30 \%$ de los pavimentos de la plaza son permeables, ya se traten de jardines, terrizos o arena, lo que permite el filtrado del agua y su posterior evapotranspiración, aportando humedad al aire, lo que será positivo, dado que, aunque no se alcance el mínimo establecido de un $20 \%$ de humedad relativa, los valores durante los meses de primavera son bajos, rondando entre 30 y el $60 \%$. Su funcionamiento sería aún mejor si los jardines estuvieran cubiertos de vegetación acolchada con baja necesidad de agua, pues dilatarían más en el tiempo la evapotranspiración.

La fuente existente en la plaza Vázquez de Mella es de una dimensión demasiado pequeña como para tener una influencia en un entorno considerable. Sus efectos de humectación del ambiente y capacidad de refrescar el aire tan sólo se percibirán estando junto a ella. Además no existe arbolado junto a la fuente, por lo que la radiación solar directa puede modificar esa sensación de frescor y humedad.

Los árboles maduros tienen las hojas a la temperatura del aire, los pequeños suelen tenerla un poco por encima de la temperatura del aire. En el caso de la plaza de Vázquez de Mella, la mayoría de los árboles son aún muy poco desarrollados, por lo que su capacidad de humedecer el ambiente y proporcionar sombra es prácticamente nula.

Los pavimentos permeables son muy escasos tanto en Vázquez de Mella como en Chamberí, donde no alcanzan el $10 \%$ de la superficie, por lo que el aporte de humedad al ambiente desde el terreno por evapotranspiración no es posible.

La plaza Chamberí es aquella que tiene una fuente con capacidad de crear un microclima en torno a ella, pues además, está rodeada de numerosos setos y árboles. Aunque los árboles del centro de la plaza son de porte medio, existe arbolado muy desarrollado que proporciona sombra y humedad al ambiente.

En ninguna de las tres plazas se emplean sistemas como los alcorques corridos o las pendientes de evacuación de agua de lluvia de las plazas direccionadas hacia los jardines, como modos más eficientes de aprovechamiento del agua de lluvia.

\section{La configuración espacial de las plazas y el viento}

$\mathrm{El}$ viento dominante en Madrid centro es del noreste $45^{\circ} \mathrm{C}$, pero es difícil predecir el comportamiento del viento en un centro urbano.

Cuando el viento alcanza una velocidad de $4-5 \mathrm{~m} / \mathrm{s}$ tiene efectos mecánicos. A partir de los $10 \mathrm{~m} / \mathrm{s}$ es molesto caminar y con más de $15 \mathrm{~m} / \mathrm{s}$ es peligroso (Kofoed y GAARDSTED, 2004).

Independientemente de los factores concretos del entorno urbano de cada una de las plazas que condicionan la dirección del viento y su velocidad, la dimensión y proporción altura-anchura de las plazas influye en el viento que pueda haber o no haber en ella.

El viento será menor cuanto más pequeña sea una plaza tendrá. El viento pasa por encima de la misma con las siguientes dimensiones Kofoed y GaARDsted, 2004:

$\mathrm{A} / \mathrm{H} 2=\mathrm{K}$, donde $\mathrm{K}<6, \mathrm{~A}=$ área de la plaza y $\mathrm{H}=$ altura de los edificios que configuran la plaza.

En la plaza del 2 de Mayo $K=20$, en Vázquez de Mella $\mathrm{K}=15$ y en Chamberí K varía entre 13 y 85, dado que los edificios al norte y este son bajos, con 3 plantas principalmente, mientras que al sur y al oeste tienen 8 plantas. 
Por lo tanto, ninguna de las tres plazas tiene unas dimensiones tan pequeñas como para que el viento pase por encima de ellas.

En la plaza Chamberí la menor altura de los edificios al norte y al este hará que el viento se ralentice al llegar a la plaza. Sin embargo, en las esquinas noroeste, oeste y sur, con edificios más altos, habrá más viento y habrá una succión vertical del mismo.

Tienen menos viento las plazas con una dirección paralela a la dirección dominante del viento y a las calles de los alrededores. Esto ocurre en las tres plazas.

Se reduce la velocidad del viento con entradas desde las zonas centrales de las plazas en lugar que desde las esquinas, hecho que se da en la plaza del 2 de Mayo.

En la plaza del 2 de Mayo existe una entrada a la misma en la dirección del viento dominante, que encauzará los vientos hacia la misma. En Vázquez de Mella esas entradas en la dirección dominante del viento son laterales, por lo que su influencia será menor.

Aunque en Chamberí no existe una entrada a la plaza dirección predominante del viento, hecho que podría hacer que hubiera demasiado viento, sí se encuentra al final de un gran eje de más de 100-125m (Kofoed y GaARdsted, 2004), la calle Luchana, que tiene una longitud de medio kilómetro. Este hecho, combinado con la ausencia de elementos arquitectónicos en la plaza para la protección del viento, puede en ocasiones resultar molesto en lo que al viento se refiere.

El ancho de cada entrada a la plaza no debería superar el $25 \%$ del perímetro total de la plaza. En ninguna de las tres plazas se da este hecho, aunque en Chamberí desembocan dos grandes vías.

La longitud idónea en lo que respecta al viento de una plaza sería:

- Para espacios estrechos o medios $(\mathrm{W} / \mathrm{H}=1-4)$ :

$$
\text { L=4-5 veces H (Plaza del } 2 \text { de Mayo y Vázquez de Mella) }
$$

- Para espacios anchos $(\mathrm{W} / \mathrm{H}=8)$

$$
\mathrm{L}=6-8 \text { veces } \mathrm{H}
$$

Donde $\mathrm{W}=$ ancho de la plaza, $\mathrm{H}=$ altura de los edificios y $\mathrm{L}=$ longitud de la plaza.

Chamberí supera estas proporciones en su eje noreste-suroeste.

La diferencia de cotas, los muretes centrales de la plaza y la vegetación son elementos de la plaza del 2 de Mayo que hacen que existan espacios protegidos del viento independientemente de su orientación. Las superficies rugosas que hay en la plaza (adoquines, terrizos, arbustos) ralentizan el viento frente a las superficies planas.

\section{Accesibilidad}

Las pendientes existentes en las plazas son suaves. Cuando existen desniveles se resuelven tanto con escaleras como con rampas, lo que hace que todos los espacios de las plazas sean accesibles a todos los usuarios.

Los bordillos de encuentro entre viales rodados y zonas peatonales se encuentran rebajados en las zonas de cruce, y éstas se señalizan a través de la diferenciación de pavimentos. En otras ocasiones, las zonas rodadas y las zonas peatonales se encuentran a nivel. Todas las plazas son accesibles a todos los usuarios y los cruces con viales rodados están correctamente señalizados.

\section{Recorridos peatonales}

Los recorridos dentro de las plazas son abiertos, pudiendo el usuario elegir aquellos que le resulten más cómodos, seguros, rápidos o interesantes.

\section{Transición público-privada}

En las plazas analizadas los edificios que dan a ellas tienen aberturas en fachada a través de ventanas y balcones con una permeabilidad de aproximadamente el $50 \%$ de huecos por fachada ciega. Vázquez de Mella es la única plaza donde esa proporción resulta más reducida, principalmente en las fachadas norte y sur.

Los accesos a portales se realizan de modo directo desde la calle.

Los edificios están alineados a la calle, generalmente sin retranqueos ni irregularidades. Los edificios tienen una arquitectura no uniforme, distinguiéndose perfectamente las unidades de edificación. Esto hace el espacio público más atractivo para el peatón. 
Los bajos de los edificios tienen una permeabilidad visual elevada, pudiéndose en muchos casos distinguir lo que ocurre en el espacio privado desde la calle a través de fachadas acristaladas parciales o de altura completa. Esta permeabilidad es más reducida en la plaza Vázquez de Mella. La permeabilidad elevada también mejora la comunicación y la conexión entre el espacio público y privado.

Los edificios en las tres plazas carecen de aleros o de zonas de protección para el peatón frente a la lluvia o el sol.

\section{Percepción general del espacio}

En todas las plazas existen edificios o algún monumento que pueda ayudar a la orientación o que sirve de referencia. En general, las esquinas de las manzanas de edificios no tienen un tratamiento diferenciado como para convertirse en referencias urbanas, tan sólo en Chamberí la esquina adquiere mayor altura.

Las visuales en las plazas son abiertas, pudiendo ver lo que sucede en muy diversos puntos de las mismas, lo que confiere a estos espacios una mayor sensación de seguridad.

El mantenimiento y limpieza de las plazas es bueno, tanto de pavimentos, como fachadas o mobiliario urbano. En general, la arquitectura no es homogénea, variando los colores y ritmos de fachada y el arbolado tiene una fuerte presencia tanto en Chamberí como en la plaza del 2 de Mayo, haciendo el espacio urbano más interesante para los ciudadanos.

\section{Resultados del estudio de usos y funciones de las plazas}

\section{Equipamientos}

En las tres plazas existe una mezcla de usos pudiendo encontrar equipamientos educacionales, religiosos, sociales, hosteleros y comercios, lo que permitirá a los vecinos realizar actividades, funciones y compras necesarias del día a día sin necesidad de trasladarse.

En general, estos usos están directamente situados en la planta baja de los edificios que dan a las plazas, por lo que son fácilmente accesibles, ya que las actividades situadas en cambios de nivel, tanto en altura como bajo rasante, serán menos accesibles para el ciudadano y por lo tanto menos empleadas.

\section{Usos dentro de la plaza}

En las plazas estudiadas existe una diferenciación de zonas dentro de las mismas pudiendo encontrar zonas estanciales, zonas de juegos de niños, zonas para ancianos, aparcamientos viales rodados y jardines.

Aquella que tiene una mayor variedad de zonas para el ciudadano es la plaza del 2 de Mayo, dando pie a ser empleada por personas de distintas edades.

La plaza con mayor presencia de viales rodados es la de Chamberí, con tres grandes viales que confluyen en a ella, siendo mayor su contaminación ambiental y acústica (AYUnTAMIENTO DE MADRID, 2006).

La localización de viales rodados en el perímetro de algunas de las plazas reduce el uso de esas franjas perimetrales de las plazas, tal y como se deduce de los estudios realizados de utilización del espacio por parte de los ciudadanos.

Los jardines y arbolado son de gran porte principalmente en la plaza del 2 de Mayo y Chamberí, sin embargo, en la plaza Vázquez de Mella el arbolado es de escaso porte a excepción de un grupo de árboles en su esquina norte.

En la plaza del 2 de Mayo existen tres terrazas de los bares situados en las plantas bajas de los edificios, aunque no están continuamente instaladas. La presencia es menor en Chamberí, con dos pequeñas terrazas, y casi nula, con sólo una terraza, en Vázquez de Mella.

\section{Bancos}

Todas ellas disponen de bancos suficientes, superando la cifra señalada por William H. White, un pie de bancos por cada 30 pies de plaza (White, 1980).

Tanto en la plaza Chamberí como en la del 2 de Mayo el mobiliario se encuentra por toda la plaza, sin embargo, en la plaza Vázquez de Mella se encuentra demasiado localizado, sin dar opciones a la gente de seleccionar en que zona de la plaza quiere estar.

En ocasiones, los bancos están colocados de modo que se dificulta la relación entre individuos, por estar, por ejemplo, localizados espalda con espalda, mirando hacia muretes, de espaldas al espacio abierto de la plaza o colocados en círculo hacia el exterior.

Existen bancos secundarios generados por el propio diseño del espacio público en las plazas, principalmente en la del 2 de Mayo. Así se ha observado gente sentada en maceteros, escaleras, salientes, vallas o muretes. En la plaza Vázquez de Mella las zonas que permiten este uso del espacio para sentarse están 
muy localizadas en torno a los bancos, y no en aquellos puntos donde no hay bancos. En la plaza de Chamberí tan sólo los maceteros de los árboles permiten este uso del espacio.

\section{Resultados del estudio de utilización de las plazas en primavera}

\section{Plaza del 2 de Mayo}

\section{Utilización de la plaza: momentos de uso}

La tarde es el momento del día en el que la plaza fue utilizada por un mayor número de gente en los días en los que se ha realizado el estudio, con un total de 509 personas contabilizadas, frente a las 186 personas de las mañanas o las 307 personas identificadas por las noches. Por lo tanto, las mañanas son el momento el día en el que menos gente ha empleado la plaza.

Esta situación se repite en todos los días de los meses analizados, como se puede ver en la figura 79.

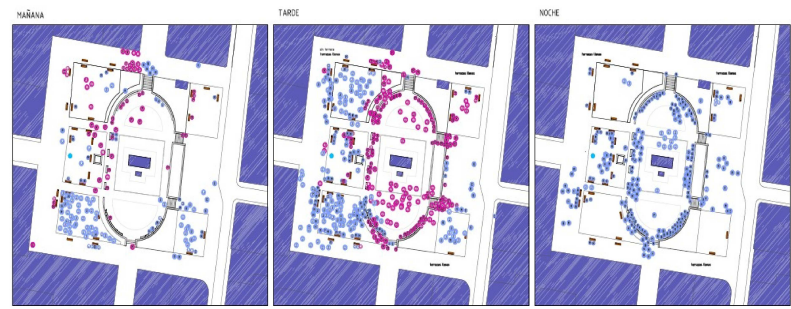

\section{Figura 76: Momentos de uso de la plaza del 2 de Mayo}

Fuente: elaboración propia

De los meses estudiados aquel en el que se identificó mayor número de personas fue mayo con 429 personas, seguido de abril con 316. En junio se redujo el número de personas que empleaban la plaza a 257.

\section{Utilización de la plaza: Edad}

Los adultos son las personas que hacen un mayor uso de la plaza. Por las noches tan sólo se han encontrado niños o personas mayores de modo ocasional, siendo la proporción de adultos de un mínimo del $86.5 \%$ hasta un máximo del $96 \%$ de las personas que se encuentran en la plaza.

Sin embargo, por las mañanas y por las tardes el uso que hacen los niños de la plaza es muy importante, suponiendo entre el $25 \%$ de las personas hasta el 50.5\%. Ocasionalmente, el número de niños ha superado al de adultos por las mañanas. La existencia del Colegio General Sanjurjo y las tres zonas de juegos de niños de la plaza hacen este espacio propicio para este colectivo.

Los ancianos emplean la plaza principalmente por la mañana, alcanzando una proporción del $16 \%$ de la gente que emplea la plaza en los momentos estudiados. Por la tarde y principalmente por la noche su uso de la plaza es muy ocasional.

\section{Utilización de la plaza: posición corporal}

Las personas contabilizadas en la plaza del 2 de Mayo han empleado la misma tanto de pie como sentadas durante las mañanas y las tardes, siendo en ocasiones más numerosas las que se encuentran de pie y otras veces las que están sentadas.

Sin embargo, durante las noches, son más numerosas las personas que se encuentran sentadas. Esto es principalmente debido a que tanto ancianos como adultos emplean la plaza generalmente sentados y, al ser estos últimos los más numerosos en la plaza durante las noches, el espacio se disfruta principalmente sentado.

Los niños, sin embargo, emplean principalmente el espacio público para jugar, y lo hacen de pie.

Utilización de la plaza: actividades

Las actividades principales son las de hablar entre adultos y ancianos y la de jugar entre los niños.

Las siguientes actividades más usuales son las de mirar lo que hace la gente y lo que sucede alrededor y la de pasear al perro. Estas actividades las realizan los adultos y los ancianos.

Por las noches se han encontrado también numerosos adultos bebiendo en la plaza.

Utilización de la plaza: posicionamiento de las personas en la plaza

La zona de la plaza a menor cota es más empleada que la zona alta, tanto de día como de noche. La causa de ello se debe principalmente a las funciones designadas al espacio de la plaza. La parte alta de la plaza se ve influenciada por el paso de tráfico rodado, mientras que toda la parte baja de la plaza 
es peatonal. Por otra parte, en la zona baja de la plaza existe una zona estancial con numerosos bancos para uso público, mientras que en la zona alta no existe un espacio de estas características. Además, en la zona baja hay dos zonas de juegos de niños, una de ellas frente a un colegio. Este es un espacio muy frecuentado por niños, por lo que estas zonas de juegos son muy utilizadas. Cabe destacar que en la zona alta de la plaza también hay una zona de juego de niños, pero ésta no es tan empleada como las de las zonas bajas.

Dentro de la zona a menor cota de la plaza también hay diferencias de uso por parte de los ciudadanos dependiendo del mes y de la hora del día:

- Por las mañanas, la gente se concentra principalmente en toda la zona oeste de la plaza, haciendo poco uso de la zona central. Este punto de la plaza es el que tiene la zona estancial y las zonas de juego de niños, pero además es la parte soleada de la plaza por las mañanas, donde además existe arbolado, pudiendo el usuario elegir si se sitúa al sol o a la sombra.

- Por las tardes de abril y mayo la gente ocupó también el espacio central en torno al monumento. Los adultos y ancianos principalmente ocuparon los bordes, cerca de los bancos corridos o en puntos con posibilidad de sentarse, y los niños emplearon todo el espacio central para jugar.

- En junio, por la tarde, el espacio central de la plaza permaneció prácticamente vacío y los niños se desplazaron a jugar a la esquina suroeste de la plaza, así como el resto de usuarios de la plaza, ya que este punto se encontraba a la sombra. La zona central de la plaza en torno al monumento es la que mayor radiación solar recibe, con una media de más de 5.650Wh/día y con unas 1.080 horas de sol recibidas en primavera.

- Por la noche la gente se desplaza hacia el espacio central de la plaza en todos los días de los meses estudiados, ocupando principalmente el perímetro de ese espacio central y más concretamente concentrándose en zonas con posibilidad de sentarse.

Respecto a la zona alta de la plaza, aquella más al este, es menos empleada que la zona baja, tal y como se ha comentado anteriormente. En esta zona se han identificado actividades muy concretas como la de esperar, hablar de pie y mirar alrededor. Estas actividades pueden ir ligadas a la mayor visibilidad que se tiene en esos puntos de la plaza, dado que se encuentra a una cota superior, pudiendo tener una visión global de todo el espacio.

El perímetro de la plaza es un espacio muy poco utilizado por las personas. En ocasiones, partes de ese perímetro se ven ocupadas por terrazas privadas, pero cuando éstas no están instaladas la gente sigue empleando poco estas zonas.

Por otra parte, a excepción de los niños, la gente ha empleado muy poco la zona central de la plaza en torno al monumento en los meses de primavera. Esta zona es la única que carece de arbolado o de bancos, además de ser la que mayor radiación solar recibe, por lo que es más compleja la realización de actividades estanciales. Tampoco se han identificado personas esperando en este punto, aún y cuando existe un monumento que podría servir de referencia.

\section{Plaza de Vázquez de Mella}

\section{Utilización de la plaza: momento de uso}

En los días en los que se ha analizado la plaza Vázquez de Mella, los ciudadanos han hecho más uso de ella durante las noches, con un total de 460 personas contabilizadas, frente a las 306 personas encontradas por la tarde o las 126 personas por la mañana.

Aún y cuando se han contabilizado más personas durante la noche a lo largo de toda la primavera, en ocasiones hay más gente en la plaza durante la tarde, como ocurre en el mes de mayo. En la figura 81, se pueden observar dichas apreciaciones.

A lo largo de los meses de abril a junio se observa una reducción en el uso de la plaza por las mañanas, mientras que por la tarde y por la noche se mantiene relativamente constante todos los meses.

Abril es el mes en el que la plaza está con mayor número de gente, seguido del mes de junio y finalmente mayo, donde se aprecia una reducción de uso respecto a los otros dos meses.

\section{Utilización de la plaza: edad}

La Plaza de Vázquez de Mella es esencialmente un espacio empleado por los adultos. La proporción mínima de adultos es del $68 \%$, alcanzando hasta el $94 \%$ de la gente que ocupa el espacio.

Se ha identificado la presencia de niños principalmente por las tardes, hasta alcanzar un máximo del $17.5 \%$ de la gente que disfruta de la plaza, pero por las mañanas su presencia es prácticamente nula y muy escasa por las noches. 


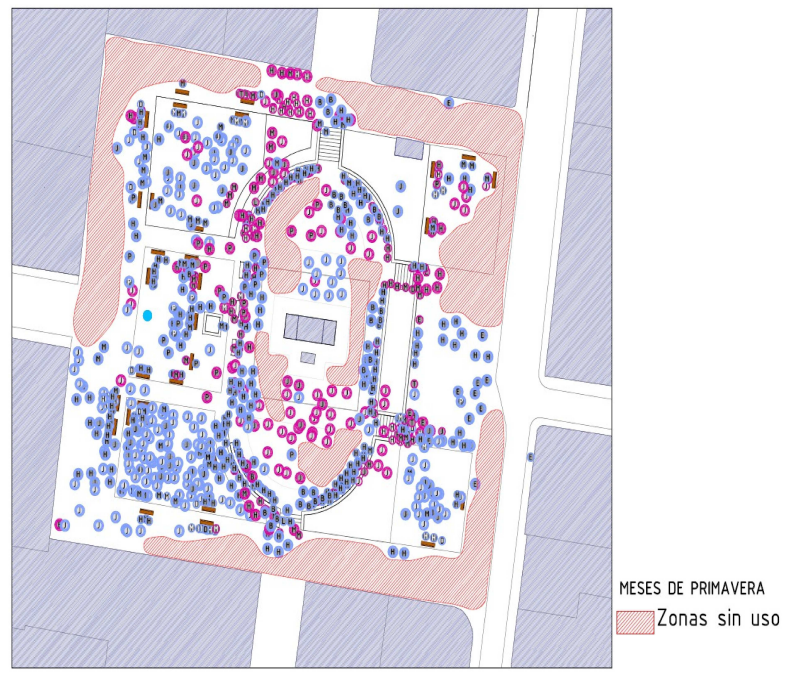

Figura 77: Superposición de las actividades y zonas sin uso de la plaza del 2 de Mayo Fuente: elaboración propia

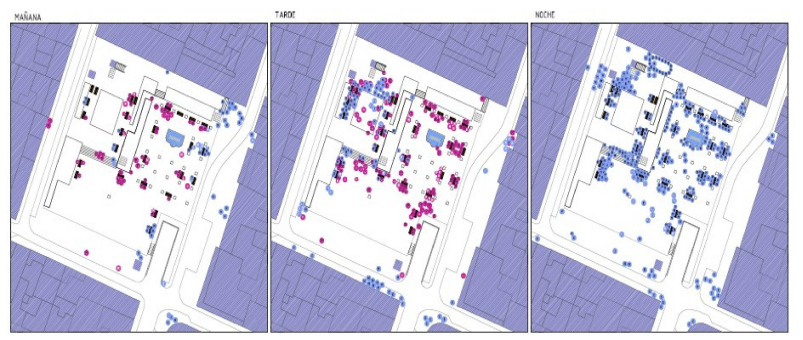

Figura 78: Momentos de uso de la plaza Vázquez de Mella Fuente: elaboración propia 
Los ancianos sin embargo, acuden a la plaza principalmente por las mañanas y ocasionalmente por las tardes. Su presencia es casi nula por las noches.

Utilización de la plaza: posición corporal

Las personas emplean la plaza principalmente sentados; en todos los momentos analizados eran más numerosas las personas sentadas que las que se encontraban en pie, ya fuera en bancos, como en escaleras, salientes o en el suelo.

Tanto los adultos como los ancianos tienden a situarse y estar en el espacio público sentados, mientras que la gente más joven permanece en pie.

Utilización de la plaza: actividades

La actividad principal que se realiza en la plaza es la de hablar con alguien. También está muy presente la de mirar lo que sucede alrededor. Destacan otras actividades como la de leer y jugar y, puntualmente por la noche, la de beber.

En esta plaza se han encontrado numerosos adolescentes, menores de 18 años, por lo que han entrado en el rango de niños, pero que emplean principalmente el espacio público para hablar en grupo o para mirar lo que sucede alrededor, en lugar de para jugar, como hacen el resto de personas de menor edad dentro del rango denominado niños.

Las personas que están esperando se concentran claramente en la esquina sur de la plaza, siendo prácticamente inexistente esta actividad en cualquier otro punto de la plaza. Lo característico de la fachada del hotel de esta esquina, así como la amplia visión que se tiene del resto de la plaza, pueden ser las causas.

Existe una zona cercana a la esquina norte de la plaza que es muy empleada por la gente. En esta zona existe arbolado que proporciona sombra, hay bancos en las zonas cercanas y se puede observar la zona de juego de niños. Numerosas personas permanecen en pie hablando entre sí y mirando lo que sucede.

Utilización de la plaza: posicionamiento de las personas en la plaza

Dentro de espacio peatonal existe una clara localización de las personas de la mitad de la plaza hacia el norte de la misma. Las causas son diversas. En primer lugar esta es la zona de la plaza donde existen bancos para poder sentarse, así como una zona de juego de niños. Es en esta zona además, donde se localiza también el poco arbolado de entidad suficiente como para poder proporcionar sombra. Los niños son las personas que ocupan el espacio en su totalidad, pero no hay un gran número de ellos en esta plaza $\mathrm{y}$, los que hay, preferiblemente emplean la zona de juego destinada a ellos.

La gente se concentra principalmente en torno a los bancos, las escaleras (que son también empleadas para sentarse) y, durante los meses estudiados, en zonas con posibilidad de tener sombra.

La parte sur de la plaza, además de tener un vial rodado, carece de mobiliario urbano y de bancos donde poder estar. Ésta es la zona más sombreada de la plaza pero, por su diseño urbano, es un espacio que posee un carácter de paso, por lo que las personas no lo emplean para actividades estanciales.

El perímetro de la plaza Vázquez de Mella es escasamente empleado. La plaza tiene viales rodados por tres de sus lados, pero incluso aquel peatonal se emplea poco, pudiendo ser debido a que se trata de una franja no suficientemente ancha para tener un carácter estancial, carece de bancos y se encuentra a una cota mayor que el resto de la plaza, con bajos de edificios sin usos hacia el espacio público.

Las zonas perimetrales de la plaza más empleadas son:

- La esquina sur anteriormente citada, donde la gente se concentra a esperar y donde existe un bajo comercial con una transparencia del $100 \%$.

- La esquina noreste, con un equipamiento de servicios sociales donde se reúnen trabajadores y usuarios, además de ser uno de los pocos puntos de la plaza que tiene sombra.

\section{Plaza de Chamberí}

\section{Utilización de la plaza: momento del día}

En los días estudiados la plaza se empleó principalmente durante las tarde. Por las mañanas era muy escasa la afluencia de gente, incrementando algo más durante la noche. Esta diferencia en el uso se hace más notable en abril, con 272 personas por la tarde, frente a las 7 personas que había por la mañana o las 45 de la noche. En mayo, la diferencia de uso de la plaza sigue siendo evidente, con 165 personas contabilizadas por la tarde frente a las 13 de la mañana y las 22 de la noche.

En junio se contabilizaron tan sólo 45 personas por la tarde, mientras que por la noche la cifra incrementó a 83 personas. Durante junio la plaza fue más empleada por la noche(véase figura 83).

Utilización de la plaza: edad de los usuarios

En la plaza de Chamberí se pueden encontrar muchos niños, llegando en ocasiones a superar el número de niños al de adultos, principalmente por la tarde y ocasionalmente por la noche. 


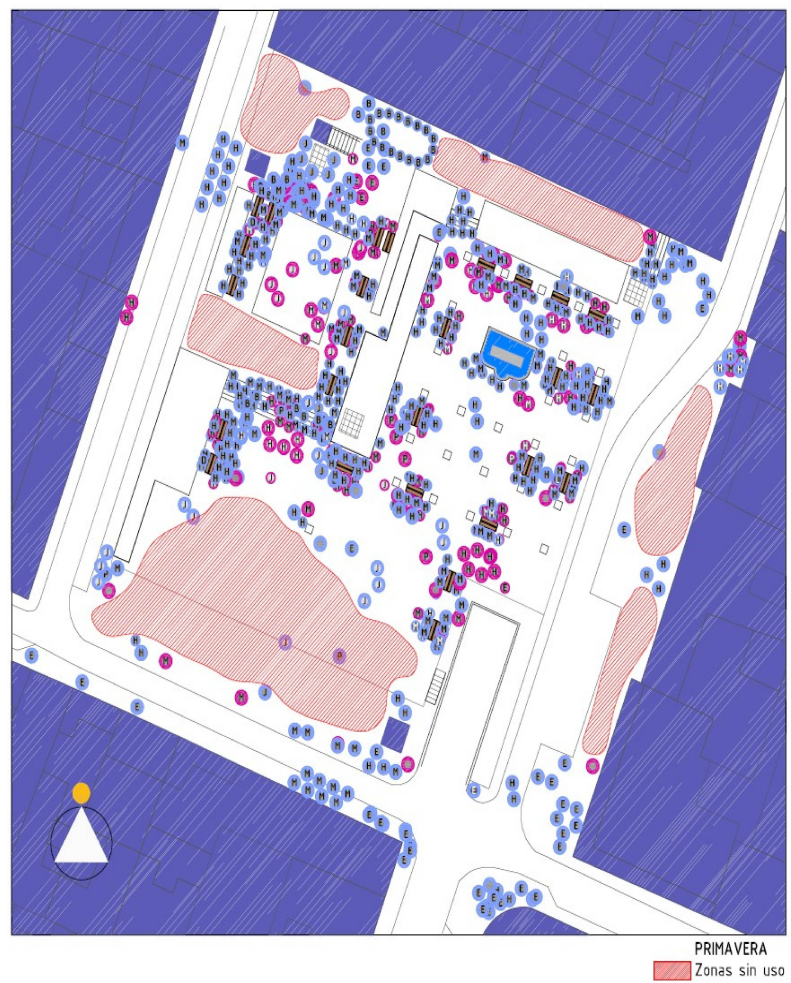

Figura 79: Superposición de las actividades y zonas sin uso de la plaza Vázquez de Mella Fuente: elaboración propia

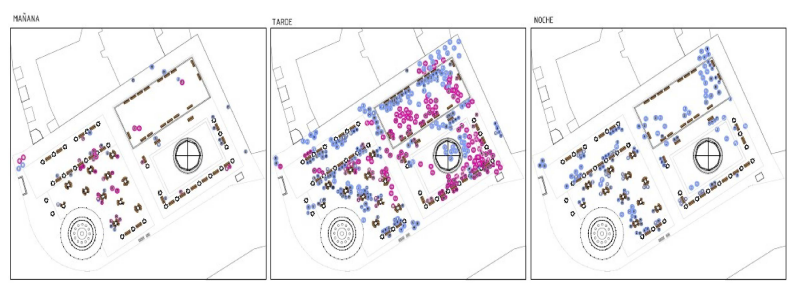

Figura 80: Momentos de uso de la plaza Vázquez de Mella Fuente: elaboración propia 
Por lo general, son los adultos los que más empleo hacen de la plaza por las mañanas, suponiendo en número entre el $70 \%$ y el $85 \%$ de las personas que están en la plaza.

\section{Utilización de la plaza: posición corporal de la gente}

De modo general, las actividades que se desarrollan en la plaza se realizan principalmente en posición sentada. Los niños permanecen y realizan sus actividades en la plaza mayoritariamente en pie, mientras que los adultos y ancianos lo hacen sentados.

\section{Utilización de la plaza: actividades}

La actividad que más triunfa en esta plaza es la de hablar con alguien. Tras esta actividad, la que más se realiza es la de mirar lo que sucede alrededor o lo que hacen los demás. La tercera actividad más realizada en la plaza es la de jugar.

La actividad principal de los niños está relacionada con el juego, aunque también se les encuentra hablando con personas de diferentes edades, durmiendo o comiendo y bebiendo.

Las personas mayores realizan dos actividades principales: hablar cuando se encuentran acompañadas o mirar lo que sucede a su alrededor o lo que hacen los demás cuando están solos.

Las personas entre 18 y 65 años son aquellas que realizan actividades más diversas, aunque la más habitual es la de hablar con alguien.

Utilización de la plaza: posicionamiento de las personas en la plaza

Existen unas zonas muy claras en la plaza donde la gente no hace uso de esos espacios. Se trata principalmente del perímetro de la plaza, especialmente aquel que da hacia viales rodados. Es posible que esto se deba al mayor carácter de paso que tiene el perímetro de la plaza, además del efecto que los coches pueden tener en el confort de estos puntos.

Pero también hay un espacio central de la plaza que se ha mantenido sin uso en los días en los que se ha realizado el estudio. Esta es la zona de la plaza donde más horas de sol se reciben durante los meses de primavera, más de 1.000 horas, y en este punto no existe arbolado que permita la protección frente al sol. Es el punto con mayor radiación acumulada, 489.600Wh, y mayor radiación media por hora, con más de 428Wh. Pero este espacio tampoco se emplea durante la noche. El calor acumulado en los pavimentos puede influir en este hecho, pero además, en esta zona, no existen referencias o mobiliario urbano, pudiendo ser ésta otra causa de su falta de uso.

Además del perímetro de la plaza y el punto central anteriormente señalado, la zona de la plaza en torno al quiosco de música es la menos empleada. El uso principal de ese espacio lo hacen los niños jugando, pero es prácticamente nulo el uso de esa zona por parte de adultos y ancianos, que se mantienen en el perímetro del mismo mirando o hablando. Se puede concluir, por lo tanto, que son los niños los que rompen el denominado efecto borde (GHEL, 2001), donde el espacio público primero se ocupa por los bordes para posteriormente ocupar los espacios centrales.

Las personas se sitúan principalmente en torno a los bancos. La esquina noroeste de la plaza parece ser una zona de encuentro o de referencia, donde la gente se mantiene en pie hablando.

Se observa que desde abril hasta junio se va dando una reducción en el número de personas que emplean la plaza. En abril, el espacio se emplea de un modo más homogéneo, mientras que en el mes de junio se observa una localización más concreta de las personas en torno a las zonas arboladas, los bancos y el área de juegos de niños, todos ellos puntos en los que se dispone de sombra. Los niños durante el mes de junio prácticamente no juegan al sol, hecho que no sucede en los meses anteriores. El perímetro se mantiene prácticamente sin uso durante los días estudiados, a excepción de la esquina norte, donde es habitual encontrar niños jugando.

\section{Comparativa entre plazas}

A continuación se señalan aspectos que se han repetido en las tres plazas analizadas:

- La plaza en la que mayor número de personas se han contabilizado es la del 2 de Mayo, con un total de 1.002 personas, de las cuales $244(24.3 \%)$ eran niños, $705(70.4 \%)$ adultos y $52(5.3 \%)$ ancianos.

- En la plaza Vázquez de Mella se encontraron 892 personas, 55( 6.1\%) niños, 773 (86.7\%) adultos y $64(7.2 \%)$ ancianos.

- La plaza de Chamberí es aquella en la que se han contabilizado menos personas, un total de 686, con $265(38.6 \%)$ niños, $340(49.6 \%)$ adultos y 81 (11.8\%) ancianos. Esta es la plaza con mayor proporción de niños y ancianos.

- Se ha registrado, por lo tanto, un total de 2.580 personas. La actividad principal desarrollada ha sido la de hablar, con un total de 1.225, por lo que casi la mitad de las personas desarrollaban esta actividad. Jugar ha sido la segunda actividad registrada en mayor número de ocasiones, con 684 


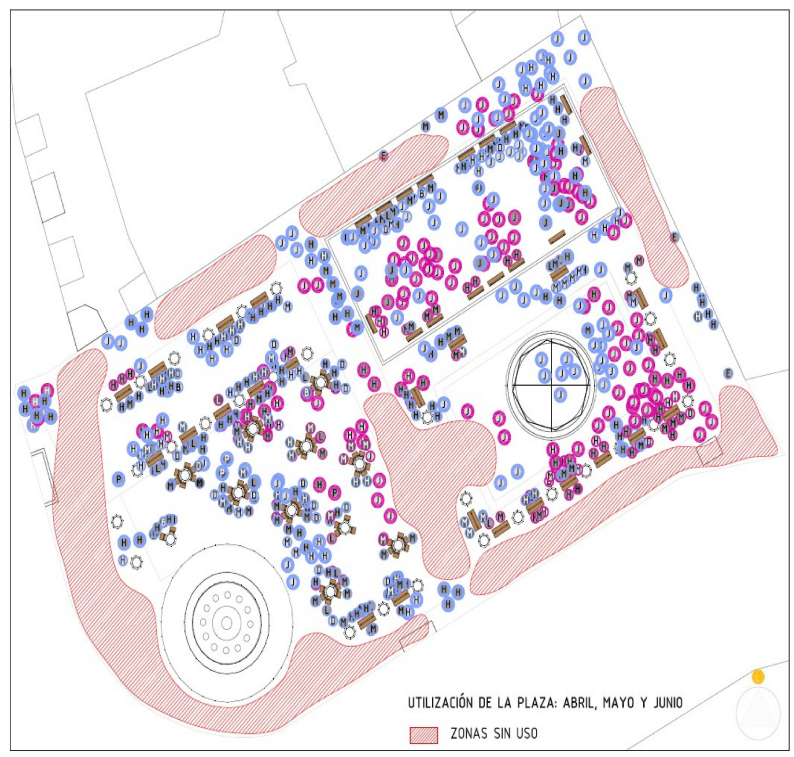

Figura 81: Superposición de las actividades y zonas sin uso de la plaza Vázquez de Mella Fuente: elaboración propia

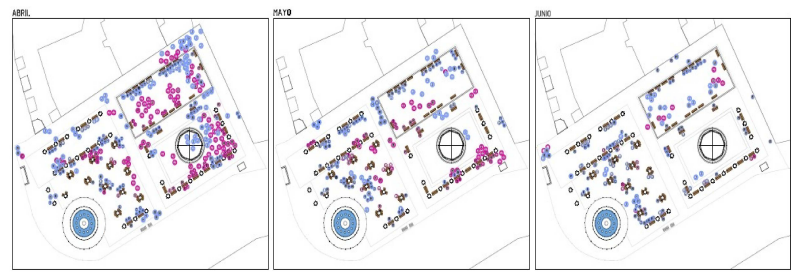

Figura 82: Uso de la plaza Vázquez de Mella en los diferentes meses Fuente: elaboración propia 
personas realizándola. Se trata principalmente de niños, pero también jugaban algunos adultos que los acompañaban. La tercera actividad que más han desarrollado las personas en las plazas es la de mirar lo que sucede alrededor, con un total de 531.

- Las tardes son el momento del día en el que las plazas han sido más empleadas.

- Los adultos y ancianos están en las plazas principalmente sentados hablando o mirando lo que sucede alrededor, sin embargo, los niños permanecen mucho más en pie, caminando o corriendo, mientras juegan.

- Las zonas con mayor radiación solar y sin protecciones o arbolado que proporcione sombra son las menos empleadas durante los meses analizados, así como las zonas de las plazas carentes de mobiliario urbano o con carácter de paso. Los niños son los únicos que emplean todo el espacio en su conjunto. Aún así, se observa en todas las plazas, que durante el mes de junio, en el que se dieron unas altas temperaturas durante el día, incluso los niños dejan de emplear estas zonas de las plazas para sus juegos, trasladándose a zonas más sombreadas.

- En las tres plazas se ha dado una reducción de su uso durante el día en el mes de junio.

- La gente se tiende a agrupar en torno a los bancos o mobiliario urbano que sirva de referencia, ocupando el espacio primero por los bordes y finalmente, si hay mucha gente, se va moviendo hacia el centro. Los niños son los únicos que emplean el espacio en su totalidad.

- Existen puntos en los que la gente se sitúa reiteradamente a esperar. Las esperas se realizan en esquinas y en puntos con buena visibilidad de conjunto del espacio y se suelen realizar de pie. Éstas son generalmente también zonas donde la gente permanece en pie hablando, esperando o por encuentros casuales. Durante los meses analizados las esperas se han realizado principalmente a la sombra.

- Según Jan GeHL el $96 \%$ de las actividades que se dan en la calle ocurren en el borde público-privado (GEHL, 1980), definido este como el límite que diferencia el espacio privado del de uso público. Sin embargo, se hace poco uso del perímetro en las tres plazas. En todas ellas existe una franja que separa la zona central de las plazas de los edificios que las configuran, especialmente en Vázquez de Mella y Chamberí, este espacio tiene carácter de paso. Son zonas no lo suficientemente anchas, que durante algunas horas del día son ocupadas parcialmente con terrazas de bares y restaurantes, aunque cuando éstas no están, este espacio sigue sin emplearse. En ocasiones, es también debido al paso de viales cercanos a esas zonas o a la falta de usos hacia el espacio público de las plantas bajas, pero no en todos los casos es así, aún y cuando se repite el mismo efecto en las tres.

\section{Conclusiones}

\section{Calidad ambiental de las plazas}

Tras el análisis de parámetros de diseño que tienen influencia en el funcionamiento microclimático de las plazas y los parámetros de diseño orientado al ciudadano, aquella plaza con un diseño más acorde a estos principios es la plaza del 2 de Mayo.

En la figura 86 está la tabla resumen en la que se puede observar la comparativa realizada entre las tres plazas estudiadas

Los principios de diseño bioclimático (HIgueras, 2009) que se han tomado en cuenta para la valoración de la calidad de las plazas son los tipos de pavimentos, las proporciones del espacio para la entrada de sol y viento, el arbolado y zonas verdes y las protecciones en edificios contra el sol o la lluvia. Los parámetros valorados de diseño urbano orientado al peatón (GEHL, 2001) han sido la accesibilidad, el mobiliario urbano y los equipamientos públicos.

Se han señalado en verde aquellas características positivas para el diseño de espacios exteriores como son:

- La mayor disponibilidad de pavimentos permeables.

- Arbolado de gran porte y jardines con plantas que consumen poca cantidad de agua.

- La existencia de zonas para protegerse del viento.

- Accesibilidad a todas las zonas de las plazas para que el usuario pueda seleccionar el punto donde situarse. 


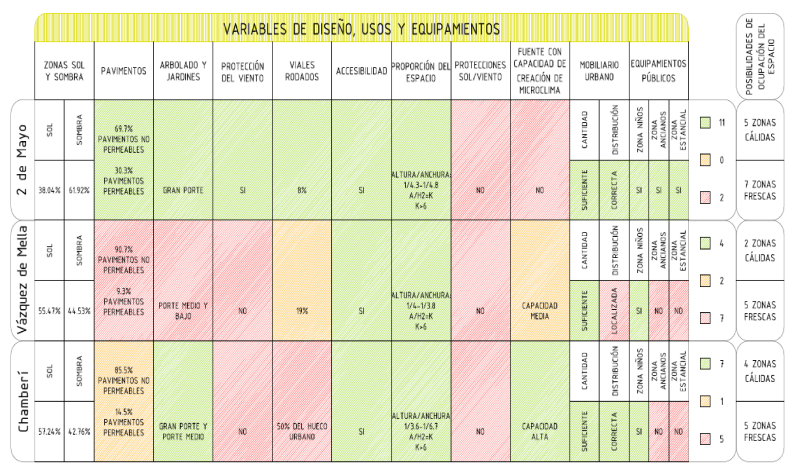

Figura 83: Tabla comparativa entre las plazas de 2 de Mayo, Vázquez de Mella y Chamberí Fuente: elaboración propia

- Dimensiones de la plaza que permitan la entrada de viento y soleamiento del espacio urbano.

- La existencia de aleros o protecciones frente a la lluvia o el sol.

- El uso de agua como regulador microclimático a través de fuentes.

- Mobiliario urbano en lo referente a bancos primarios y secundarios para la creación de zonas estanciales, tanto al sol como a la sombra.

- La existencia de zonas con funciones concretas para el disfrute de la gente.

En rojo se han señalado la carencia de alguno de los aspectos de diseño señalados anteriormente.

En el estudio de utilización del espacio se ha observado que el diseño de las plazas, principalmente en lo referente a la disponibilidad de bancos o de asientos secundarios (GEHL, 2001) y de equipamientos, resulta imprescindible para que un espacio público sea empleado por la gente.

\section{Posibilidades de ocupación de las plazas}

Una vez analizadas todas las variables que afectan a los aspectos climáticos teóricos, a las mediciones in situ, a las características físicas y materiales, a las funciones y a los usos que las personas hacen de las plazas se han realizado cruces entre ellas para establecer las relaciones existentees entre ellas.

Este cruce de variables se ha realizado a través de la distinción de espacios de diverso carácter material, funcional y climático dentro de las plazas, de modo que se pueda determinar cuántas posibilidades ofrecen al usuario cada una de las plazas.

En el presente trabajo no se busca un modelo de confort del espacio, sino que se ha considerado que cuanto más numerosas sean las posibilidades de ocupación de un espacio por diferencias en las condiciones ambientales, físicas y de uso, más opciones habrá de que la gente que las emplea pueda encontrar un lugar en el que se sienta confortable dentro de las plazas.

Así, se ha buscado un sistema de representación de esas opciones diversas que ofrece cada una de las plazas y en el que se tienen en cuenta los siguientes parámetros:

- Disponibilidad de sol/sombra.

- Existencia de arbolado.

- Tipo de pavimentos.

- Disponibilidad de asientos.

- Espacios con funciones concretas o equipamientos públicos.

Se ha hecho una distinción principal a la hora de caracterizar el espacio de la plaza, y es aquel de separarlas en zonas cálidas y zonas frescas, al igual que se ha realizado en el estudio climático de las plazas y con los mismos criterios (véase la figura 87). 


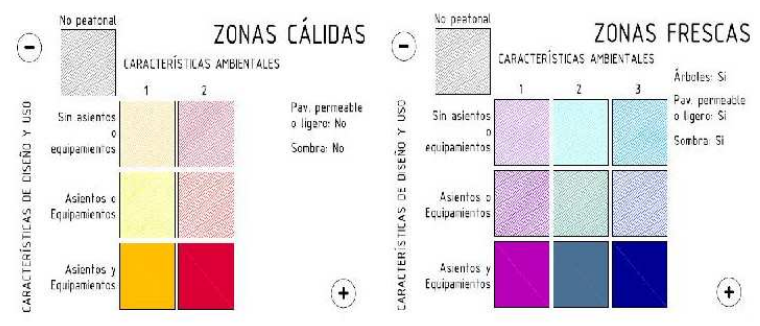

FiguRA 84: Leyenda de la caracterización de las plazas en función de zonas y equipamientos Fuente: elaboración propia

Zonas cálidas: Serán aquellas que permanecen constantemente soleadas en los meses estudiados a partir de las 9:00h y hasta las 19:00h, primera y última hora en las que se han realizado los estudios de campo. Las zonas cálidas tendrán una mayor o menor intensidad. Serán de una intensidad menor aquellas que tan sólo cumplan uno de los criterios establecidos (1) y más intensas aquellas que cumplan los dos (2), esto es, que además de estar totalmente soleadas tengan pavimentos con una alta inercia térmica.

Zonas frescas: se han denominado de este modo a los espacios de las plazas que reciben sombra en los meses de primavera entre las 9:00h y las 19:00h. Su intensidad también puede ser mayor o menor. Si cumplen uno de los criterios establecidos (1), dos de ellos (2) o tres (3). Los criterios fijados, además del de estar sombreados, son la disponibilidad de pavimentos de baja inercia térmica y/o de arbolado con porte suficiente para crear sombra.

Estas características climáticas y ambientales se han cruzado además con una de diseño, que es la existencia o no de bancos o asientos secundarios y con una característica ligada al uso, que es la disponibilidad de equipamientos públicos con funciones concretas asociadas a los mismos. Los espacios pueden disponer de una o de las dos características citadas.

Así, según se señala en la leyenda, los espacios menos deseables serán los no peatonales, por tratarse de viales rodados o jardines ornamentales sin acceso, por ejemplo. Los más deseables serán los que dispongan de bancos y equipamientos y dependerán de las condiciones climáticas y de si se requiere aportación de calor o estrategias para mitigarlo.

Para la caracterización de las plazas, en base a los criterios expuestos, se han creado retículas desde $5 \times 5 \mathrm{~m}$ hasta $7 \times 7 \mathrm{~m}$, dependiendo de la mejor adecuación a la configuración física de cada una de ellas.

\section{Plaza del 2 de Mayo}

Como se observa en el esquemade la figura 88, la plaza del 2 de Mayo ofrece muy diversas opciones para estar en ella, tanto al sol como a la sombra con diferentes intensidades. Esto la convierte en una plaza confortable, entendiendo como tal que las personas que a ella acuden tienen una gran variedad de posibilidades para elegir donde quieren disfrutar de este espacio.

Se han contabilizado las personas que estaban en la plaza en los momentos en los que se han realizado los trabajos de campo dentro de las horas de sol. Son un total 695 personas durante el día de abril a junio.

\section{Plaza de Vázquez de Mella}

Las zonas no peatonales ocupan un tercio del espacio de la plaza. Las posibilidades que ofrece esta plaza son limitadas. Aunque se dispone de espacios tanto a la sombra como al sol, no hay variedad de intensidad en estos espacios, encontrando sólo espacios soleados con pavimentos de alta inercia térmica o espacios en sombra prácticamente en su totalidad, con pavimentos de alta inercia térmica y sin árboles. Son muy escasas las zonas a la sombra con bancos o equipamientos y con árboles o pavimentos permeables o de baja inercia térmicavéase figura 89 .

Las opciones para poder sentarse al sol son más elevadas que para hacerlo a la sombra.

Se contabilizaron un total de 434 personas de mañana a tarde en los meses de abril, mayo y junio. 

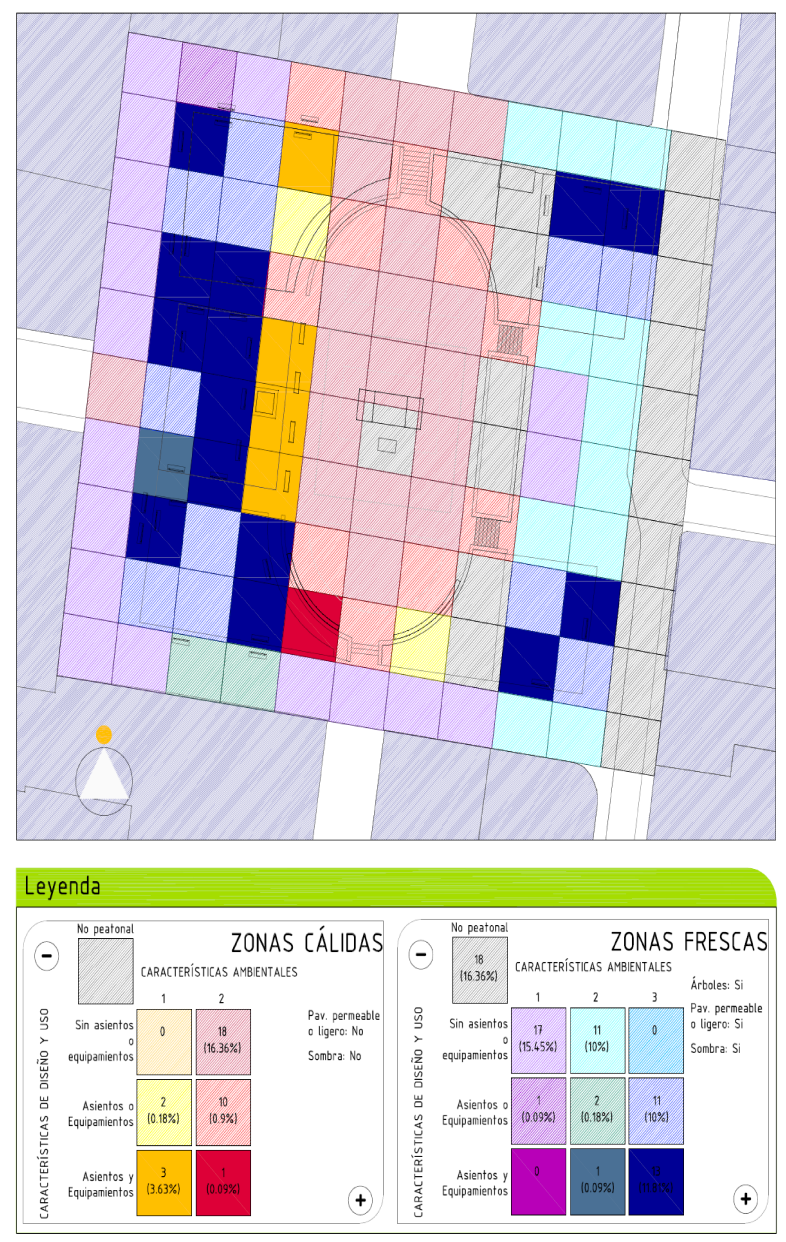

Figura 85: Posibilidades de ocupación de la plaza del 2 de Mayo Fuente: elaboración propia 

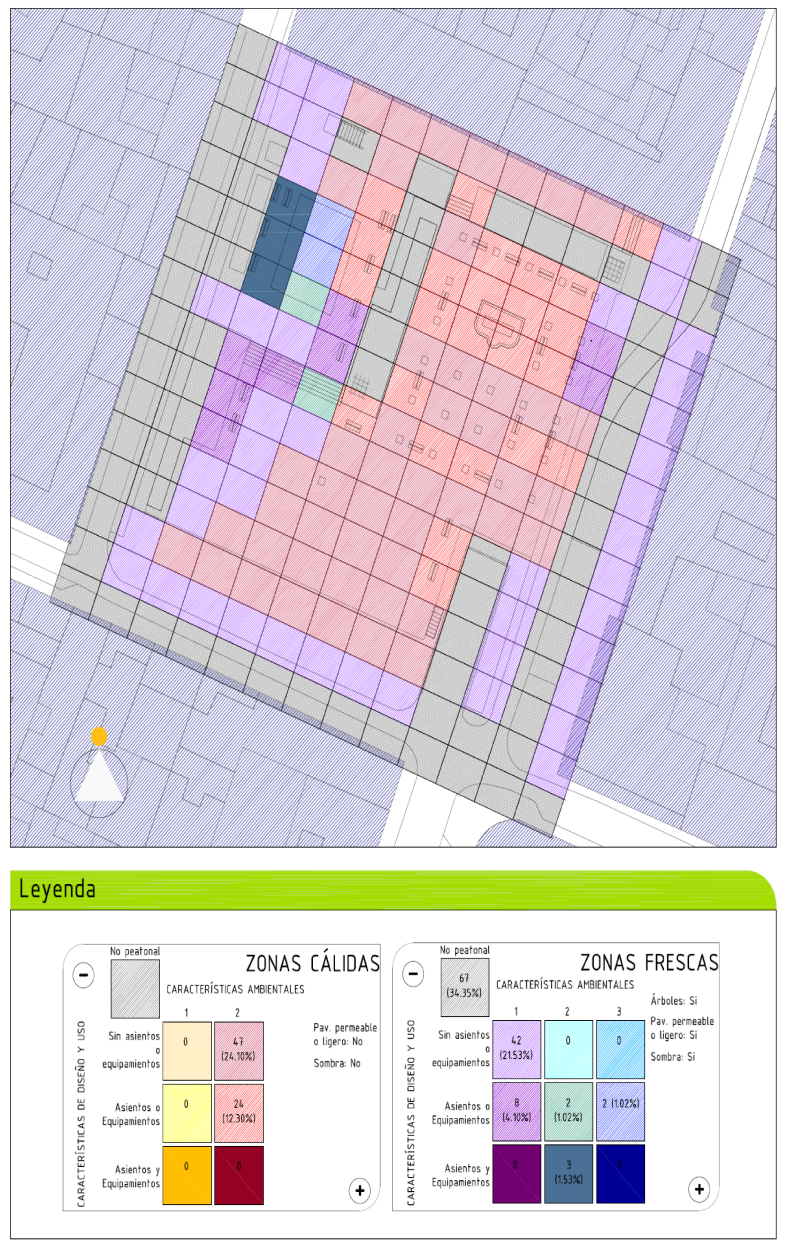

Figura 86: Posibilidades de ocupación de la plaza Vázquez de Mella Fuente: elaboración propia 

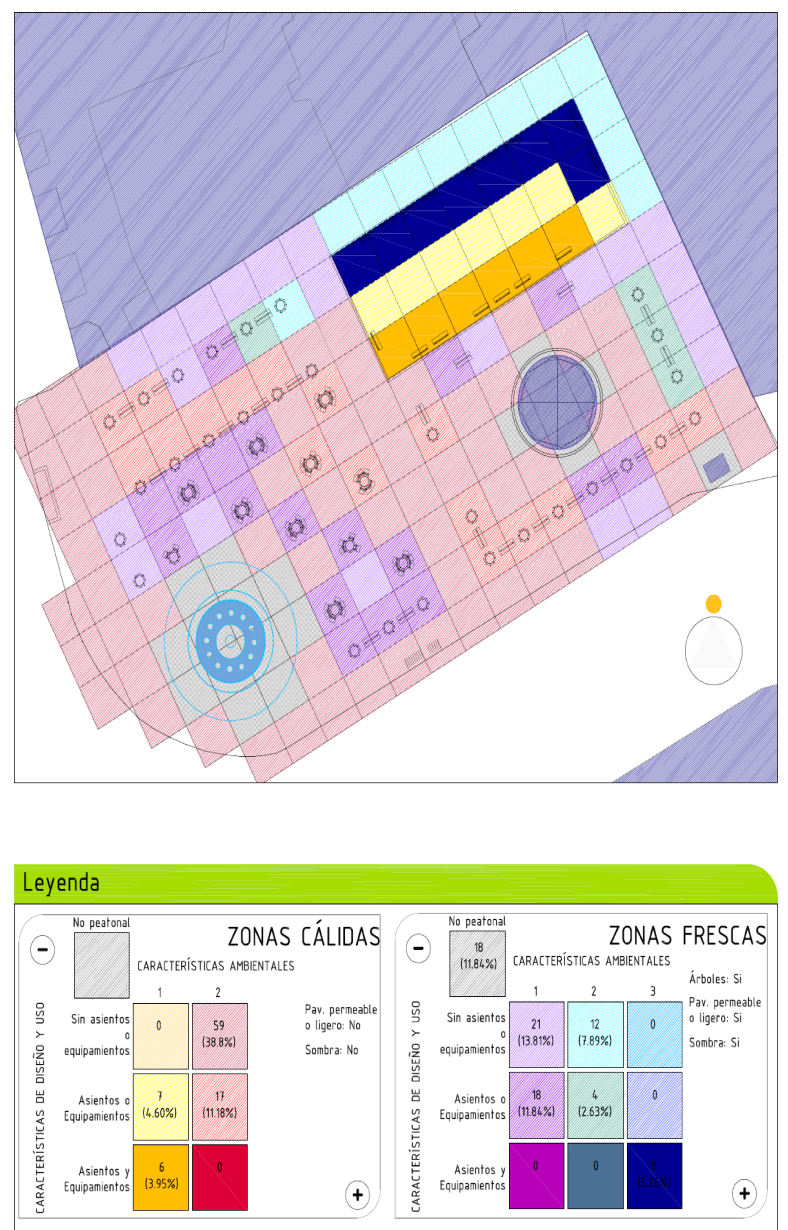

Figura 87: Posibilidades de ocupación de la plaza Chamberí Fuente: elaboración propia 


\section{Plaza de Chamberí}

Como se puede ver en la figura 90, la plaza de Chamberí ofrece diversas posibilidades de estar en ella a los usuarios. Las opciones a la sombra son algo más amplias, con diversas intensidades y ofreciendo espacios con asientos y equipamientos públicos. Aún así, el espacio soleado en la plaza es mayor que el sombreado, pero más uniforme.

Así, se puede concluir que la plaza del 2 de Mayo tiene una mayor variedad de zonas estanciales y usos para el ciudadano que las otras, tanto al sol como a la sombra y con diferentes intensidades, desde espacios de carácter más cálido a más fresco. Esto la convierte en una plaza confortable, entendiendo como tal que las personas que a ella acuden tienen una gran variedad de posibilidades para elegir donde quieren disfrutar de este espacio.

\section{Localización de la gente en las plazas}

Una vez valoradas las posibilidades que ofrece cada una de las plazas, éstas se han cruzado con los datos obtenidos de los trabajos de campo en los que se ha identificado el uso que la gente hace del espacio y con los datos del estudio climático teórico para Madrid Centro.

En estudio de clima teórico se han señalado en rojo las horas en las que se realizaron los trabajos de campo, de modo que se puedan distinguir las estrategias recomendadas por el mismo para encontrarse en bienestar.

El arropamiento para abril y mayo es de 1 clo y para junio de 0.7 clo.

Las actividades metabólicas son de entre 1.15 met y 2.95 met.

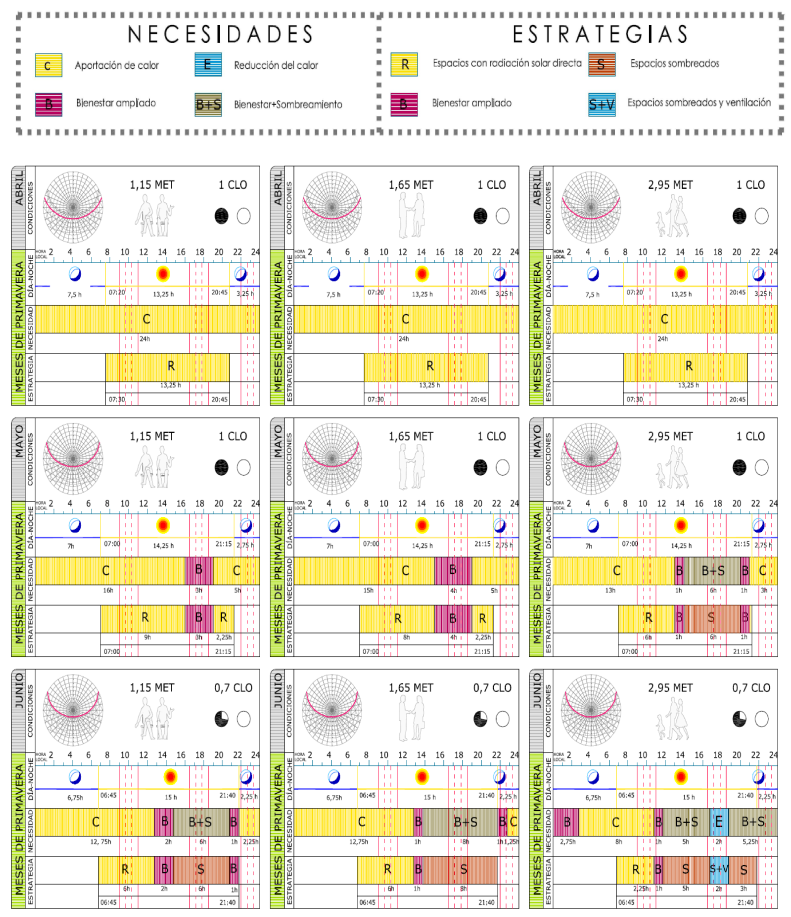

FiguRA 88: Estrategias bioclimáticas necesarias en las plazas y leyenda

Fuente: elaboración propia

Las estrategias según el estudio de clima teórico serán las siguientes (véase también figura 91):

- En abril será necesaria la aportación de calor.

- En las mañanas de mayo y junio entre las 9:00h y las 11:00h será necesaria la aportación de calor independientemente de la actividad que se esté realizando.

- Las tardes de mayo para actividades en las que se esté sentado o parado de pie se estará en bienestar, sin necesidad de sombreamiento. Para actividades en las que se camine o para los niños jugando será necesario el sombreamiento. 
- Las mañanas de junio será necesaria la aportación de calor.

- En junio por la tarde será necesario el sombreamiento, independientemente de la actividad. Para actividades que requieran caminar o para los niños jugando, será necesaria también la ventilación entre las 16:30h y las 18:30h.

A continuación, se verán los usos que la gente hizo de las plazas en los meses de abril, mayo y junio.

\section{Plaza Del 2 de Mayo, meses de abril, mayo y junio}

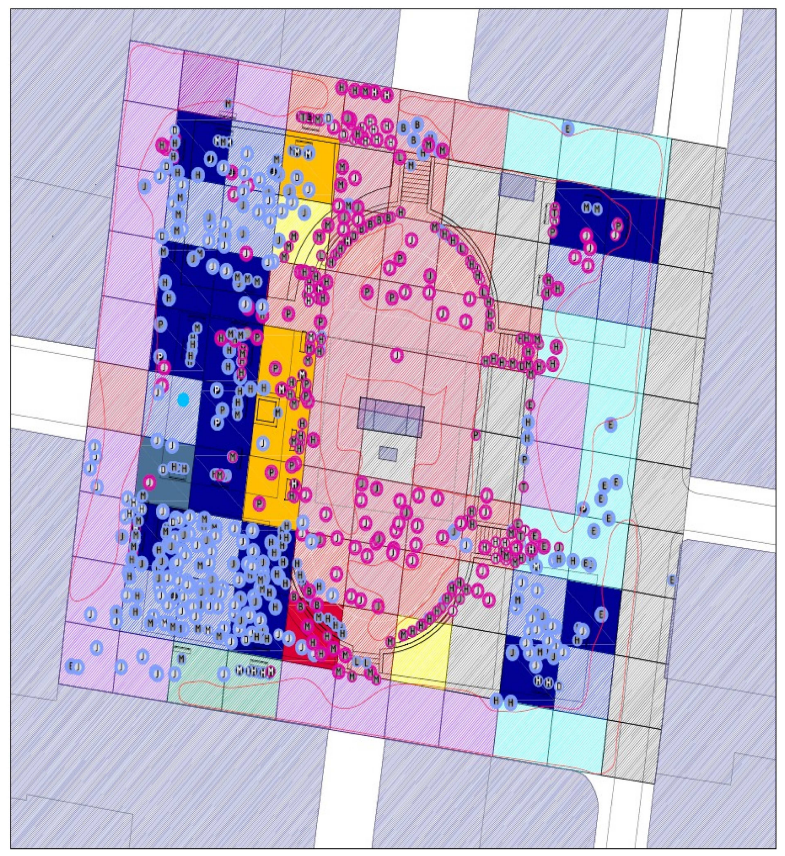

Figura 89: Plano resumen con superposición de las actividades, zonas sin uso y posibilidades de ocupación de la plaza del 2 de Mayo

Fuente: elaboración propia

Durante los meses analizados en la plaza del 2 de Mayo se encontraron más personas a la sombra $(371$, el $53.4 \%)$ que al sol $(324$, el $46.6 \%)$.

La mayor parte de las zonas que no se emplearon de la plaza, tanto al sol como a la sombra, corresponden a zonas cálidas o frescas carentes de equipamientos o de asientos. Se emplearon menos, además, aquellas zonas soleadas con pavimentos pesados y aquellas zonas a la sombra sin árboles y con pavimentos pesados.

De las zonas que se encontraban a la sombra la gente se ha situado principalmente en aquellas que además tienen arbolado y pavimentos de baja inercia térmica, esto es, aquellas con mayor potencialidad de ser más frescas en primavera.

En las zonas más soleadas, con pavimentos de alta inercia térmica y sin equipamientos ni bancos han sido empleadas prácticamente sólo por los niños para jugar en ellas. Los adultos han escogido aquellas con bancos y las que se encuentran en zonas con pavimentos ligeros.

De los meses estudiados, aquel en el que se identificó mayor número de personas fue mayo, con 429 personas, seguido de abril con 316. En junio se redujo el número de personas que empleaban la plaza a 257.

Es difícil extraer conclusiones sobre el comportamiento de los niños, dado que las zonas especialmente diseñadas para ellos se encuentran a la sombra de los árboles, por lo que son más numerosos los niños a la sombra. De todos modos, observando en detalle, durante los meses de abril y mayo existen numerosos niños jugando en la zona central de la plaza al sol, mientras que en el mes de junio se han desplazado hacia la esquina suroeste de la plaza, que se encuentra a la sombra, y no es posible encontrar ningún niño en la zona central. 


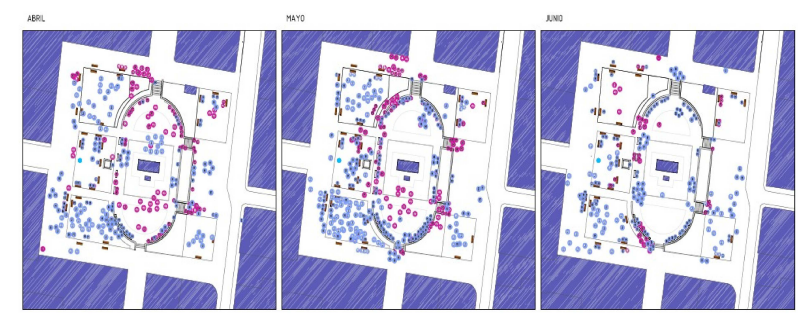

Figura 90: Ocupación de la plaza del 2 de Mayo durante los meses de abril, mayo y junio Fuente: elaboración propia

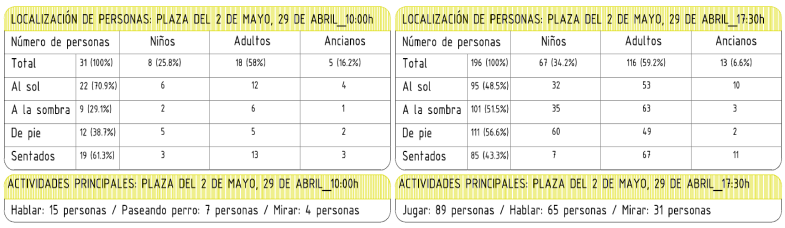

Figura 91: Tabla resumen de las actividades realizadas en la plaza del 2 de Mayo en el mes de abril

En el mes de abril la gente identificada se sitúa principalmente al sol durante la mañana, con una proporción significativa de 22 personas al sol frente a 9 a la sombra, coincidiendo con las estrategias recomendadas por el estudio de clima. Por la tarde sin embargo, el número de personas al sol y a la sombra es muy similar, mientras que el estudio de clima sigue recomendando la aportación de calor. En abril se localizaron más personas al sol independientemente de su edad. Fuente: elaboración propia

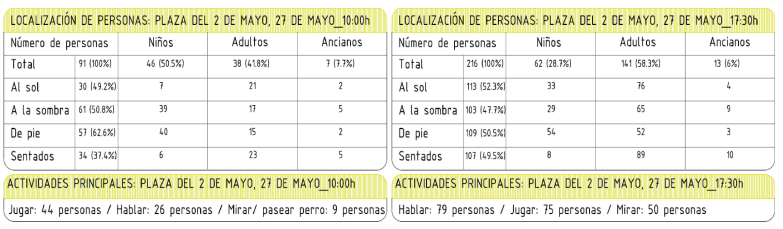

Figura 92: Tabla resumen de las actividades realizadas en la plaza del 2 de Mayo en el mes de mayo

En el mes de mayo, por la mañana, al contrario de lo recomendado por el estudio de clima la gente se localiza principalmente a la sombra, encontrando 61 personas a la sombra frente a 30 protegidas del sol. Por la tarde, el número de personas al sol y a la sombra es muy similar. El estudio de clima señala que

para estar sentado o parado de pie se está en situación de bienestar, sin que aún sea necesario el sombreamiento. Para actividades en las que se camina si sería recomendable protegerse del sol, pero sin embargo se encuentran numerosos niños jugando al sol en el centro de la plaza.

Los adultos se siguen situando principalmente al sol, pero los ancianos sin embargo, se encuentran a la sombra.

Fuente: elaboración propia 


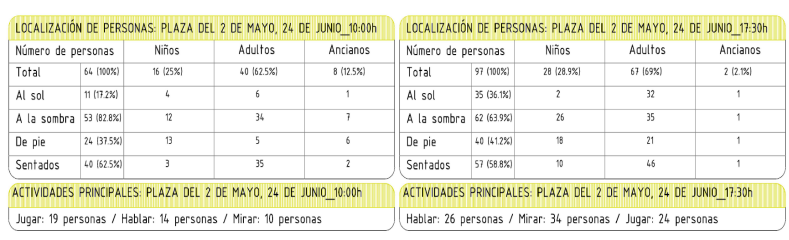

Figura 93: Tabla resumen de las actividades realizadas en la plaza del 2 de Mayo en el mes de junio

En junio todas las personas de diferentes edades se sitúan principalmente a la sombra. El estudio de clima señala la necesidad de aportación solar por las mañanas, pero las personas permanecen principalmente a la sombra. Por otra parte, a partir de la tarde el estudio teórico si señala la necesidad de sombreamiento e incluso la de enfriamiento a través de la ventilación, coincidiendo con el uso que la gente ha hecho del espacio público. En la plaza se registró una velocidad de viento máxima de $1.5 \mathrm{~m} / \mathrm{s}$.

Fuente: elaboración propia

Plaza de Vázquez de Mella, meses de abril, mayo y junio

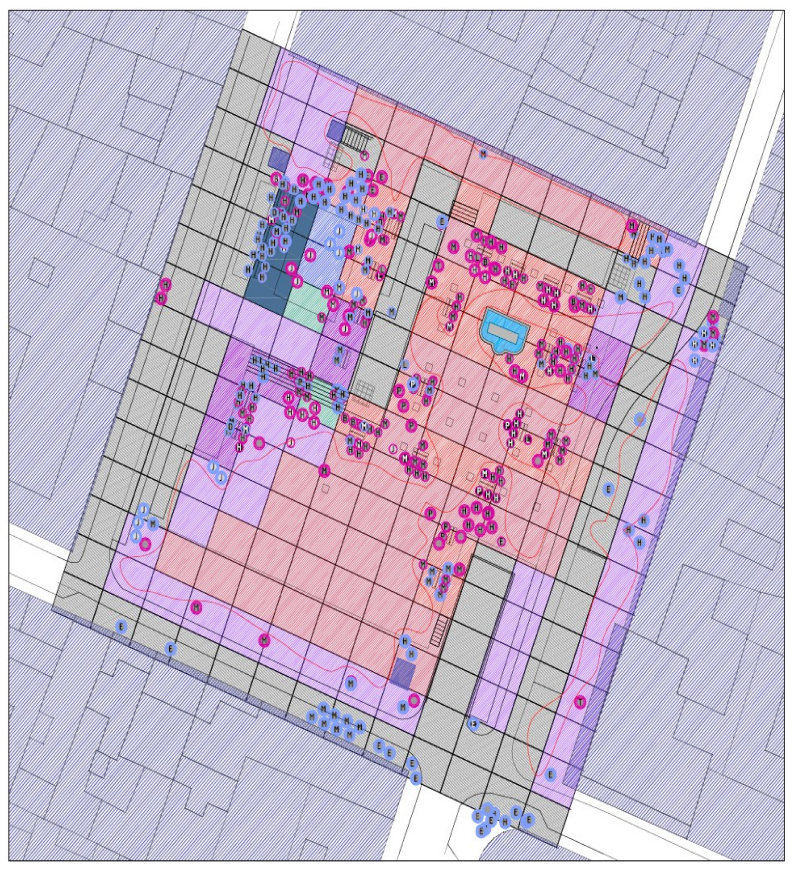

Figura 94: Plano resumen con superposición de las actividades, zonas sin uso y posibilidades de ocupación de la plaza Plaza de Vázquez de Mella

Fuente: elaboración propia

Vázquez de Mella es una plaza con muy poca disponibilidad de espacios a la sombra y con escaso arbolado. Durante los días analizados se encontraron más personas al sol, 242, que a la sombra, 190.

Existe una gran zona de la plaza que no es empleada por la gente durante las horas de luz de los meses de primavera. Se trata principalmente de una gran zona constantemente soleada, con pavimentos pesados, sin arbolado y sin equipamientos ni bancos, esto es, las zonas más cálidas dentro del área soleada y que carecen de equipamientos y mobiliario urbano.

Dentro de las zonas en sombra, las menos empleadas son aquellas con un carácter menos fresco, esto es, las zonas sombreadas pero que no tienen árboles y que tienen pavimentos que almacenan mucha energía térmica. 
La zona más empleada de la plaza es aquella que tiene una zona de juego de niños, bancos, pavimento de arena y arbolado con porte suficiente para dar sombra, además de recibir sombra de los edificios a última hora de la tarde.

Del análisis de los trabajos de campo realizados se puede deducir que la gente se agrupa y emplea más aquellas zonas de la plaza con accesibilidad a bancos o zonas donde sentarse.

Abril es el mes en el que la plaza está con mayor número de gente, seguido del mes de junio y finalmente mayo, donde se aprecia una reducción de uso respecto a los otros dos meses.

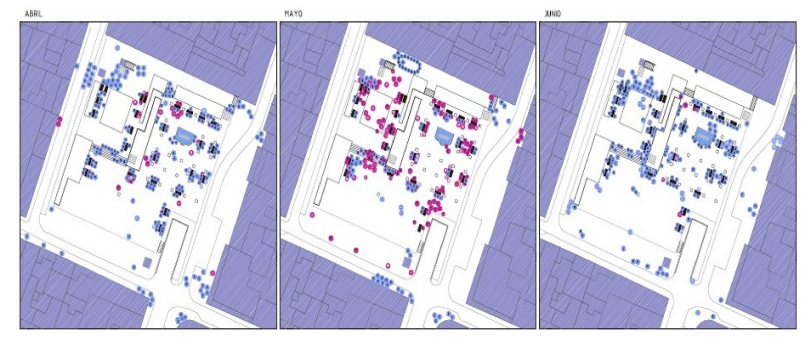

Figura 95: Ocupación de la plaza de Vázquez de Mella durante los meses de abril, mayo y junio

Fuente: elaboración propia

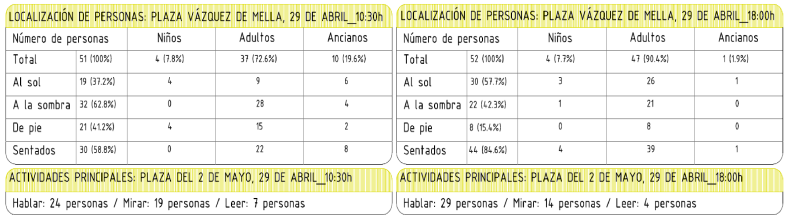

Figura 96: Tabla resumen de las actividades realizadas en la plaza Vázquez de Mella en el mes de abril

Aunque durante la mañana de abril analizada el $62.8 \%$ de la gente contabilizada se encontraba a la sombra, la mayor parte de las personas durante la tarde de abril y la mañana y tarde de mayo permanecen al sol, tal y como señala como estrategia el estudio de clima. Fuente:elaboración propia

\section{Plaza de Chamberí, meses de abril, mayo y junio}

Chamberí es una plaza con mucha exposición al sol, pero el arbolado existente crea zonas de sombra. En los días analizados de abril, mayo y junio se encontraron más personas a la sombra, 318, que al sol, 218 .

Al igual que ocurre en las otras dos plazas, en las zonas al sol más calurosas y sin equipamientos o bancos es difícil encontrar personas realizando algún tipo de actividad estancial. Lo mismo ocurre con aquellas zonas a la sombra menos frescas y sin equipamientos o mobiliario urbano. Las personas tienden a agruparse en torno a los equipamientos y asientos y sólo los niños ocupan la mayor parte de la plaza.

Los espacios a la sombra más empleados son los que tienen un carácter más fresco, por disponer de pavimentos ligeros y arbolado.

En junio se contabilizaron tan sólo 45 personas por la tarde, mientras que por la noche la cifra se incrementó a 83 personas. Durante junio la plaza fue más empleada por la noche.

Durante los días analizados, en las mañanas de abril y mayo las personas realizaban sus actividades al sol. Por las tardes de estos meses sin embargo, había más gente situada a la sombra. En abril no existen grandes diferencias en número entre la gente al sol $(43.2 \%)$ y a la sombra $(56.8 \%)$, sin embargo, esa diferencia va incrementando notablemente durante mayo, con un $61.1 \%$ de la gente a la sombra, y durante junio, en el que el $77 \%$ de la gente estaba situada a la sombra. Este comportamiento se hace patente en las personas de todas las edades, aunque es especialmente claro en los adultos y en los ancianos. 


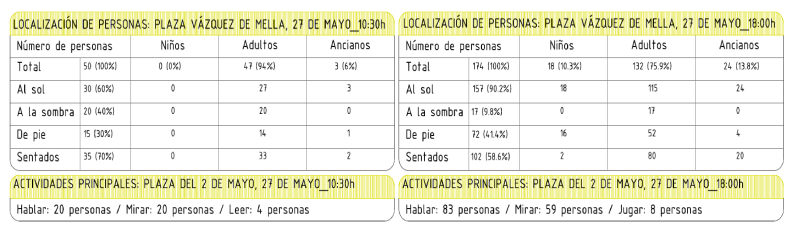

Figura 97: Tabla resumen de las actividades realizadas en la plaza Vázquez de Mella en el mes de mayo

Vázquez de Mella es una plaza con escasas zonas de sombra. En esos puntos de sombra también se pueden encontrar durante los meses de abril y mayo algunos grupos de personas.

Fuente: elaboración propia

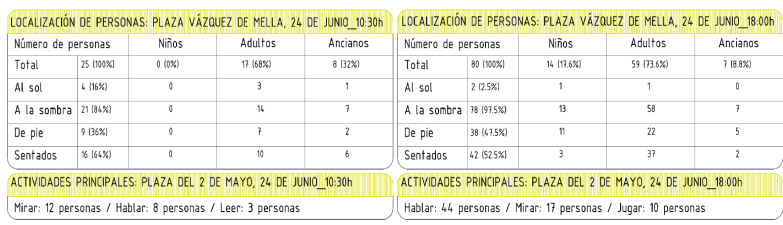

Figura 98: Tabla resumen de las actividades realizadas en la plaza Vázquez de Mella en el mes de junio

Durante la mañana y tarde de junio se puede observar a la gente agrupada en las pocas zonas a la sombra. Son muy pocas las personas que se mantienen al sol, por la mañana son sólo 3 y por la tarde tan sólo 2 frente a las 78 que permanecen a la sombra. El estudio de clima señala que por la mañana sería necesaria la aportación de calor para estar en bienestar, por lo que no coincide con el uso que la gente ha hecho del espacio.

Sin embargo, el estudio de clima señala la necesidad de sombreamiento e incluso de ventilación para alcanzar el bienestar (en la plaza se registró una velocidad de viento máxima de $2.88 \mathrm{~m} / \mathrm{s}$ ), coincidiendo con la localización a la sombra de la mayor parte de la gente en la plaza.

Fuente: elaboración propia 


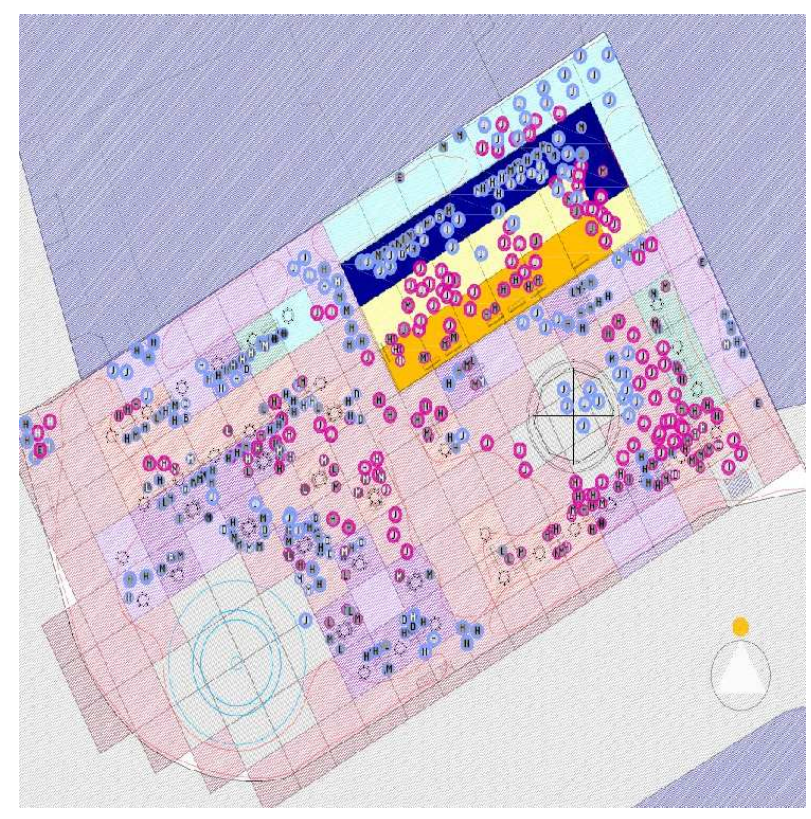

FigURA 99: Plano resumen con superposición de las actividades, zonas sin uso y posibilidades de ocupación de la plaza de Chamberí

Fuente: elaboración propia

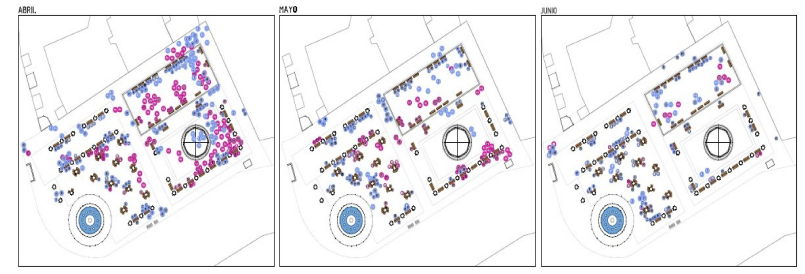

FiguRA 100: Ocupación de la plaza de Chamberí durante los meses de abril, mayo y junio Fuente: elaboración propia 
Los niños, aunque también tienden a estar más al sol, según avanzan los meses de primavera, se sitúan mucho más a menudo a la sombra.

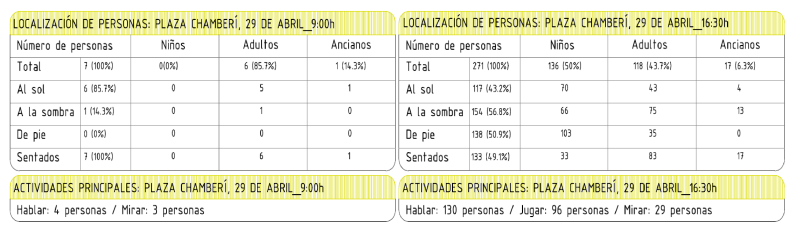

FigurA 101: Tabla resumen de las actividades realizadas en la plaza plaza de Chamberí en el mes de abril

Fuente:elaboración propia

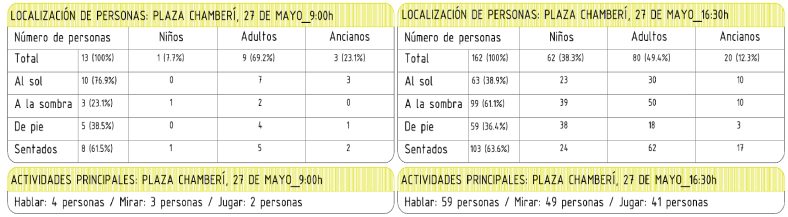

FigurA 102: Tabla resumen de las actividades realizadas en la plaza de Chamberí en el mes de mayo

Fuente: elaboración propia

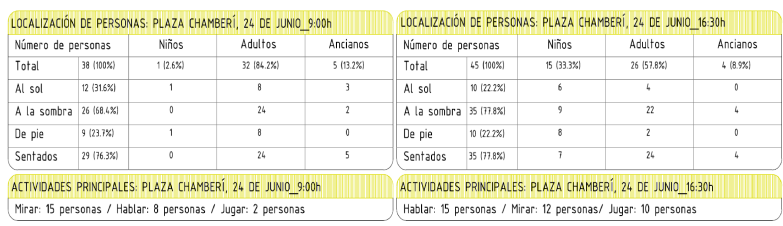

Figura 103: Tabla resumen de las actividades realizadas en la plaza de Chamberí en el mes de junio

Fuente: elaboración propia

En los meses estudiados se contabilizaron 546 personas de mañana a tarde.

Así, de la comparativa entre la utilización del espacio por parte de la gente y las estrategias obtenidas mediante la elaboración de climogramas de bienestar adaptado, se observa que, en numerosas ocasiones, el comportamiento de la gente no es el esperado o no se corresponde a la estrategia que resultaría necesaria para encontrarse en bienestar. En el mes de junio, es el momento estudiado en el que el uso del espacio y las estrategias bioclimáticas se corresponden en mayor medida.

\section{Verificación de la hipótesis}

Tras el análisis de parámetros de diseño como pavimentos, arbolado, protecciones del viento, uso del agua, etcétera, que tienen influencia en el funcionamiento microclimático de las plazas (HiGUERAS, 2009) así como el estudio de localización del mobiliario urbano y de equipamientos; se puede afirmar que aquella plaza con un diseño más acorde a los principios de diseño bioclimático es la plaza del 2 de Mayo.

La plaza del 2 de Mayo, en los momentos en los que se han realizado los trabajos de campo dentro de las horas de sol, ha sido aquella con mayor afluencia de gente realizando actividades estanciales, con un total de 695 personas, frente a las 434 de Vázquez de Mella y las 546 de Chamberí. 
La plaza de Vázquez de Mella es la que menos posibilidades de elección ofrece al ciudadano y, aunque en principio la afluencia total de gente a la plaza de Chamberí fue la menor, al contabilizar tan sólo las personas que acudieron a las plazas en las horas de sol, momento en el que los condicionantes climáticos son más relevantes, Chamberí supera en número de usuarios a Vázquez de Mella.

Del estudio realizado se deduce que la plaza con mayor diversidad en sus características físicas, de uso y microclimáticas, y que da más número de opciones de elegir donde localizarse al usuario para seleccionar los lugares en los que se encuentra más confortable, es la plaza del 2 de Mayo. Ésta también ha sido la plaza más empleada durante los días de primavera analizados, confirmándose así la hipótesis inicial de trabajo.

Este resultado coincide con el enfoque más reciente para la evaluación de la sensación de confort en el espacio público. Los índices de confort tradicionalmente más empleados han sido los racionales ${ }^{6}$, como el de OLGYAY y más recientemente se han utilizado los índices de confort híbridos ${ }^{7}$, como los empleados en los CBA, que combinan la estructura de OLGYAY (1963), con las estrategias básicas de Givoni (1976) y la teoría de bienestar de ASHRAE (1992) (NEILA, 2004). Las investigaciones más recientes sobre el bienestar en espacios abiertos como las de Nikolopoulou ET AL.(2004) se basan en los índices adaptativos definidos por HumphreYs (1978) y posteriormente desarrollados por AROZTEGUI (1995), cuyo principio es que si las condiciones ambientales térmicas no son las apropiadas para que los usuarios estén en bienestar, éstos harán los cambios necesarios para sentirse térmicamente confortables.

Por lo tanto, se concluye que la confortabilidad de un espacio abierto, como son las plazas, vendrá definido en gran medida por esas posibilidades de elección, por la creación de espacios diferenciados y por las acciones que el propio usuario realice para alcanzar el bienestar.

Así, las herramientas de diseño bioclimático serán básicas para adquirir el conocimiento suficiente de las condiciones ambientales existentes y determinar las condiciones en las que hay mayor probabilidad de que la gente se encuentre en confort. Los estudios de sombreamiento y las simulaciones de iluminación y radiación solar son herramientas eficaces para la caracterización de espacios urbanos existentes pudiendo, a partir de esta caracterización, realizar tomas de decisiones, corregir situaciones no deseables y definir espacios adaptables a las variaciones climáticas.

Cabe señalar que las estrategias derivadas del estudio de clima para alcanzar el confort no se corresponden en muchas ocasiones con el comportamiento de los usuarios y con la ocupación que han hecho del espacio en los días analizados. Esto hace patente la dificultad de definir con exactitud el confort en espacios abiertos en momentos con temperaturas tan variables a lo largo del mes como sucede en la primavera madrileña y pone de manifiesto la necesidad de espacios flexibles.

Mientras que en espacios cerrados el confort viene determinado básicamente por las condiciones higrotérmicas, los factores a tener en cuenta en espacios abiertos son muchos más, como la radiación solar, el viento o la temperatura de las superficies circundantes (Álvarez et AL.,1992). Según señala ScuDo (2005) los modelos de confort deberían aproximarse a la microescala para cumplir los requerimientos de la planificación de espacios abiertos confortables.

Una de las causas por las que existe esa diferencia entre las estrategias recomendadas por el estudio de clima a través de climogramas y la localización de la gente en la plaza deriva del hecho de trabajar con temperaturas medias para poder realizar una generalización. Aunque se podría trabajar con medidas de temperatura y humedad horarias, lo más habitual es emplear las temperaturas medias del mes de la estación meteorológica más cercana.

Por una parte, en muchas ocasiones existe una falta de datos que se adecúen al área a estudiar, por la ausencia de estaciones meteorológicas cercanas al lugar. Por otra parte, el hecho de trabajar con temperaturas medias que tienen en cuenta los registros a lo largo de todo el día no es estrictamente aplicable al estudio climático de espacios públicos, dado que las horas en los que estos espacios son empleados se centran en las horas de luz, pues su uso por la noche es muy reducido y puntual a lo largo de los días de la semana. Así, las temperaturas medias con las que se realizan estos estudios suelen ser inferiores a las que resultarían de la temperatura media de las horas de luz.

\section{Consideraciones finales}

Una de las soluciones al problema de la desviación de las temperaturas medias para espacios públicos es el cálculo de la temperatura media alcanzada durante las horas de luz, teniendo acceso a los datos de temperaturas hora a hora a lo largo de los días de cada mes en zonas cercanas al área estudiada.

\footnotetext{
${ }^{6}$ Los índices de confort racionales emplean modelos que calculan el balance térmico de una persona y los relacionan con sus respuestas fisiológicas a diferentes condiciones ambientales.

${ }^{7}$ Los índices de confort híbridos complementan los índices racionales con índices empíricos como el arropamiento o la actividad metabólica.
} 
Esta opción resulta factible dentro del marco de un proyecto de investigación, pero su realización en la aplicación de herramientas de diseño bioclimático en el mercado resulta inabarcable.

A través de proyectos de investigación se podrían desarrollar tablas de temperaturas medias de las horas de luz de diversos lugares que fueran accesibles a profesionales para su aplicación directa en los proyectos de diseño urbano.

Las políticas públicas podrían encaminarse a poner a disposición pública la información de las estaciones meteorológicas existentes en las áreas urbanas, realizando, además, un control en la toma de datos regulado para asegurar su fiabilidad.

Por otra parte, para el fomento del empleo de todas estas herramientas dirigidas al diseño de espacios confortables, los ayuntamientos podrían requerir a través de los pliegos de condiciones técnicas para la rehabilitación de plazas y espacios públicos, la inclusión de nuevos estudios previos de soleamiento, iluminación y caracterización climática de los mismos, así como estudios antropológicos que analicen la identidad de los ciudadanos con ese espacio y estudios sociológicos que tengan en cuenta el uso que la gente hace e ellos, tal y como comenzó a realizarse con los planes directores de rehabilitación del patrimonio y de entornos históricos. De este modo, se fomenta la colaboración público-privada en la regeneración del espacio público, incluyendo a universidades o a grupos de investigación de diversas áreas de conocimiento en estos análisis previos, que ponen a disposición de los estudios de arquitectura y urbanismo los conocimientos especializados en estas materias, de modo que estos se pongan en práctica en el día a día y no se conserven tan sólo como conocimientos teóricos.

Además, sería interesante la elaboración de algún tipo de certificación de calidad para los espacios públicos que cumplan con estos requerimientos, similar a la certificación energética de edificios regulada por el Procedimiento básico para la certificación de eficiencia energética de edificios de nueva construcción (RD 47/2007), pero en el que se incluyan parámetros sociales que el espacio público debería cumplir.

En los últimos diez años se señala reiteradamente la necesidad de mezcla de usos en la ciudad como parámetro de sostenibilidad y habitabilidad de la misma. Un ejemplo conocido es el concepto de complejidad expuesto por RUEDA $(2006)^{8}$

, como uno de los cuatro ejes esenciales para una ciudad sostenible. Del mismo modo, a pequeña escala, resulta imprescindible la creación de espacios con mezcla de posibilidades.

El presente trabajo no trata exclusivamente del análisis de tres plazas de Madrid y del uso que se hace de ellas o de la evaluación de herramientas de caracterización ambiental. A través del análisis de espacios a pequeña escala y de la determinación de la importancia de la mezcla de posibilidades de espacios cotidianos, se trata de poner de manifiesto la necesidad de intervenir en toda la ciudad, conservando sus valores tradicionales de complejidad y calidad y creando nuevos espacios públicos ricos en posibilidades de utilización. El estado del espacio público, de la ciudad, es el reflejo de la salud de la sociedad.

Cabe concluir diciendo que la propuesta es hacer más compleja y habitable la ciudad entera, centros, periferias y nuevos crecimientos, ya que, más allá del diseño bioclimático, los ciudadanos necesitan de espacios complejos que les permitan elegir aquello que más les conviene en cada caso. La ciudad como espacio saludable y democrático que permite el desarrollo personal.

\section{Bibliografía}

AA.VV.

1990 Libro verde sobre el Medio Ambiente Urbano

Comisión Unión Europea.

URL:http://www.bcnecologia.net/index.php?option=com_content\&task=view\&id=122\&Itemid=95\&lang $=\mathrm{SP}$ Recurso consultado el 26-04-2010.

Aguilera Klink, Federico (ED.)

1995 Economía de los recursos naturales: un enfoque institucional. Textos de S.V. Ciriacy-Wantrup y

K.W. Kapp.

Madrid: Fundación Argentaria-Visor.

Álvarez, S.; Cejudo, J.M.; Guerr, J.J.; Molina, J.L.; Rodriguez, E.A.; Velázquez, R.

1992 Control climático en espacios abiertos: Proyecto Expo 92

Grupo de termodinámica, Universidad de Sevilla. Edita: Secretaría General Técnica del CIEMAT. ISBN: $978-84-7834-158-7$.

\footnotetext{
${ }^{8}$ La complejidad atiende a la organización urbana, al grado de mixticidad de usos y funciones implantadas en un determinado territorio (Rueda, 2006, ). El concepto de complejidad de RuedA, José FARIÑA lo considera una medida de diversidad porque mide probabilidades (FARIÑA, 2008).
} 
Aroztegui, J.M.

1995 «Índice de temperatura neutra exterior»

III Encontro Nacional de Conforto no Ambiente Construído (ENCAC 3), Gramado, Brasil.

American Society of Heating Refrigerating and Air Conditionig Engineers (ASHRAE)

1992 ANSI-ASHRAE 55-1992 Thermal environmental conditions for human occupancy ASHRAE, Atlanta.

Ayuntamiento de MAdrid

2005a Diagnóstico de sostenibilidad del distrito de Centro

Área de Gobierno de Medio Ambiente y Servicios a la Ciudad Dirección General de

Sostenibilidad y Agenda 21. Depósito legal: M-26947-2006.

Ayuntamiento de MAdrid

2005b Diagnóstico de sostenibilidad del distrito de Chamberí

Área de Gobierno de Medio Ambiente y Servicios a la Ciudad Dirección General de

Sostenibilidad y Agenda 21. Depósito legal: M-26947-2006.

Ayuntamiento de MADRID

2006 Mapa Estratégico de Ruido 2006

URL:http://www.mambiente.munimadrid.es/opencms/opencms/calaire/contAcustica/mapa_ruido_2006

Recurso consultado el 15-07-2010.

Ayuntamiento de MADRID

2008 Manual de criterios de sostenibilidad en el mantenimiento de zonas verdes urbanas Dirección de Servicios de Parques y Jardines del Área de Medio Ambiente.

URL:http://www.dphuesca.es/pub/documentos/documentos_Criterios_Sostenibilidad_Zonas_Verdes_Urbanas._Ay Recurso consultado el 8-05-2010.

Ayuntamiento De Madrid

2009 Calidad del aire

Dirección General de Calidad, Control y Evaluación Ambiental, Servicio de Calidad del Aire.

URL: http://www.mambiente.munimadrid.es/opencms/opencms/calaire/com Recurso consultado el 7-07-2010.

Bloomer, K.C. Y Moore, C.W.

1982 Cuerpo, memoria y arquitectura: Introducción al diseño arquitectónico

Madrid: Tursen, S.A. Hermann Blume Ediciones. ISBN: 8472142469, 9788472142466.

Bustillos Bravo, I.; Laceras Merino, C.; Martín Moratalla, M.A.

1983 Seminario de Planeamiento y Ordenación del Territorio: Espacios Públicos en el Centro Histórico de Madrid, Tipos, Configuración y génesis

Instituto Juan de Herrera, ETSAM. Gerencia Municipal de Urbanismo del Ayuntamiento de

Madrid y Dirección General de Acción Territorial y Urbanismo del Ministerio de Obras

Públicas (MOPU). Depósito Legal: M-4336-1985.

Caballero, E

2004 «Microclimas urbanos: la importancia de los materiales»

El Clima entre el Mar y la Montaña. Aportaciones presentadas al IV Congreso de la Asociación

Española de Climatología. Santander, 2-5 de noviembre de 2004, Asociación Española de

Climatología y Universidad de Cantabria, Serie A, $\mathrm{n}^{\mathrm{O}} 4$.

Chrisomallidou, N.; Chrisomallidis, M.; Theodosiou, T.

2004 «Design principles and applications»

Designing open spaces in the urban environment: A bioclimatic approach, Centre for Renewable

Energy Sources (CRES), Department of Buildings, Grecia, pp. 37-41.

EMVS

2006 Guía de vegetación para ambientes urbanos

Empresa Municipal de la Vivienda, Madrid. ISBN: 84-934362-5-9.

FARIÑA TOJO, J.

1990 Clima, territorio y urbanismo

Escuela Técnica Superior de Arquitectura de Madrid, Madrid. 
FARIÑA TOJO, J

1998 La ciudad y el medio natural

Ediciones Akal, Madrid. ISBN: 978-84-460-1657-1.

FARIÑA TOJO, J.

2008 Indicadores de sostenibilidad urbana

URL: http://elblogdefarina.blogspot.com/2008/05/indicadores-de-sostenibilidad-urbana.html

Recurso consultado el 12-08-2010.

GARcía VÁzQuez, C.

2004 La ciudad hojaldre

Editorial GG, Barcelona. ISBN: 84-252-1970-I

GEHL, JAN

1968 «Mennesker til fods»

Arkiteklen 70, $\mathrm{n}^{\mathrm{O}} 20$, pp. 429-446

GEHL, JAN

1980 The Residential Street Environment

Built Environment 6

$\mathrm{n}^{\mathrm{O}} 1$, pp. $51-61$

GEHL, JAN

2001 Life between buildings. Using Public Space

Arkitektens Forlag. The Danish Architectural Press. ISBN 87-7407-283-8.

Givoni, B.

1969 Man Climate and Architecture

Elsevier, Universidad de Wisconsin, Madison

Esta es la primera edición del libro, el cual se referencia en el texto por la siguiente edición:

Givoni, B.

1976 Man Climate and Architecture

Londres: Applied Science Publishers.

Givoni, B. y Noguchi, M.

2000 «Issues in outdoor comfort research»

Passive and low energy architecture, $\mathrm{n}^{\mathrm{O}}$ 17, Cambridge. Proceedings. London: J\&J, pp. 562-565.

Hernández AjA, Agustín

1997 La ciudad de los ciudadanos

Ministerio de Obras Públicas Transporte y medioambiente. Madrid.

Higueras, Ester

2006 Urbanismo bioclimático

Editorial GG, Barcelona, 2006. ISBN: 978-84-252-2071-5. 43-35

Higueras, Ester

2009 Buenas prácticas en arquitectura y urbanismo para Madrid: Criterios bioclimáticos y de eficiencia energética

Edición Área de Gobierno de Urbanismo y Vivienda del Ayuntamiento de Madrid. ISBN: 978-84-7812-718-4.

Humphreys, M. A.

1978 «Outdoor temperatures and comfort indoors»

Building Research and Practice, Vol. 6, n $\mathrm{n}^{\mathrm{O}}$ 2, pp. 92-105.

Citado por Marqués Y PeInAdo, 2009

JACOBS, J

1992 The Death and Life of the Great American Cities

Vintage Books.

Kofoed, N.U. y GaArdsted, M.

2004 «Considerations of the wind in urban spaces»

Designing open spaces in the urban environment: A bioclimatic approach, CRES Department of Buildings, Grecia, pp. 7-11.

LYNCH, KEVIN

1960 The image of the city

MIT Press ISBN 0262620014, 9780262620017. 
Esta es la primera edición del libro, del cual también se hace referencia en el texto a través de la siguiente edición:

LYNCH, KEVIN

1998 La imagen de la ciudad

Editorial GG, Barcelona. ISBN: 8425217482, 9788425217487.

Marqués Monteiro, L.; Peinado Alucci, M.

2006 «Calibration of outdoor thermal comfort models» $23^{\text {rd }}$ International Conference on Passive and Low Energy Architecture (PLEA), Geneva Switzerland 6-8 September 2006, Ginebra, Suiza.

Marqués Monteiro, L.; Peinado Alucci, M.

2009 «Outdoor termal confort: comparative study of a sidewalk, a square and a park in a downtown area»

The Seventh International Conference on Urban Climate, Yokohama, Japan.

NEILA, J.

2004 Arquitectura bioclimática en un entorno sostenible Editorial Munilla-Lería. ISBN: 84-89150-64-8.

Nikolopoulou, M., Lykoudis, S., Kikira, M.

2004 «Modelli di comfort termico per gli spazi apertii»

Progettare gli spazi aperti nell'ambiente urbano: un approccio bioclimatico, CRES, Department of Buildings, Grecia, pp. 2-7.

OKe, T.R.

1988 «Street design and urban canopy layer climate»

Energy and Buildings, $\mathrm{n}^{\mathrm{O}}$ 11, pp. 103-113

OLGYAY, V.

1963 Design with climate: bioclimatic approach to architectural regionalism

Princeton University Press. Princenton, New Jersey. ISBN-10: 0442011105, ISBN-13:

978-0442011109.

Pallasmaa, J.

2005 Los ojos de la piel

Editorial GG, Wiley Academy, Chichester, West Sussex. ISBN-13: 978-84-252-2135-4/ISBN-10: 84-252-2135-8.

Pezzi Peñalver, F.

2008 «El arco de Monteleón»

Revista Aforos, $\mathrm{n}^{\mathrm{O}}$ 71. Colegio de Ingenieros Técnicos de Obras Públicas de Madrid.

Rueda, SALVAdor

2006 «Un nuevo urbanismo para una ciudad más sostenible»

Conferencia ETSA Sevilla., URL:

http://www.bcnecologia.net/documentos/Un\%20nuevo\%20urbanismo\%20para\%20una\%20ciudad\%20mas\%20sostenib Recurso consultado el 2-05-2010.

RuEdA, SAlvador

2006 Plan Especial de indicadores de sostenibilidad ambiental de la actividad urbanística de Sevilla Agencia de Ecología Urbana de Barcelona. URL:

http://www.bcnecologia.net/index.php?option=com_content\&task=view\&id=126\&Itemid=118\&lang=SP Recurso consultado el 2-05-2010.

Scudo, G.; Dessí, V.; Rogora, A.

2004 «Evaluation of radiant conditions in urban spaces»

Designing open spaces in the urban environment: A bioclimatic approach, CRES, Department of Buildings, Grecia, pp. 12-16.

Scudo, G.

2005 'La qualità ambientale nella progettazione urbana: il contributo dell'approccio bioclimatico alla sostenibilità"

Il comfort ambientale degli spazi aperti.

EdicomEdizioni. ISBN: 978-88-86729-49-9. 
Serra Florensa, R.; Coch Roura, H.

2001 Arquitectura y energía natural

Ediciones UPC. ISBN: 8483014971, 9788483014974.

TOYo ITO

2000 Escritos

Colegio Oficial de Aparejadores y Arquitectos Técnicos de Murcia. Artes gráficas Soler, S. L.

Valencia. ISBN: 84-89882-12-6.

Watson I.D., Johnson G.T.

1987 «Graphical estimation of sky-view factors in urban environments»

Journal of Climatology, n ${ }^{\mathrm{O}}$, pp. 193-197.

William H. White

1980 The social life of small urban spaces

Ed. Project for public spaces. Washington, D.C. ISBN-10: 097063241X, ISBN-13: 978-0970632418.

\section{Otros documentos digitales}

- Blog Madrid 2008-09, sobre la asignatura de Historia de la arquitectura de la Escuela Técnica Superior de Arquitectura de La Coruña (ETSAC). Recurso consultado el 19-07-2010.

- Archivo fotográfico de la Comunidad de Madrid Recurso consultado el 19-07-2010.

- Entrada sobre Chamberí en la Wikipedia. Recurso consultado 7-07-2010.

- Entrada sobre la plaza del 2 de Mayo en el blog Viendo Madrid. Recurso consultado el 3-07-2010.

- Entrada sobre el Cuartel de Artillería de Monteleón en el blog Urbanidade. Recurso consultado el 19-07-2010.

- Página web monumentamadrid. Recurso consultado el 09-08-2012.

- Decreto 78/1999, de 27 de mayo, por el que se regula el régimen de protección contra la contaminación acústica B.O.C.M Martes 8 de junio de 1999 y corrección del B.O.C.M. de 1 de julio número 154.

- Plan general de ordenación urbana municipal (PGOUM, 1997). Rehabilitación Integrada del Casco y Centro Histórico de Madrid. Disponible en http://www.madrid.es/ Recurso consultado el 17-042010 